NBSIR $75-807$

\title{
TURBULENT NATURAL CONVECTION OF LIQUID DEUTERIUM, hYOROGEN, AND NITROGEN WITHIN ENCLOSED VESSELS
}

David E. Daney

Cryogenics Division Institute for Basic Standards National Bureau of Standards Boulder, Colorado 80302

February 1975

Prepared for:

Lawrence Livermore Laboratory

University of California

P. O. Box 808

Livermore, California 94550 



\section{TURBULENT NATURAL CONVECTION OF LLQUID DEUTERIUM, HYDROGEN, AND NITROGEN WITHIN ENCLOSED VESSELS}

David E. Daney

Cryogenics Division

Institute for Basic Standards

National Bureau of Standards

Boulder, Colorado 80302

February 1975

Prepared for:

Lawrence Livermore Laboratory University of California

P. O. Box 808

Livermore, California 94550

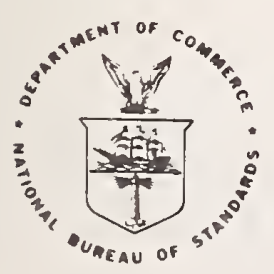

U.S. DEPARTMENT OF COMMERCE, Frederick B. Dent, Secretary 

1. Introduction ................... 1

1.1 Previous Work . . . . . . . . . . . . 2

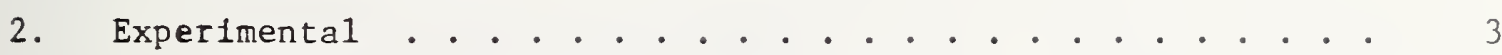

2.1 Experimental Approach . . . . . . . . . . . 3

2.2 Apparatus - General Scheme . . . . . . . . 6

2.3 Apparatus Details ............. 9

2.4 Test Vessels . . . . . . . . . . . . '

2.5 Instrumentation . . . . . . . . . . . . 1 is

2.6 Data Reduction . . . . . . . . . . . . 21

2.7 Thermal Properties ... . . . . . . . 23

3. Results ................ . . 23

4. Discussion .................. 35

4.1 Temperature Profiles........... . . 35

4.2 Nusse1t Numbers . . . . . . . . . . . 41

5. Summary and Conclusions ............... 43

6. Acknowledgments ............... . . 45

7. Nomenclature ............. . . 46

8. References ............... . . . 48

APPENUlX A Heat Capacity During Cooling........... 51

APPENDIX B Velocity in the Core of a Vertical Cylinder .... . 53

B.1 Quasi-Steady Cooling........... 53

B.2 Internal heat Generation . . . . . . . . . 56

APPENDIX C Experimental Results ............ 58

\section{LIST OF FIGURES}

Figure

2.1 Experimental apparatus . . . . . . . . . . 7

2.2 Complete experimental assembly . . . . . . . . . 10

2.3 Test vessel - $17.1 \mathrm{~cm}$ diameter hemisphere . . . . . . . 12

2.4 Test ve.sel - vertical c linder . . . . . . . . . 13 
2.5 Test vessel - sphere ............ 14

2.6 Hemisphere heater . . . . . . . . . . 15

2.7 Wall thermocouple installation-copper walls . . . . . . 20

3.1 Summary of Nusselt number data for all cooling experiments in copper walled vessels. The correlations and curves are for the $\mathrm{LD}_{2}$ data only . . . . . . . 26

3.2 Vertical temperature distributions of the copper walled hemispheres, sphere, and horizontal cylinder for the warming experiments. The fluid is liquid deuterium . . .

3.3 Vertical cylinders (copper wall) - vertical temperature distribution for cooling experiments . . . . 28

3.4 Nusselt number data for warming experiments in copper walled vessels ...............

3.5 Vertical temperature distributions of the hemispheres, sphere, and horizontal cylinder for the warming experiments. Unless specified, the fluid is liquid deuterium.

3.6 Vertical cylinders (copper wall) - vertical temperature distribution for warming experiments . . . . . . .

3.7 Transient response of $\mathrm{LD}_{2}$ within a copper sphere . . . . 33

3.8 Transient response of $\mathrm{LD}_{2}$ within a vertical copper cylinder $(L / D=2)$

4.1 Dimensionless temperature, T*, within $17.1 \mathrm{~cm}$ diameter hemisphere for cooling experiments. Measurements are in the vertical plane bisecting the hemisphere . . . . . .

4.2 Comparison of the vertical temperature distribution within the sphere during cooling with the inverted temperature distribution during warming . . . . . . . .

C.1 Sphere (copper wall) - Nusselt number for cooling experiments

C.2 Sphere (copper wall) - vertical temperature distribution for cooling experiments . . . . . . . . . . .

C.3 Horizontal cylinder (copper wall) - Nusselt number for cooling experiments

C.4 Horizontal cylinder (copper wall) - vertical temperature distribution .................

C.5 Copper hemispheres - Nusselt number for cooling experiments .

C.6 Copper hemispheres - vertical temperature distribution

C.7 Stainless steel hemisphere - Nusselt number for cooling and heater experiments 
C.8 Plastic-copper hemisphere - Nusselt number for cooling and heater experiments . . . . . . . . . . . . . .

C.9 Stainless steel and plastic-copper hemisphere - vertical temperature distribution for cooling experiments . . . . . .

C.10 Stainless steel and plastic-copper hemispheres with heaters - vertical temperature distribution . . . . . . . .

C.11 Vertical cylinders (copper wall) - Nusselt numbers for cooling and heater experiments . . . . . . . . . . . . . .

C.12 Vertical cylinders (copper wall) - vertical temperature distribution for cooling experiments . . . . . . . . . .

C.13 Vertical cylinder (copper wall) with heater $(\mathrm{L} / \mathrm{D}=2$ ) vertical temperature distribution . . . . . . . . . . . . .

C.14 Sphere (copper wal1) - vertical temperature profile for warming experiments . . . . . . . . . . . . .

C.15 Horizontal cylinder (copper wall) - vertical temperature distribution for warming experiments . . . . . . . . . . . .

C.16 Copper hemisphere $(D=17.1 \mathrm{~cm})$ - vertical temperature distribution for warming experiments . . . . . . . . . . .

C.17 Vertical cylinders (copper wal1) - vertical temperature distribution for warming experiments . . . . . . . . . .

\section{LIST OF TABLES}

Table

2.1 Test vesse1 characteristics . . . . . . . . . . . .

2.2 Thermal properties of the test fluids at 4 atmospheres...

3.1 Summary of Nusselt number correlations for liquid deuterium cooling experiments

C.1 Correlation results using the expression $\mathrm{Nu}=\mathrm{C}_{1} \mathrm{Ra}^{\mathrm{n}} \cdot \cdot \cdot$ 
Quasi-steady natural convection of liquid deuterium, hydrogen, and nitrogen within a sphere, hemisphere, horizontal cylinder, and vertical cylinder has been studied experimentally for the case of a nearly isothermal wall. A single expression relating the Nusselt and Rayleigh numbers,

$$
\mathrm{Nu}=0.104 \mathrm{Ra}^{0.352} \text {, }
$$

fits the deuterium and nitrogen data over the range $7 \times 10^{8}<\mathrm{Ra}<6 \times 10^{11}$, while the hydrogen Nusselt numbers are 8 percent lower. The temperature field within the vessels is virtually free of horizontal temperature gradients. A single dimensionless temperature profile characterizes the vertical temperature distribution for each vessel shape, with the profiles for the sphere, hemisphere, and horizontal cylinder being nearly identical.

Key words: Cryogenic; heat transfer; hemisphere; horizontal cylinder; liquid deuterium, liquid hydrogen, liquid nitrogen; natural convection; sphere; vertical cylinder. 
TURBULENT NATURAL CONVECTION OF LIQUID DEUTERIUM, HYDROGEN, AND NITROGEN WITHIN ENCLOSED VESSELS

by

David E. Daney

\section{Introduction}

Natural convection heat transfer within enclosures occurs in a number of applications. Cooling of turbine blades, heating and cooling of buildings and liquid storage tanks, cooling of nuclear fuel elements, and industrial process cooling are only a few examples. of particular interest to the cryogenic engineer are the warming and thermal stratification of cryogenic fluids (both liquid and supercritical) in storage and rocket propellant tanks. Cooling of liquid hydrogen and liquid deuterium moderators and targets for high energy physics experiments is another potentially useful cryogenic application of natural convection heat transfer. However, this latter application has been used only at very low heating rates because there is insufficient natural convection heat transfer design information. In order to provide such information the experimental investigation reported here was undertaken.

The three parameters of primary interest in the design of these vessels are the average heat transfer coefficient, the average bulk fluid temperature, and the maximum fluid temperature. The bulk temperature gives average fluid density and, hence, the mass of fluid within a vesse1. The maximum temperature gives the proximity to the boiling point, which in some applications is to be avoided. Also of considerable theoretical interest is the temperature field within a vessel because of the information it contains about the flow patterns. In this study the average heat transfer coefficient and the temperature field were determined for turbulent natural convection heat transfer with liquid deuterium $\left(\mathrm{LD}_{2}\right)$, liquid hydrogen $\left(\mathrm{LH}_{2}\right)$, and liquid nitrogen $\left(\mathrm{LN}_{2}\right)$ enclosed within spheres, hemispheres, horizontal cylinders, and 
vertical cylinders with nearly uniform wall temperatures. Quasi-steady cooling (that is, cooling with a constant wall to fluid temperature difference) was the primary mode studied, although results are also given for quasi-steady heating, transient cooling, and heating with spatially distributed electrical heaters. The Rayleigh numbers ranged from $7 \times 10^{8}$ to $6 \times 10^{11}$ and the temperatures range from $20 \mathrm{~K}$ to $26 \mathrm{~K}$ for $\mathrm{LH}_{2}$ and $\mathrm{LD}_{2}$ and 78 to $88 \mathrm{~K}$ for $\mathrm{LN}_{2}$.

\subsection{Previous Work}

A considerable body of literature exists on the subject of natural convection within enclosures, but it is concerned primarily with laminar free convection, or with transient free convection. None of this previous work addresses either the quasi-steady turbulent convection considered here or the fluids used in this study. Although numerical solution of the governing two-dimensional partial differential equations has been successful for laminar flow, computation times have generally been on the order of an hour on an IBM 7090.1,2] At high Rayleigh numbers numerical solutions become impractical because the thin boundary layer flows which have been observed experimentally [3] would require such a fine grid spacing near the container walls that computation times would become excessive. Approximate analysis using the integral method has been successively applied to open thermosyphons, [4] narrow tubes with internal heat generation, [5] and transient convection in vertical cylinders with uniform wall heating; [3] but it apparently has not been successively applied to other enclosure geometries or to the uniform wall temperature case.

of the previous experimental studies of natural convection within enclosures, Schmidt ${ }^{[6]}$ gives $\mathrm{Nu}$ vs. Ra and some temperature profile data for transient turbulent free convection in spheres up to $50 \mathrm{~cm}$ in diameter using water and various alcohols. Evans and Stefany, [7] and Maas [8] investigated transient laminar free convection in horizontal cylinders using water, n-butanol, methanol and water-glycerine mixtures. Deaver and Eckert ${ }^{[9]}$ studied quasi-steady laminar free convection within horizontal cylinders using water and ethylene glycol. A considerable effort, 
both analytical and experimental, has been spent on transient free convection in vertical cylinders and on the associated thermal stratification. Clark ${ }^{[10]}$ has summarized this work; and some of the more relevant experimental studies are by Evans and Stefany, [7] Evans, Reid and Drake, ${ }^{[3]}$ Schwind and Vliet, ${ }^{[1]}$ and Tatom and Car1son. [12]

\section{Experimental}

\section{1 Experimental Approach}

Selection of the quasi-steady cooling method with constant wall-tofluid temperature difference offers a number of advantages. The steady state is more amenable to analysis than the transient state, so steady state experimental data are more easily compared with theory. Because simple, well-defined boundary conditions result, automatic data acquisition and reduction are easily accomplished. Finally, quasi-steady cooling simulates steady state free convection with uniform internal heat generation -- an important consideration for cold neutron moderator experiments.

This analogy between quasi-steady cooling and uniform internal heat generation results because of the similar effects on the convection process caused by the fluid heat capacity and by uniform internal heat generation. Inspection of the energy equation shows this analogy is exact. For a low Mach number, constant pressure, and constant thermal conductivity system, the energy equation is

$$
\rho \mathrm{C}_{\mathrm{p}}\left[\frac{\partial \mathrm{T}}{\partial \mathrm{t}}+\overrightarrow{\mathrm{W}} \cdot \nabla \mathrm{T}\right]=\mathrm{k} \nabla^{2} \mathrm{~T}+\mathrm{q}_{\mathrm{v}} \cdot
$$

Rearranging equation (2.1) so that the terms defining the velocity and temperature field are on the right hand side gives

$$
\rho C_{p} \frac{\partial T}{\partial t}-q_{v}=k \nabla^{2} T-\rho C_{p} \vec{W} \cdot \nabla T \text {. }
$$

The individual contributions that the terms on the left hand side of equation (2.2) make to the velocity and temperature fields are indistinguishable since the variables are separable in this fashion. Thus, the 
velocity and temperature fields within a vessel for the constant rate of cooling case,

$$
\rho C_{p} \frac{\partial T}{\partial t}=\text { Constant }
$$

and

$$
\mathrm{q}_{\mathrm{v}}=0 \text {, }
$$

should be the same as for the steady state uniform internal heating case,

$$
\mathrm{q}_{\mathrm{V}}=\text { Constant }
$$

and

$$
\rho C_{p} \frac{\partial T}{\partial t}=0
$$

More formally, by transforming equation (2.2) using $\phi=T-\bar{T}_{w}$, the requirements for quasi-steady cooling are:

$$
\rho C_{p} \frac{\partial \bar{T}_{W}}{\partial t}=\text { Constant }
$$

and

$$
\mathrm{T}-\overline{\mathrm{T}}_{\mathrm{W}}=\text { Constant. }
$$

In controlling the experimental conditions the latter criterion was used, whereas in the selection of the data to be analyzed, both criteria were used.

In selecting correlating parameters, we assumed that steady-state parameters are also valid for quasi-steady conditions - an assumption that is supported by these experimental results. Thus we use the expression

$$
\mathrm{Nu}=\mathrm{C}_{1} \mathrm{Ra}^{\mathrm{n}}
$$

to correlate the heat transfer coefficient data. The characteristic temperature difference used in the Nusselt number and Rayleigh number is $\mathrm{T}_{\mathrm{b}}-\mathrm{T}_{\mathrm{w}}$ and, the fluid properties were evaluated at the bulk fluid temperature $\mathrm{T}_{\mathrm{b}}$. We use the surface average heat transfer coefficient, so that the Nusse1t number is given by 


$$
N u=\frac{\bar{h} D}{k}=\frac{(\bar{q} / A) D}{\left(T_{b}-\bar{T}_{w}\right) k} .
$$

The characteristic length is the vessel diameter for the sphere, hemispheres, and horizontal cylinder; and the height for the vertical cylinders.

The temperature profile data were correlated using the dimensionless temperature

$$
T^{*}=\frac{T-\bar{T}_{W}}{T_{b}-\bar{T}_{W}},
$$

which is simply the local temperature difference, $T-\bar{T}_{w}$, normalized by the characteristic temperature difference, $T_{b}-\bar{T}_{w}$.

The parameter $T^{*}$ yields a single dimensionless temperature profile for each shape when the flow is fully developed, because identical T* profiles imply similitude of velocity fields. This connection between the velocity and temperature fields is most easily visualized by considering the uniform internal heat generation case. If we follow a fluid element rising within the vessel, then, (in the absence of heat transfer or mixing) the temperature rise of that element is proportional to the time of travel from our datum point, and the slope of the temperature, $\mathrm{dT} / \mathrm{dx}$, is inversely proportional to the velocity. Changing the heating rate or the magnitude of the velocity will change the temperature difference at a given point within the vessel, but it will not change the temperature difference relative to the volume average (bulk) temperature difference within the vessel. For instance, in the simple one-dimensional case of a fluid with internal heat generation rising at constant velocity within an insulated vertical cylinder, the temperature rise at the mid-point will always be one-half the temperature rise at the top, and the temperature rise at $1 / 4$ the height will be $1 / 4$ the total temperature rise regardless of the heating rate or cylinder height. Heat transfer and mixing complicate the picture, but as these results demonstrate, the T* profile within a given geometry is constant for fully developed turbulent flow. 
From the definition of $\mathrm{T}^{*}$, we find that at the wall

$$
\mathrm{T}_{\mathrm{W}}^{*} \equiv 0
$$

and for the bulk fluid

$$
\mathrm{T}_{\mathrm{b}}^{*} \equiv 1
$$

We obtain the actual temperature at any point within a vessel using the identity

$$
T-\bar{T}_{W} \equiv T^{*}\left(T_{b}-\bar{T}_{w}\right)
$$

where $\mathrm{T}-\overline{\mathrm{T}}_{\mathrm{W}}$ is obtained from the Nusselt-Rayleigh number correlation.

\subsection{Apparatus - General Scheme}

Figure 2.1 is a schematic of the experimental apparatus. The different test fluids used in the experimental vessels required different bath fluids: a liquid hydrogen bath for the liquid deuterium and hydrogen tests, and a liquid nitrogen bath for the liquid nitrogen tests. Consider a liquid hydrogen experiment. The hydrogen bath is warmed to about $28 \mathrm{~K}$ by bubbling warm hydrogen gas through the liquid and pressurizing the dewar to about $7.5 \mathrm{~atm}$. After the fluid in the test vessel has come to within $0.5 \mathrm{~K}$ or less of the bath temperature, the valve to the vent line is cracked, and the temperature of the bath falls as the bath pressure is bled down to atmospheric pressure or below. During the process a constant temperature difference is maintained between the fluid in the test vessel and the vessel wall by observing the signal from one of the differential thermocouples and adjusting the valve-opening accordingly. If the fluid properties were independent of temperature, cooling with a constant rate of heat removal would result. In practice, however, variation of the thermal properties with temperature results in a slowly decreasing heat transfer rate. 


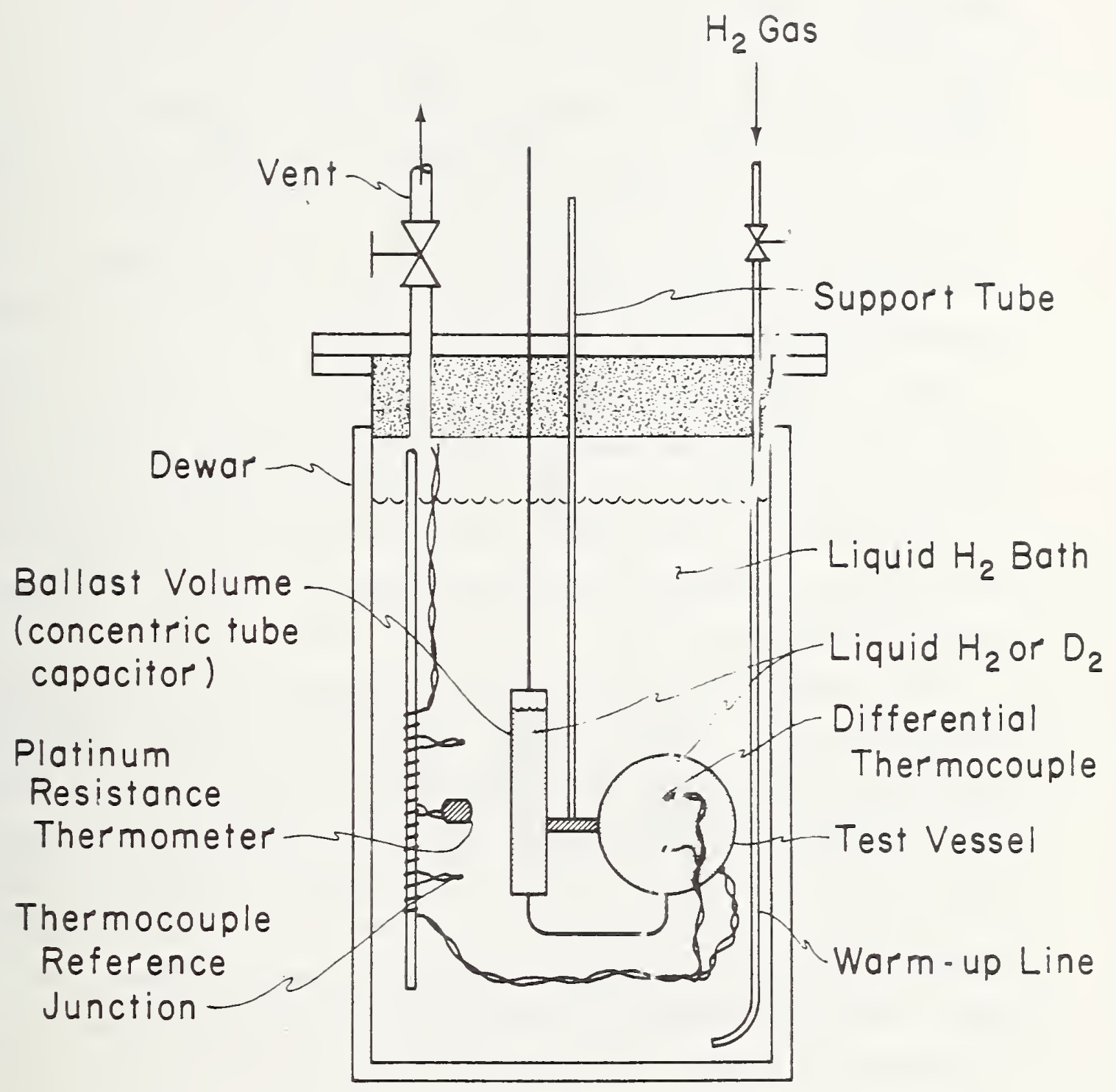

Figure 2.1. Experimental apparatus. 
During the cooling (or heating) process, temperatures within the test vessel, and at the test vessel wall were measured with differential thermocouples referenced to the bath temperature, and the absolute temperature of the bath was measured with a fast response platinum resistance thermometer. From these measured temperatures the quantities of interest may be calculated: $\overline{\mathrm{T}}_{\mathrm{w}}, \mathrm{T}_{\mathrm{fluid}}-\overline{\mathrm{T}}_{\mathrm{w}}, \mathrm{T}_{\mathrm{b}}-\overline{\mathrm{T}}_{\mathrm{w}}$, and $\partial \mathrm{T}_{\mathrm{b}} / \partial t$ (which gives $q$ ). The bulk temperature, $\mathrm{T}_{b}$, and the average wall temperature $\overline{\mathrm{T}}_{\mathrm{w}}$ are obtained from weighted averages of the fluid and wall temperature measurements.

Most of the data were collected during the cooldown mode of operation. The constant-temperature-difference operation was easier to achieve in this mode, and the bath was uniform providing a good reference temperature for the thermocouples. Data were also collected during warm-up, although the experiment was more difficult to control, and the accuracy was lower.

Some experiments were also conducted using spatially distributed heaters (concentric coils of $1.5 \mathrm{~mm}$-diameter heater wire) to simulate internal heat generation. Because the quasi-steady experiments require special equipmert and are somewhat diffj.cult to perform, these much simpler heater experiments were made to determine if they would yield results similar to the quasi-steady experiments. If similar results were obtained, then complex systems involving several modes of heat transfer might be simulated using heaters in those places where internal heat generation occurs. 


\subsection{Apparatus Details}

Figure 2.2 is a schematic of the complete experimental assembly. The $46 \mathrm{~cm}$-diameter by $165 \mathrm{~cm}$-deep test dewar is multilayer-insulated and has a 6.7 atm gauge design pressure. It is flanged at the top and may be unbolted from the top plate and lowered into a pit in order to gain access to the experimental vesse1 and instrumentation.

An airmotor driven hoist can be used to raise the experimental vessel into the vapor space above the liquid bath. This feature makes it possible to warm the experimental vessel above the bath temperature, allowing a greater temperature span to be traversed during an experiment. However, it was found to be too difficult to control the temperature of the experimental vessel in this mode of operation, so the practice was abandoned after the first two series of tests.

The ejector pump is used to pump the bath below atmospheric pressure (0.82 atm in Boulder), thus reducing the minimum attainable bath temperature to $15 \mathrm{~K}$ for hydrogen. This extension of the operating range is particularly useful at the higher cool-down rates because it allows more time to achieve quasi-steady conditions. High pressure nitrogen gas is used to power the ejector since safety considerations require that there be no contamination of the hydrogen by air within the apparatus and its associated piping.

The use of 150 liters of liquid hydrogen at pressures ranging from plus 6.7 atm to minus 0.7 atm gauge in the test dewar presents a serious potential hazard which required careful consideration. The test dewar and main control panel were placed in a room (6 meters high) with explosion-proof electrical fixtures and an exhaust fan on the roof, which changed the air in the room once every two minutes. All electronic equipment was located in a separate room with an auxiliary air-purged control panel for operation of the experiment. Thus, the personnel were isolated from the dewar when it was pressurized. 


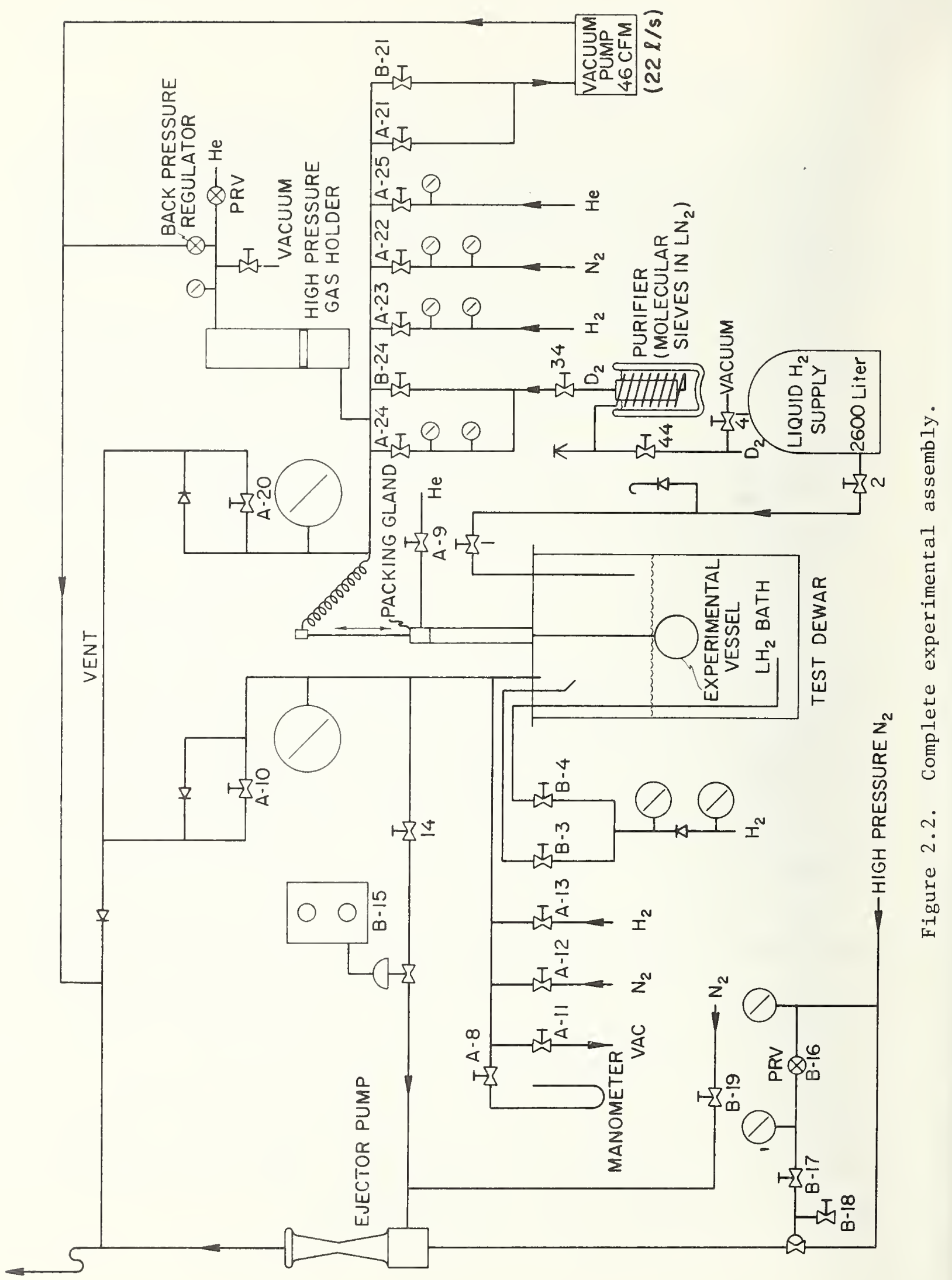


The valves with the A prefix are located on the main control panel adjacent to the test dewar, and the $B$ prefix valves are on the auxiliary panel in the instrument and control room. Provision has been made for evacuating and purging both the dewar and the test vessel with nitrogen and hydrogen gas. The bath is warmed by bleeding in gas via valve B-4, and cooled by bleeding down the dewar pressure via remotely operated valve $\mathrm{B}-15$.

It was found during the first experiments that a gradual loss of 1iquid from the ballast volume (see figure 2.1) occurred each time the experimental vessel was temperature cycled because gas was vented through the relief valve when the experimental bath was warmed. In order to prevent this loss, the high pressure gas holder was added to the system. A standard industrial air cylinder with a $10 \mathrm{~cm}$-bore by $61 \mathrm{~cm}$ stroke was adapted for this purpose. By maintaining a constant pressure (4 atm absolute) on the top side of the piston, the test vessel pressure was held constant during each test.

\subsection{Test Vessels}

The design of the test vessels (see figures 2.3 through 2.5) was governed largeiy by the test environment of differential pressures up to $3.4 \mathrm{~atm}$ in either direction, and temperatures down to $15 \mathrm{~K}$. Wood's metal solder provided a hermetic seal of the final assembly joint, and an alumina-filled epoxy sealed the thermocouple leads. Wires with enamel and polyimide insulations gave a leak-tight bond with the epoxy. Nearly adiabatic walls were provided by high density $\left(0.1 \mathrm{gm} / \mathrm{cm}^{3}\right.$ to prevent crushing by the pressure) styrofoam or glass reinforced epoxy.

Because of the high coefficient of thermal expansion of liquid hydrogen and liquid deuterium (about two percent per degree Kelvin), a liquid ballast volume (see figure 2.3) must be connected to the test vessel to assure that the vessel remains full at all times. To prevent boiling or vapor formation in the test vessel, the surface of the liquid in this ballast volume is pressurized to about 4 atm with helium gas. No evidence of helium gas desorption in the test vessel was observed. 


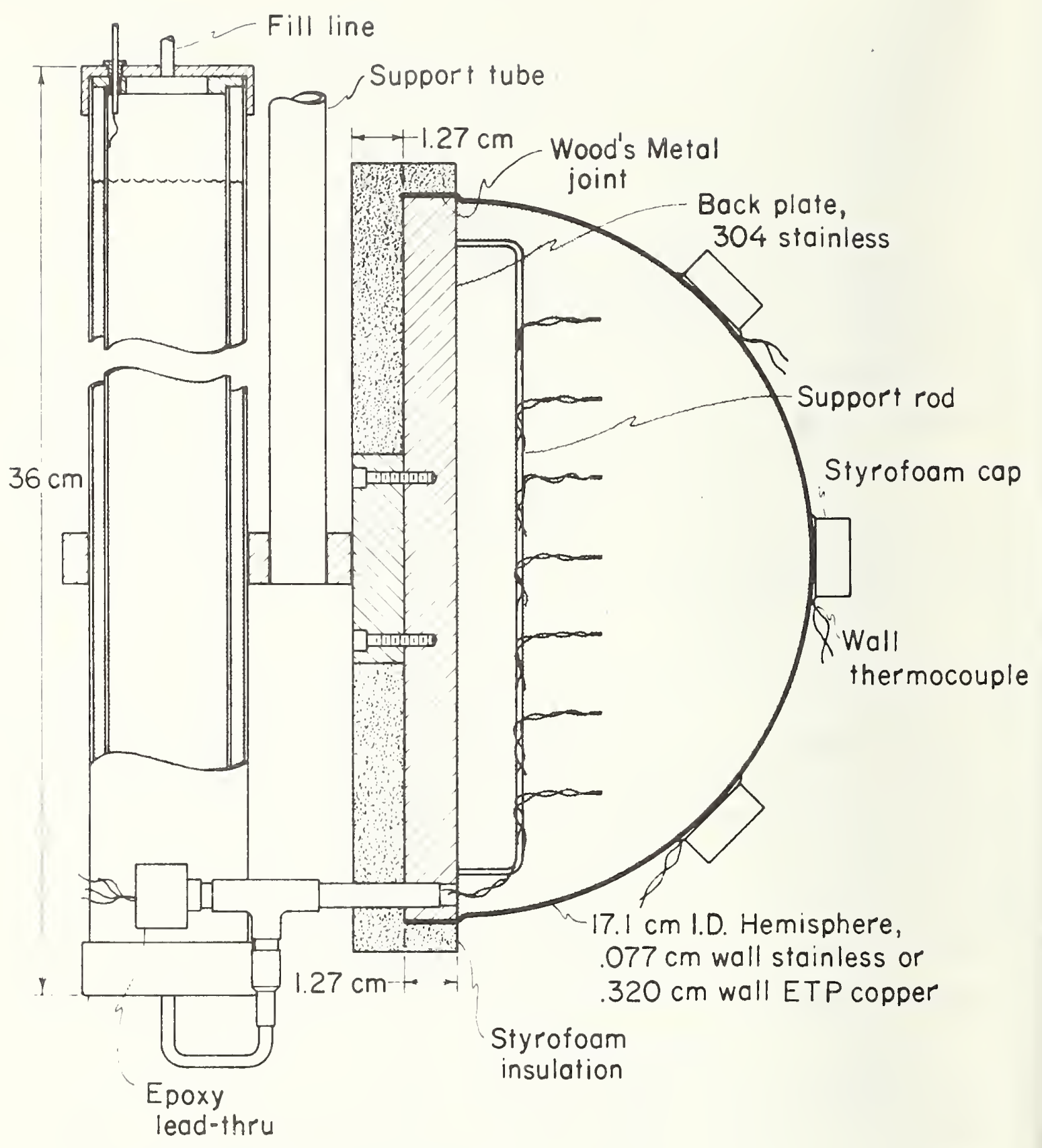

Ballast volume and concentric capacitor liquid level sensor.

Figure 2.3. Test vesse1 - $17.1 \mathrm{~cm}$ diameter hemisphere. 


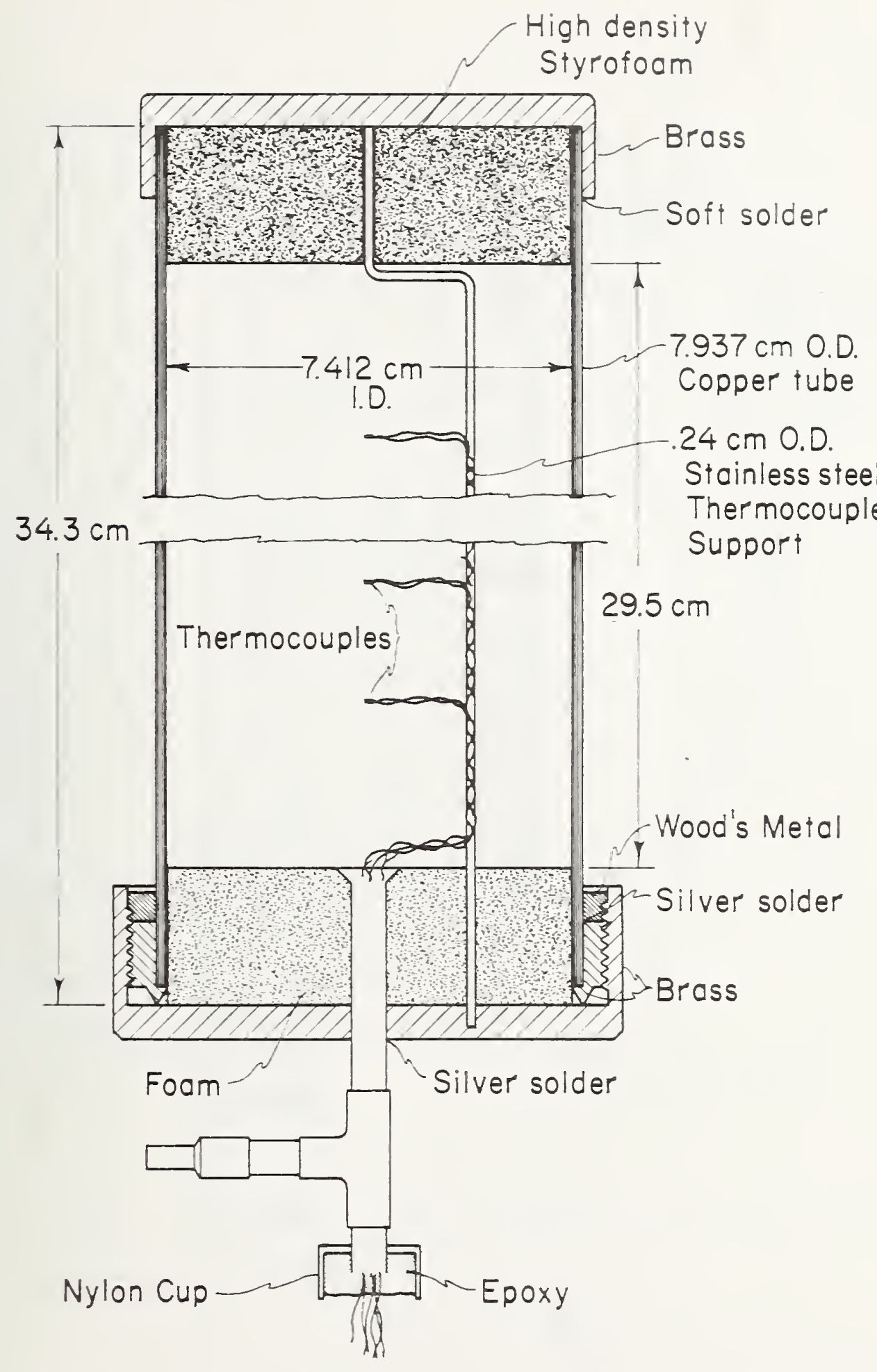

Figure 2.4. Test vessel - vertical cylinder. 


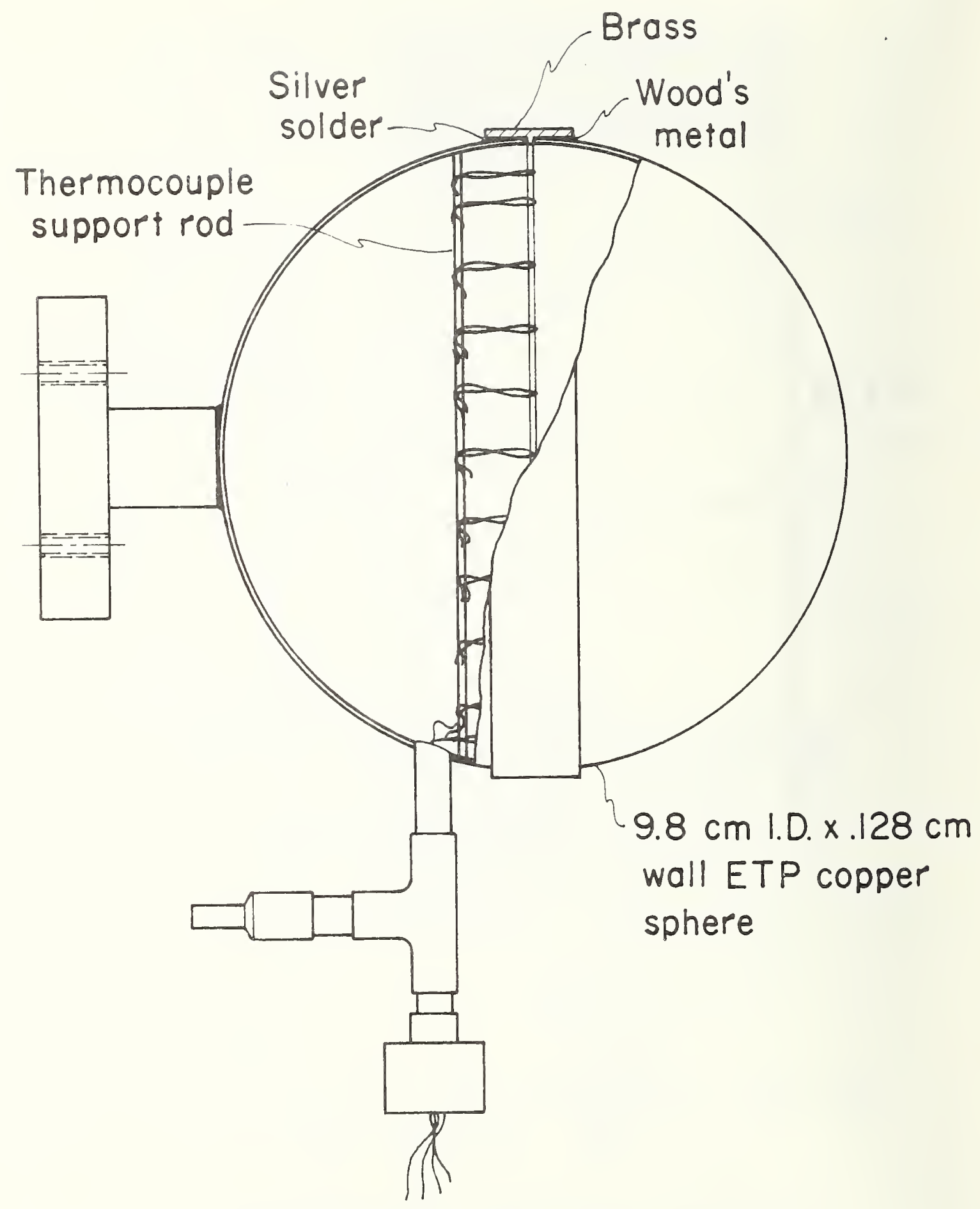

Figure 2.5. Test vessel - sphere. 


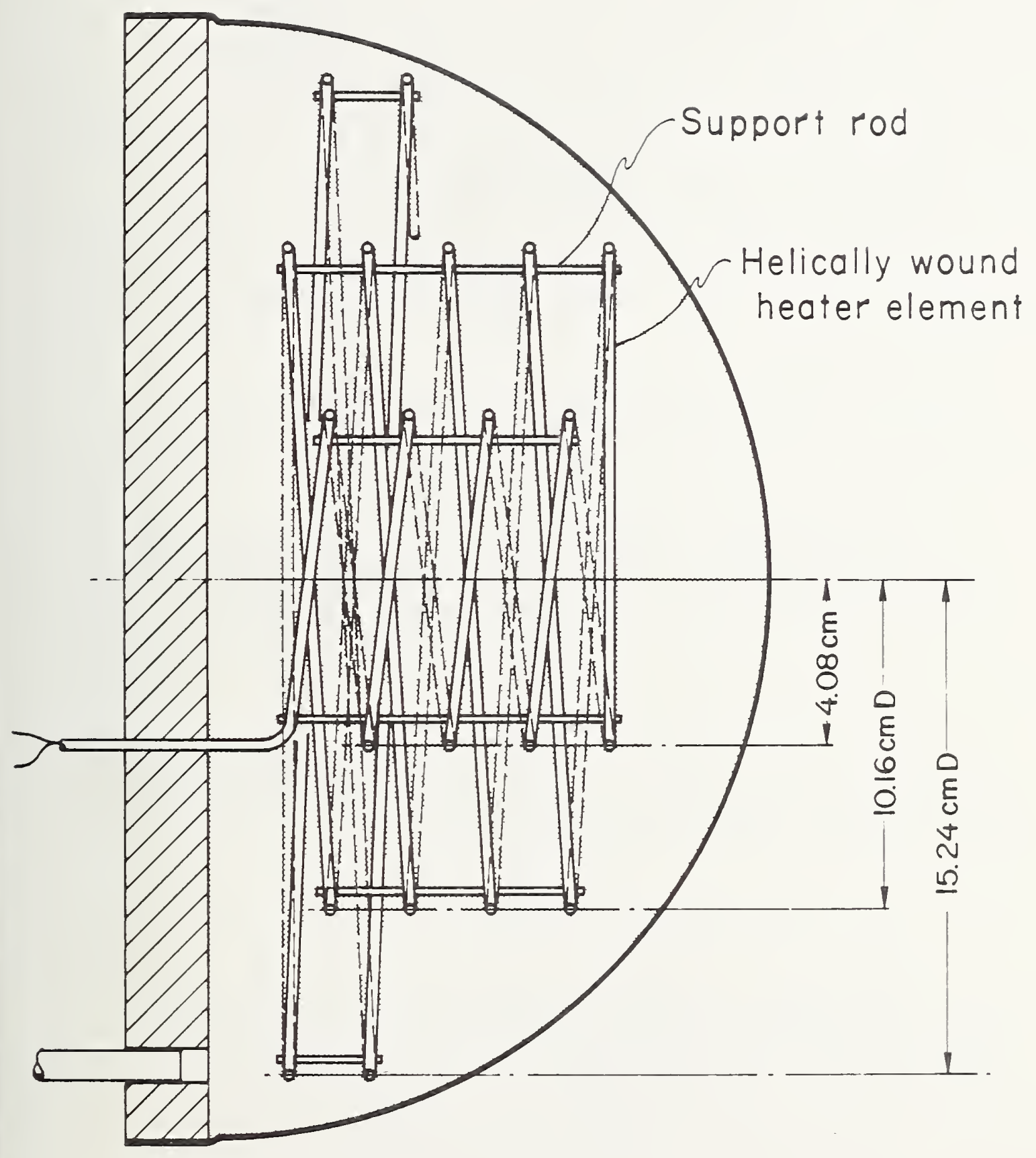

Figure 2.6. Hemisphere heater. 
Several experiments were run using a spatially distributed heater to simulate internal heat generation, as discussed in section 2.2. The heater used in the hemispheres (figure 2.6) has three concentric helical coils wound from a single length of heater element. This element has two 30-gauge resistance wires embedded in ceramic powder, and clad in a $1.5 \mathrm{~mm}$-diameter thin walled sheath of stainless steel. Braces soldered to the element give it the structural rigidity required to hold its shape. The heater element used in the vertical cylinder was simply a 5-cm diameter vertical helix, 10 turns 1ong. Both heaters have sufficient surface area to prevent boiling at the heat fluxes achieved in the experiment.

In order to study the effects of the wall resistances on the convection process, three hemispheres with different wall resistances were tested:

1) a 3 mm-wall copper hemisphere with a negligible resistance across the wall and a resistance across the outside boiling boundary layer which was determined experimentally to be

$$
\mathrm{T}_{\mathrm{W}}-\mathrm{T}_{\text {bath }}=3.9(\mathrm{q} / \mathrm{A})_{\mathrm{W}}
$$

2) a $0.76 \mathrm{~mm}$-wall stainless steel hemisphere with a calculated total resistance (wall plus outside film) of

$$
\mathrm{T}_{\mathrm{W}}-\mathrm{T}_{\text {bath }}=7.7(\mathrm{q} / \mathrm{A})_{\mathrm{W}}
$$

3) a plastic-copper laminated hemisphere having a $0.05 \mathrm{~mm}$-thick layer of polyparaxylyene vapor deposited on the inside, and having a thermal resistance given by

$$
\mathrm{T}_{\mathrm{W}}-\mathrm{T}_{\text {bath }}=10.0(\mathrm{q} / \mathrm{A})_{\mathrm{W}} .
$$

A summary of the experimental vessel geometries and characteristics is given in Table 2.1. 


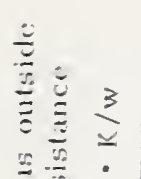

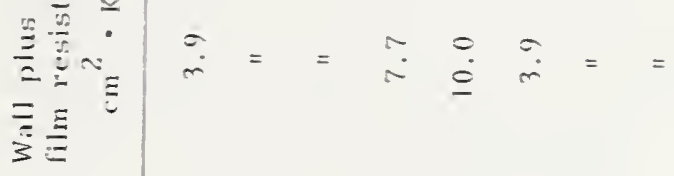

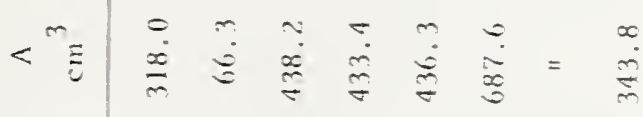

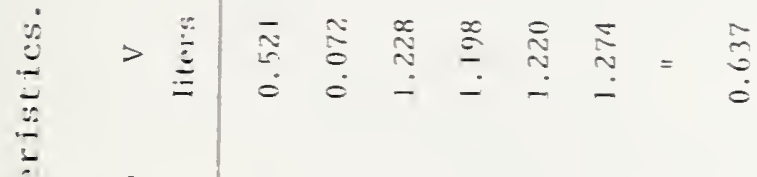

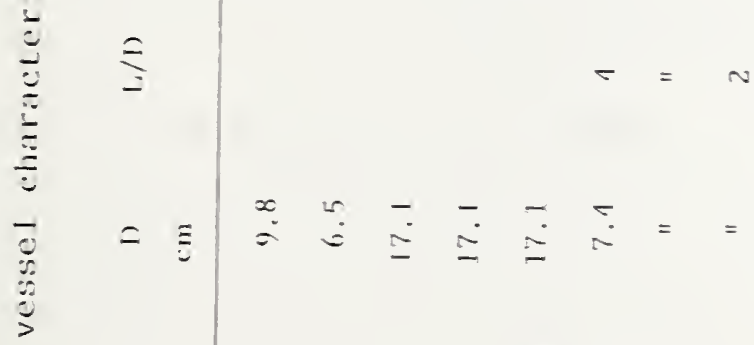

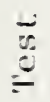

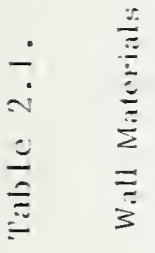

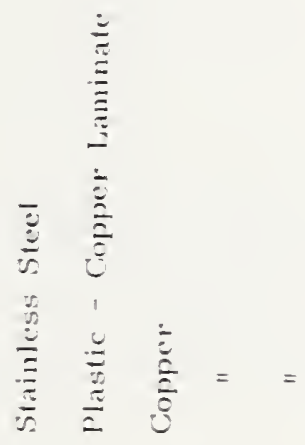

$$
\begin{aligned}
& \text { 产言= = } \\
& \text { | }
\end{aligned}
$$




\section{5 Instrumentation}

Chromel vs. gold - 0.07 atomic percent iron differential thermocouples were chosen to measure the enclosed fluid and vessel wall temperatures because of the high sensitivity these thermocouples exhibit at liquid hydrogen temperatures (approximately $16 \mu \mathrm{V} / \mathrm{K}$ ). The wire diameters are $0.15 \mathrm{~mm}$ for the gold-iron and $0.22 \mathrm{~mm}$ for the chromel, including the $.01 \mathrm{~mm}$ thick enamel insulation. The reference junctions lie in the liquid bath as illustrated in figure 2.1. Thirty-six gauge thermocouplegrade copper wires traverse the distance from the bath to outside the dewar top plate, and the 20-meter long copper leads from the dewar to the instrument room have both electrostatic shielding (braided copper) and electro-magnetic shielding (iron conduit).

Thermal tempering of the thermocouples within the test vessels was accomplished by simply cantilevering the wires horizontally for about $4 \mathrm{~cm}$ from their support rod as shown in figure 2.3. Two factors make this technique suitable. First, except for a thin boundary layer near the wall, temperature gradients were found only in the vertical direction. Second, from temperature profile data collected in the vertical cylinder experiments, core velocities are estimated to be on the order of $1 \mathrm{~cm} / \mathrm{sec}$. Thus the horizontal thermocouples traverse an isothermal region where they are subjected to cross-flow velocities on the order of $1 \mathrm{~cm} / \mathrm{sec}$. Under these conditions the thermal tempering error is calculated to be less than $10^{-3} \mathrm{~K}$.

The thermocouple junctions which measure the fluid temperature are generally aligned on the vertical axis in the sphere, vertical cylinders, and horizontal cylinders; and aligned along a vertical line displaced from the back plate, $1.0 \mathrm{~cm}$ for the $17.1 \mathrm{~cm}$-diameter hemispheres, and $0.5 \mathrm{~cm}$ for the $6.5 \mathrm{~cm}$ diameter hemisphere. In a few tests some of the thermocouple junctions were distributed horizontally in an attempt to measure horizontal temperature gradients.

Measurement of the wall temperature has often presented something of a problem in heat transfer measurements, and the most common technique-- 
that of inserting thermocouples in long, small diameter holes parallel to the wall surface--was not practical here. Both the two-dimensionally curved wall surfaces and the desire to keep the wall as thin as structurally possible (in order to reduce the wall's heat capacity) dictated that another technique be chosen. As illustrated in figure 2.7, the thermocouple is wound in a spiral for thermal tempering. The polyimide film, which is epoxied to the outside of the wall, provides electrical insulation from the wall, and the styrofoam cap provides thermal insulation from the bath. This technique is suitable only for walls with a high thermal conductance if the wall temperature drop from the edge to the center of the cap is to be kept small. Thus the inside wall temperature for the stainless steel and copper-plastic walled vessels was obtained using the outside film resistance measured for the copper vessels and a calculated wall resistance. The thermal resistance across the polyimide film is the principal source of wall temperature error -amounting to about one percent of $\mathrm{T}_{b}-\overline{\mathrm{T}}_{\mathrm{w}} \cdot$ The measured average wal1to-bath temperature difference (given in section 2.4 as $\overline{\mathrm{T}}_{\mathrm{w}}-\mathrm{T}_{\mathrm{b} \text { ath }}=$ 3.9 (q/A)) is in good agreement with previously measured boiling liquid hydrogen temperature differences. [15]

The bath temperature was measured by a small (5 mm square by $1 \mathrm{~mm}$ thick), fast-response, ceramically encapsulated, platinum-resistance thermometer (PRT), which sits in the midst of the thermocouple reference junctions as indicated in figure 2.1. The systematic error in the PRT calibration is believed to be $0.05 \mathrm{~K}$ or less -- a more than adequate accuracy since the bath temperature is needed primarily for the determination of the thermal properties.

The microvolt level thermocouple signals were amplified by high quality, wide band, chopper stabilized, differential DC amplifiers. A 16 channel data logger unit (consisting of a digital volt meter, a scanner, a digital clock, and a magnetic tape drive) recorded the thermocouple and PRT outputs on magnetic tape at a rate of one scan per second. The rms noise of the complete data acquisition system is about $1 / 2$ microvolt (equivalent to $.03 \mathrm{~K}$ ) and the drift of the system between zero 


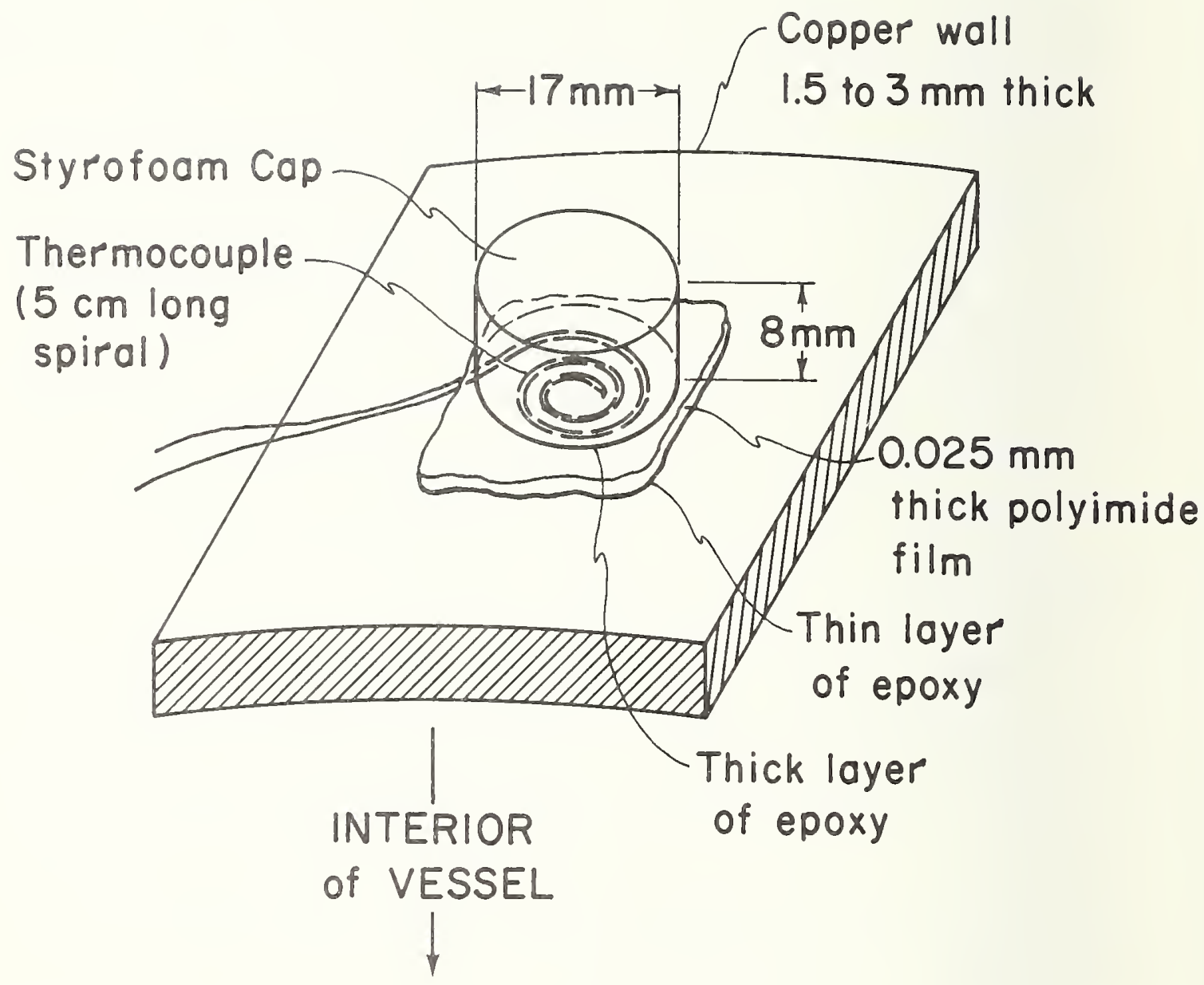

Figure 2.7. Wall thermocouple installation - copper walls. 
readings is about $1 / 3$ microvolt referred to the input. In one experiment, two thermocouples were imbedded in a copper block which was heated above the hydrogen bath temperature by as much as $8 \mathrm{~K}$, and the agreement was generally better than $0.05 \mathrm{~K}$. Dip tests of the thermocouples in liquid nitrogen and liquid hydrogen indicated a maximum discrepancy of $1.2 \%$ between the observed emf and the thermocouple reference table used here. [13]

To summarize the error discussion, the agreement between thermocouples was generally better than $0.05 \mathrm{~K}$, and the estimated systematic error was 3 percent or less of $\mathrm{T}-\overline{\mathrm{T}}_{\mathrm{W}}$. The systematic error in the heat flux is estimated to be less than 10 percent for the insulated wall vessels (a11 vessels except the sphere) and about 5 percent for the sphere. The overall systematic error of the correlations is estimated to be less than 13 percent for all of the fluids used in this study. For other fluids, an additional systematic error of 10 percent could be present because of the uncertainty in the thermal properties (principally the thermal conductivity) of liquid deuterium. The random error in Nusselt number for the overall correlation is typified by a standard deviation of 11 percent.

The liquid level in the ballast volume was determined from the capacitance of this concentric tube device (see figure 2.3). It was originally hoped that an accurate determination of the bulk temperature in the experimental vessel could be made from this liquid level measurement (in a manner analogous to mercury-glass thermometry) but the practical calibration problems involved were too time consuming for the variable density, variable dielectric constant fluids. However, this liquid level sensor was a useful aid in the operation of the experiment.

\subsection{Data Reduction}

Data reduction is a two-step process. First, the emfs are converted to temperatures and heating rates by a digital computer. Then, these temperature and heating rate data are scanned by eye, and points sufficiently quasi-steady in nature are selected for evaluation of the Nusselt number, Rayleigh number, and dimensionless temperature profile. 
The bulk temperature of the fluid is calculated from a weighted average of the interior thermocouple readings. Weights are assigned as the fraction of the total volume occupied by a horizontal segment having the thermocouple located at its vertical center. An absence of horizontal temperature gradients in the bulk of the fluid makes this the appropriate method of weighting. The boundary layer is neglected in this calculation, but its contribution should be small, since attempts to directly measure the inside wall temperature indicated that the boundary layer is only a fraction of a millimeter thick.

The average wall temperature is calculated from a weighted average in a manner similar to the bulk temperature calculation. Weights are assigned according to the fraction of the total wall surface area between horizontal planes equidistant from the thermocouples.

Because the inside wall temperature of the stainless steel and the plastic-copper hemispheres could not be measured, these wall temperatures were calculated using the wall and film resistances given in table 2.1 .

The heat transferred is determined from the time rate of change of the bulk temperature according to the expression

$$
q=\rho V C \frac{\partial T_{b}}{\partial t} \text {. }
$$

For warm-up type experiments, in which fluid is expelled from the vessel, $C$ is simply the specific heat at constant pressure, $C_{p}$. For cool-down experiments, however, allowance must be made for fluid entering the vessel cooler than the fluid within the vessel. In this case, as shown in appendix $\mathrm{A}$,

$$
C=C_{p}+\beta\left(i_{j}-i\right)
$$

where $i_{j}$ is the specific enthalpy of the fluid entering the vessel, and $i$ is the specific enthalpy of the fluid within the vessel. 
In evaluating the Nusselt and Rayleigh numbers, the characteristic temperature difference is $T_{b}-\vec{T}_{w}$, and the fluid properties are evaluated at the bulk fluid temperature, $T_{b}$. The characteristic length is the vessel diameter for the spheres, hemispheres, and horizontal cylinders; and the height for the vertical cylinders.

\subsection{Thermal Properties}

Table 2.2 1ists the thermal properties of the test fluids as a function of temperature. Because of the large relative span in absolute temperature covered by deuterium and hydrogen, the properties of these two fluids exhibit a particularly strong temperature dependence.

A large uncertainty is assigned to the thermal conductivity of liquid deuterium because of the discrepancy (20 percent) between the conductivity values given by Powers et al.24] and Roder and Diller [25] for liquid hydrogen. The Roder and Diller values for hydrogen are believed to be correct, and since Powers et a1. used the same apparatus for $L D_{2}$ and $L H_{2}$, the Powers values for $L D_{2}$ have been reduced by 20 percent. In spite of this correction a 20 percent uncertainty is possible in the $\mathrm{LD}_{2}$ thermal conductivity. As will be discussed in section 4.2, however, intercomparison of the $\mathrm{LH}_{2}$ and $L D_{2}$ Nusselt numbers indicates that this uncertainty may be closer to 10 percent.

\section{Results}

Figures 3.1 through 3.6 and table 3.1 summarize the results for the copper walled vessels. Appendix C gives the complete results for each vessel shape, wall material, and type of experiment. The curves and expressions for Nu given on the graphs were obtained from a least squares curve fit to the expression $\mathrm{Nu}=\mathrm{C}_{1} \mathrm{Ra}^{\mathrm{n}}$. Both floating exponents and fixed fractional exponents were tried in these curve fits, and when the increase in the standard deviation was less than 5 percent of the standard deviation for the floating exponent [i.e., $\odot$ (fractional exponent) < $1.05 \sigma$ (floating exponent) ], the more convenient fractional exponents are given. Only the liquid deuterium and liquid nitrogen data were used to obtain the expressions and curves shown in the figures 
产:

$\mathrm{un}^{\circ}$ gु $x$

$\frac{0}{\infty} \frac{0}{n}=$

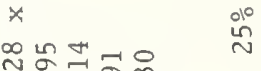

N듬요

เं

'웅

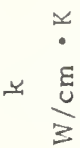

$x$

*

-

1요

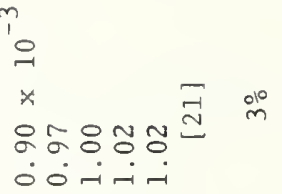

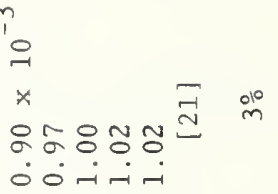

in

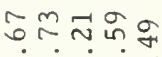

inisi

mo

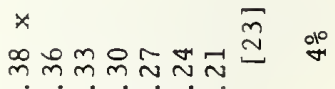
-i-i-i-i

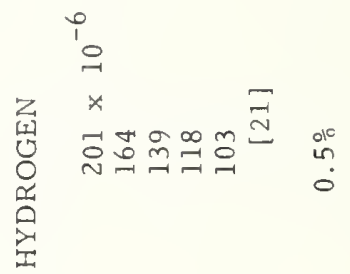

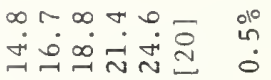

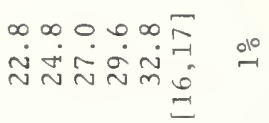

국유ㅇㅛㅠ

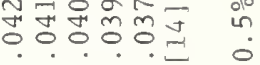

00000

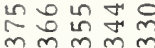

लํํㅇํㅇㅇㅇㅇ

0000:

$\stackrel{010}{\circ}$

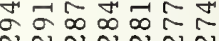

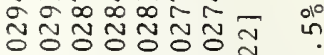
0.0000․․

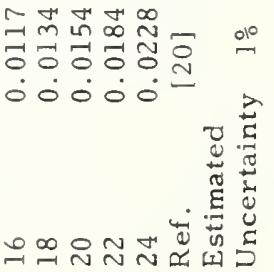

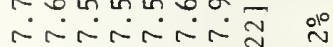

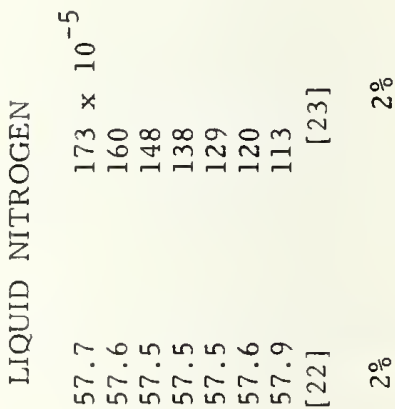

$2 \stackrel{x}{2}$

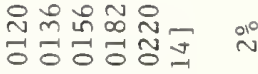

$0000:=$

焉离离
กินีกิ์

ㅇㅇㅇㅇㅇㅇㅇㅇㅇㅇㅠ 순 000000.

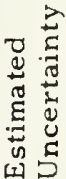

$\sim$

$\frac{\pi}{3}$ 
because the hydrogen data have a mean negative deviation of 8.4 percent from the deuterium and nitrogen data. The standard deviation of the curve through the cooling data for $\mathrm{LD}_{2}$ in copper vessels, $\mathrm{Nu}=0.104 \mathrm{Ra}^{0.352}$, is 10.4 percent.

The warming data (figure 3.4), although of lower accuracy than the cooling data, demonstrate that, as expected, the Nusselt numbers are essentially the same for heating and cooling. The 7.2 percent systematic difference between the heating and cooling data is within the experimental error.

Use of the dimensionless temperature,

$$
T *=\frac{T-\bar{T}_{W}}{T_{b}-\bar{T}_{W}},
$$

results in a single dimensionless temperature profile for each shape when the flow is fully developed. Because of the virtual absence of horizontal temperature gradients within the vessels (except in the boundary layer), the temperature in any given horizontal plane is characterized by a single temperature. The standard deviation of $\mathrm{T} *$ is about 0.03 at most points within the vessels. At the top of the vertical cylinders, $\sigma$ of $\mathrm{T} *$ is as large as 0.08 .

Wall temperature profile data are omitted for the stainless steel and plastic-copper hemispheres (Appendix C) because no direct measurements were made. For these vessels, only an average wall temperature was calculated as discussed in section 2.6. A single wall thermocouple was mounted (at the horizontal pole) on the $6.5 \mathrm{~cm}$ diameter hemisphere because of this vessel's small size. Generally larger wall temperature gradients occur in the warming experiments (comparing figure C.6 with figure C.16 and figure C.12 with figure C.17) because of the lower outside wall heat transfer coefficients in these experiments.

Following the quasi-steady cooling period, transient cooling of the vessels occurred with a nearly constant bath temperature. Figures 


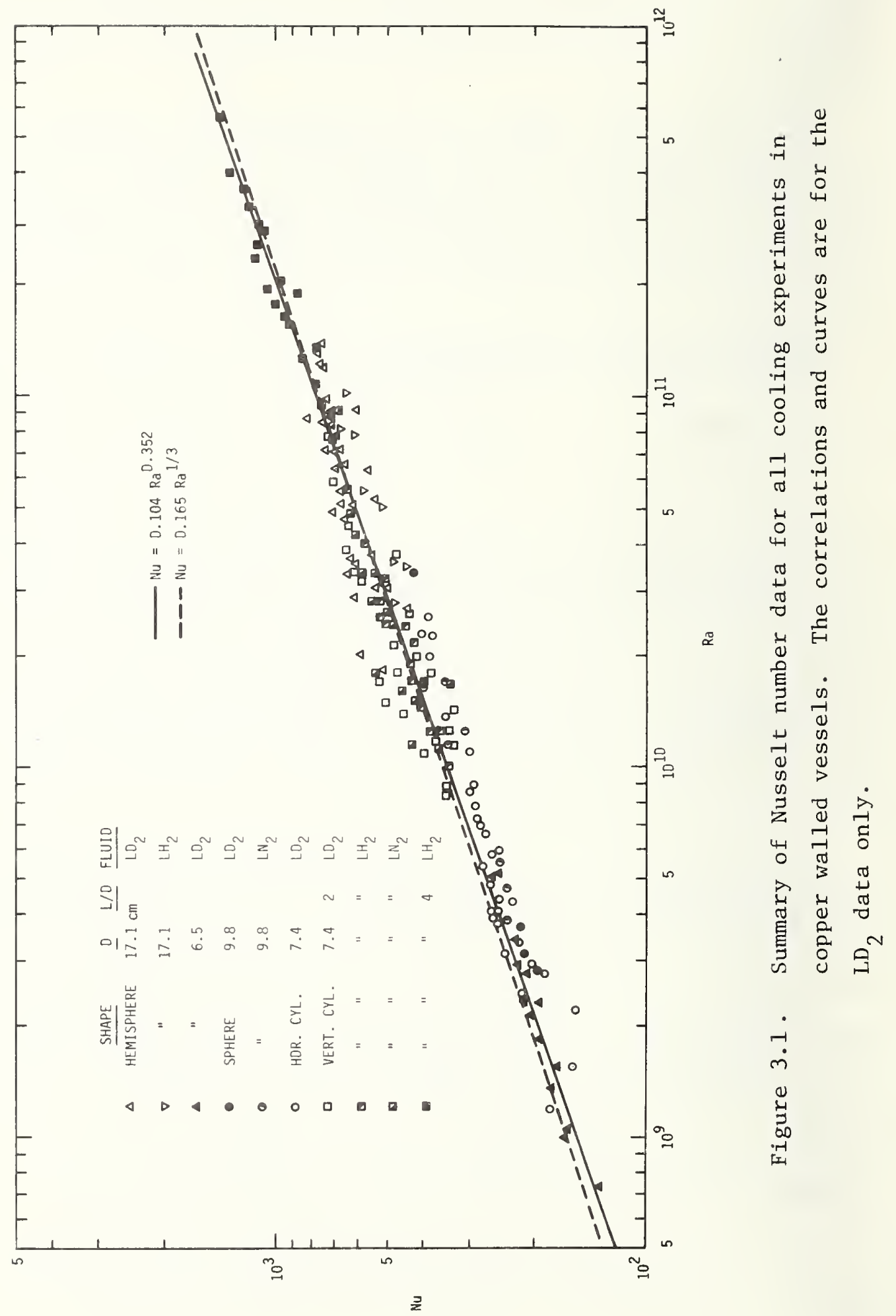




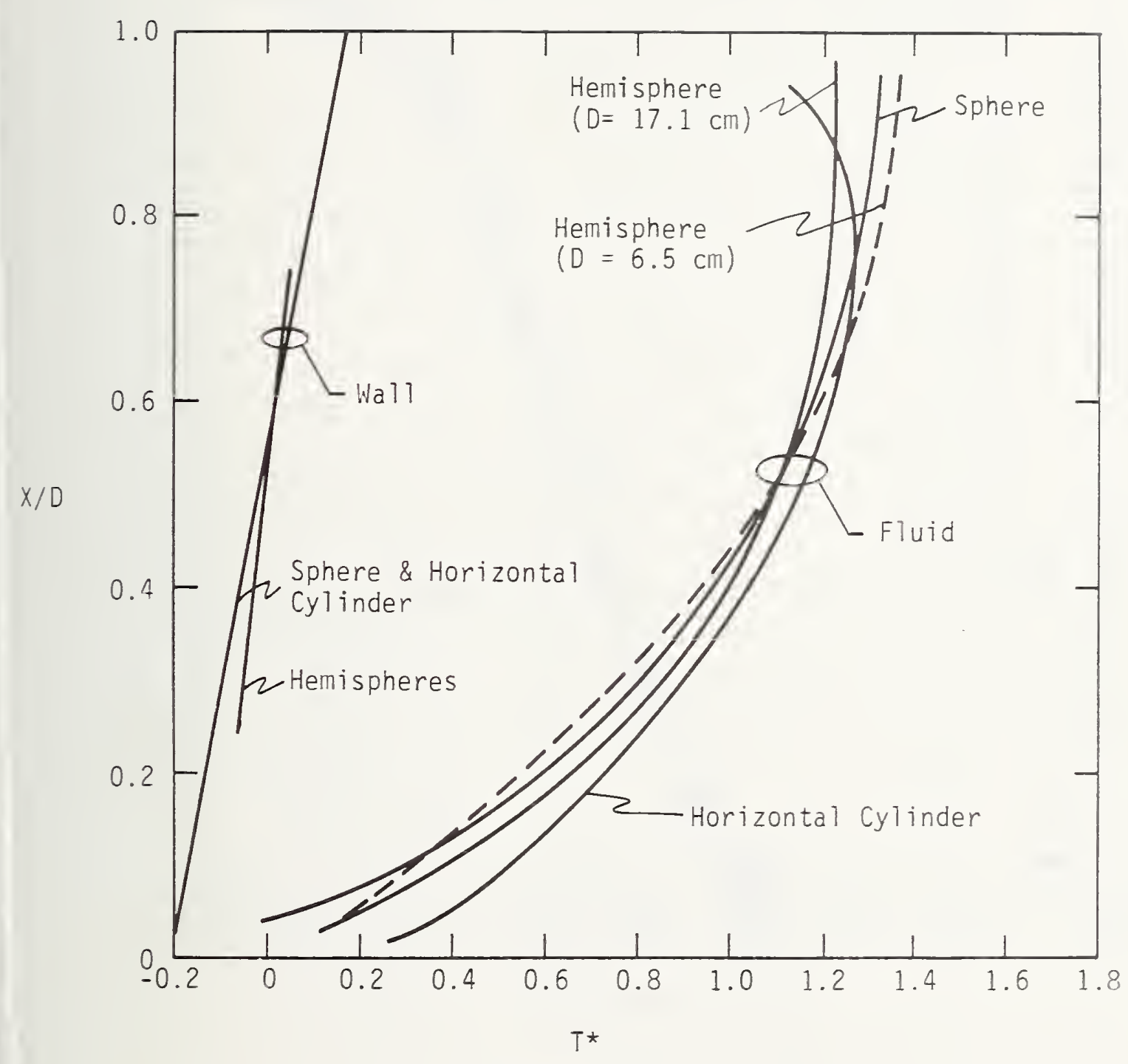

Figure 3.2. Vertical temperature distributions of the copper walled hemispheres, sphere, and horizontal cylinder for the warming experiments. The fluid is liquid deuterium. 


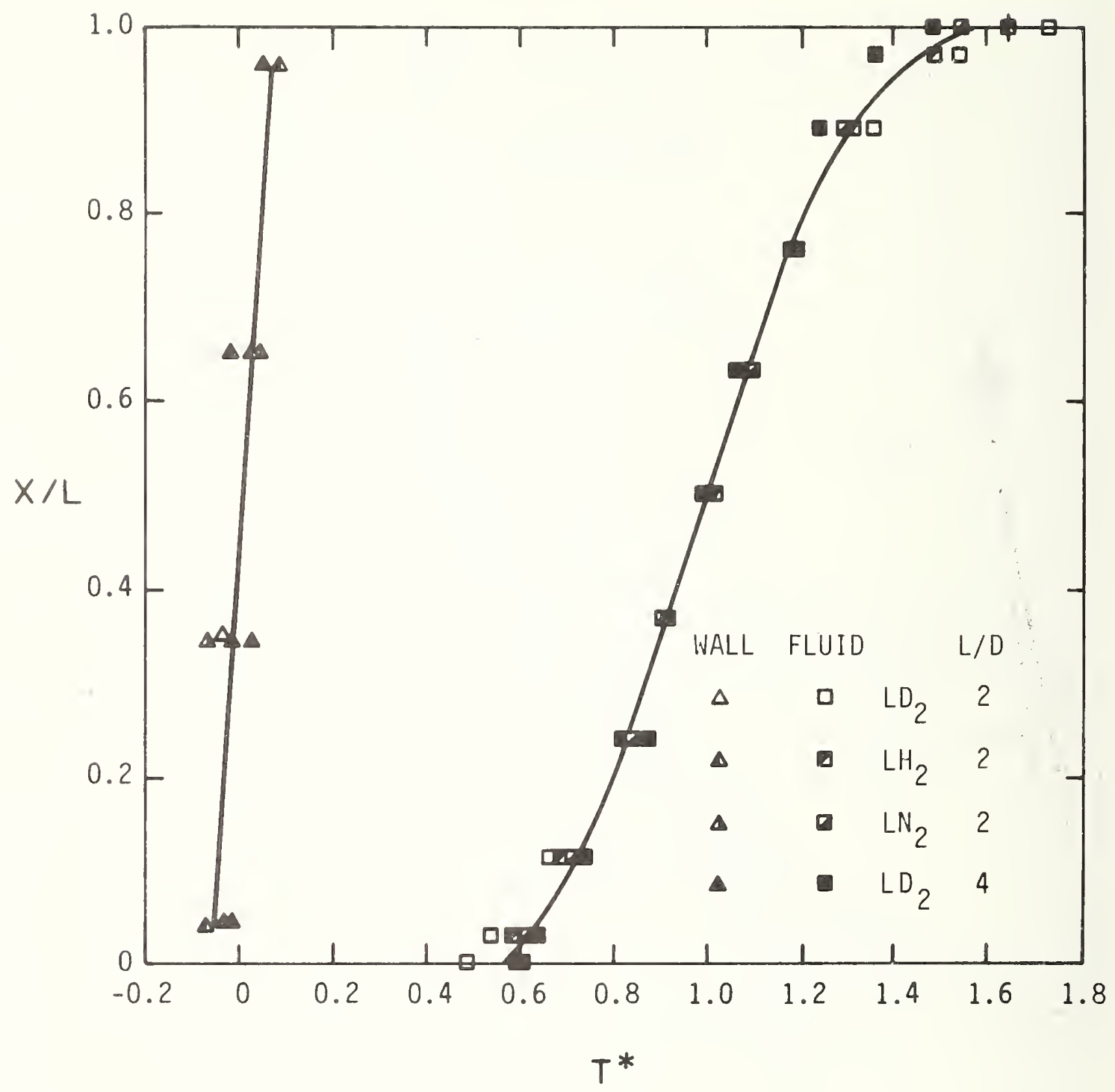

Figure 3.3. Vertical cylinders (copper wall) - vertical temperature distribution for cooling experiments. 


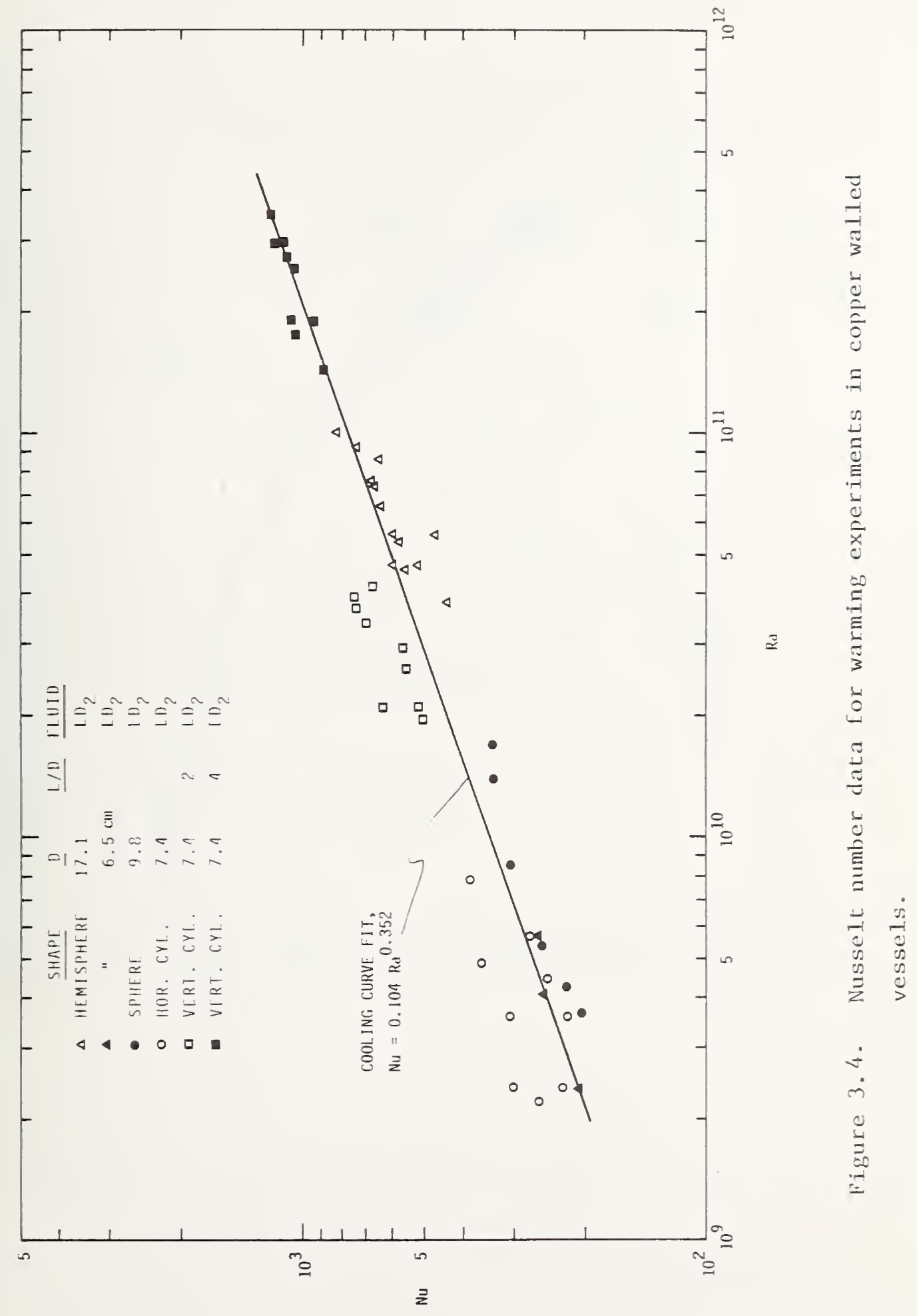




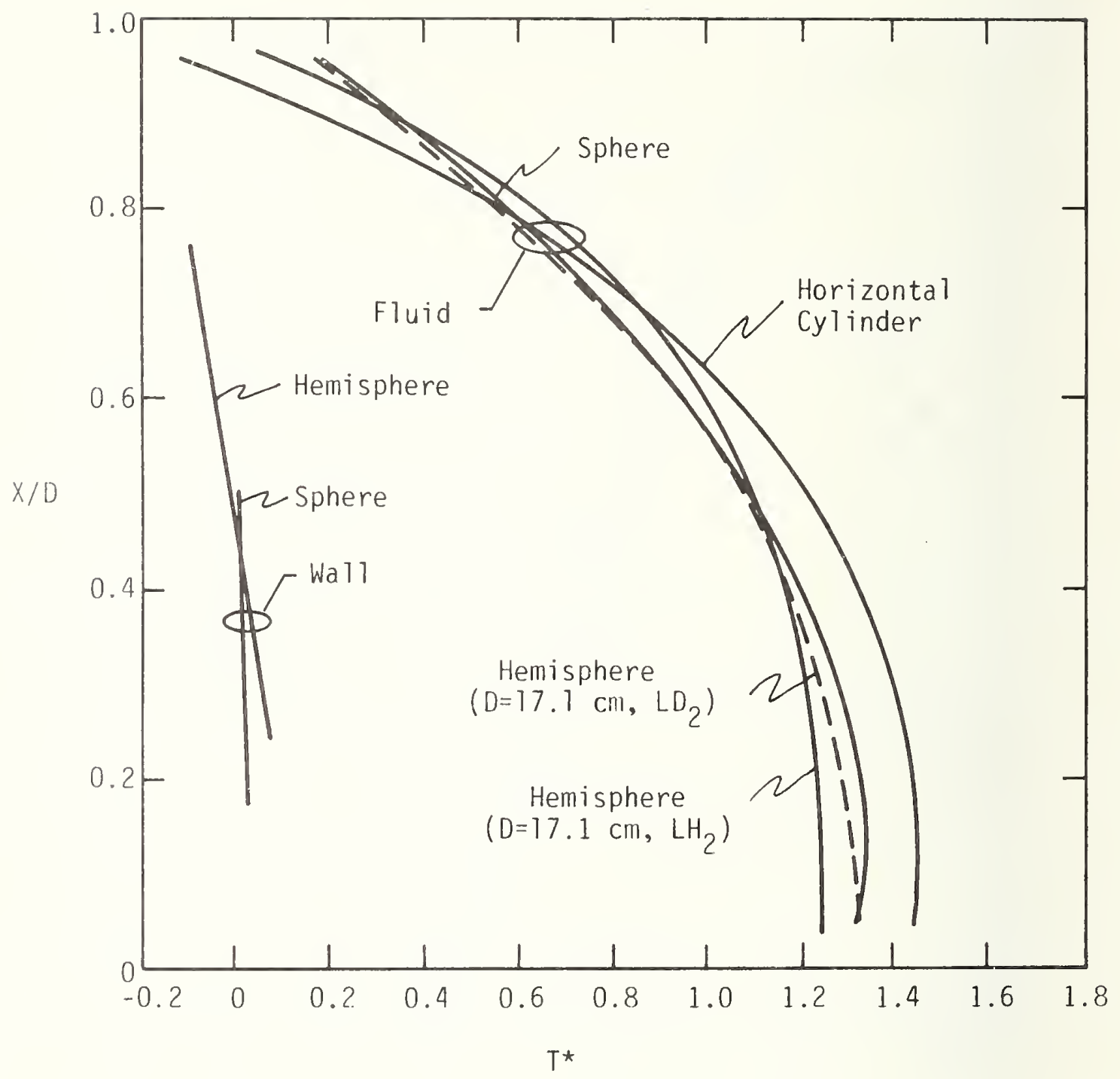

Figure 3.5. Vertical temperature distributions of the hemispheres, sphere, and horizontal cylinder for the warming experiments. Unless specified, the fluid is liquid deuterium. 


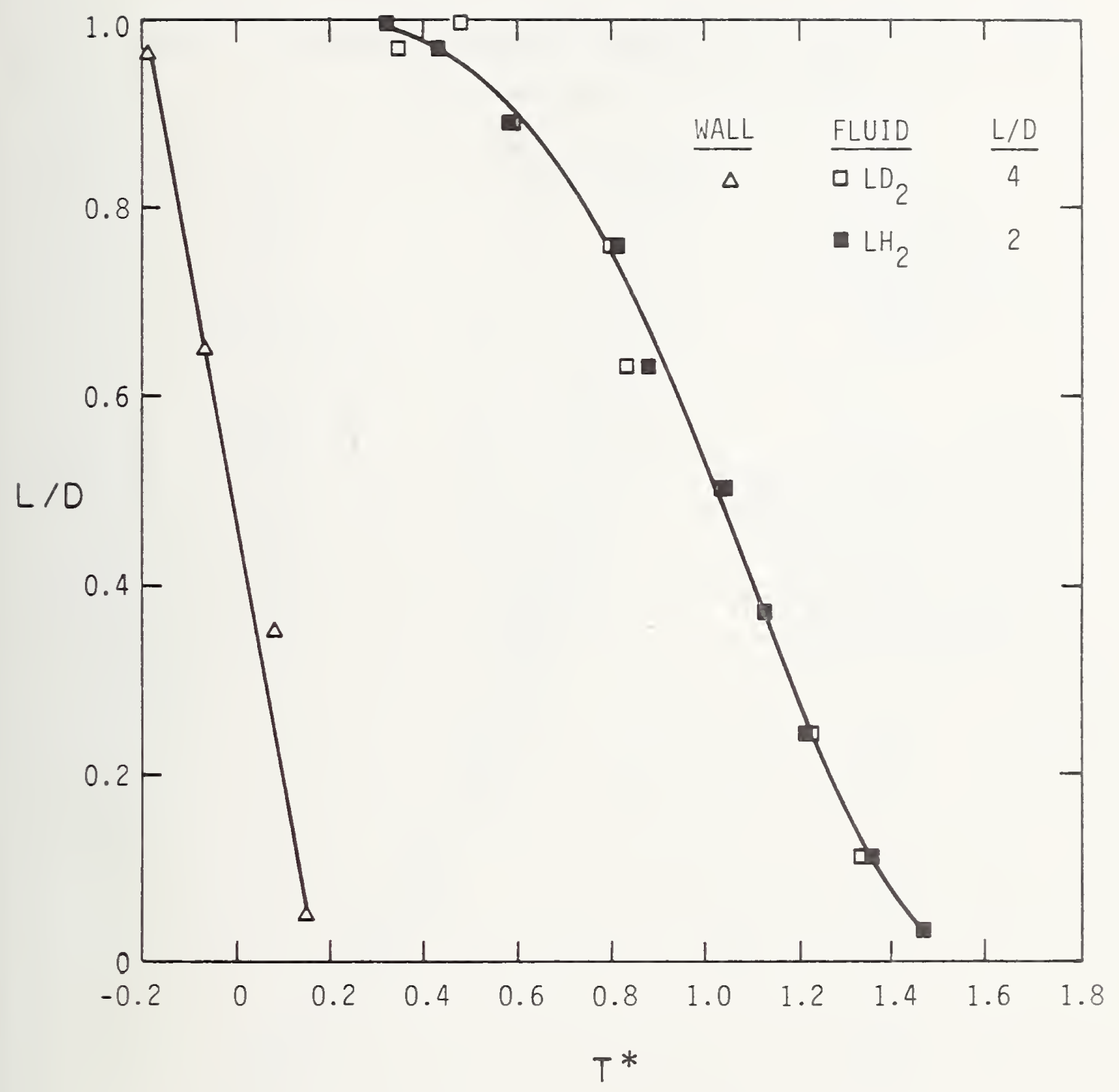

Figure 3.6. Vertical cylinders (copper wall) - vertical temperature distribution for warming experiments. 
Table 3.1. Summary of Nusselt number correlations for liquid deuterium cooling experiments.

$$
\mathrm{Nu}=\mathrm{C}_{1} \mathrm{Ra}^{\mathrm{n}}
$$

\begin{tabular}{lccc}
\multicolumn{1}{l}{ Test Vessel } & & $\mathrm{C}_{1}$ & $\mathrm{n}$ \\
All Shapes & 0.104 & 0.352 \\
$" \quad$ & 0.166 & $1 / 3$ \\
Sphere & 0.446 & 0.284 \\
Hemispheres (Copper) & 0.164 & $1 / 3$ \\
Horizontal Cylinder & 0.151 & $1 / 3$ \\
Vertical Cylinders & 0.171 & $1 / 3$
\end{tabular}




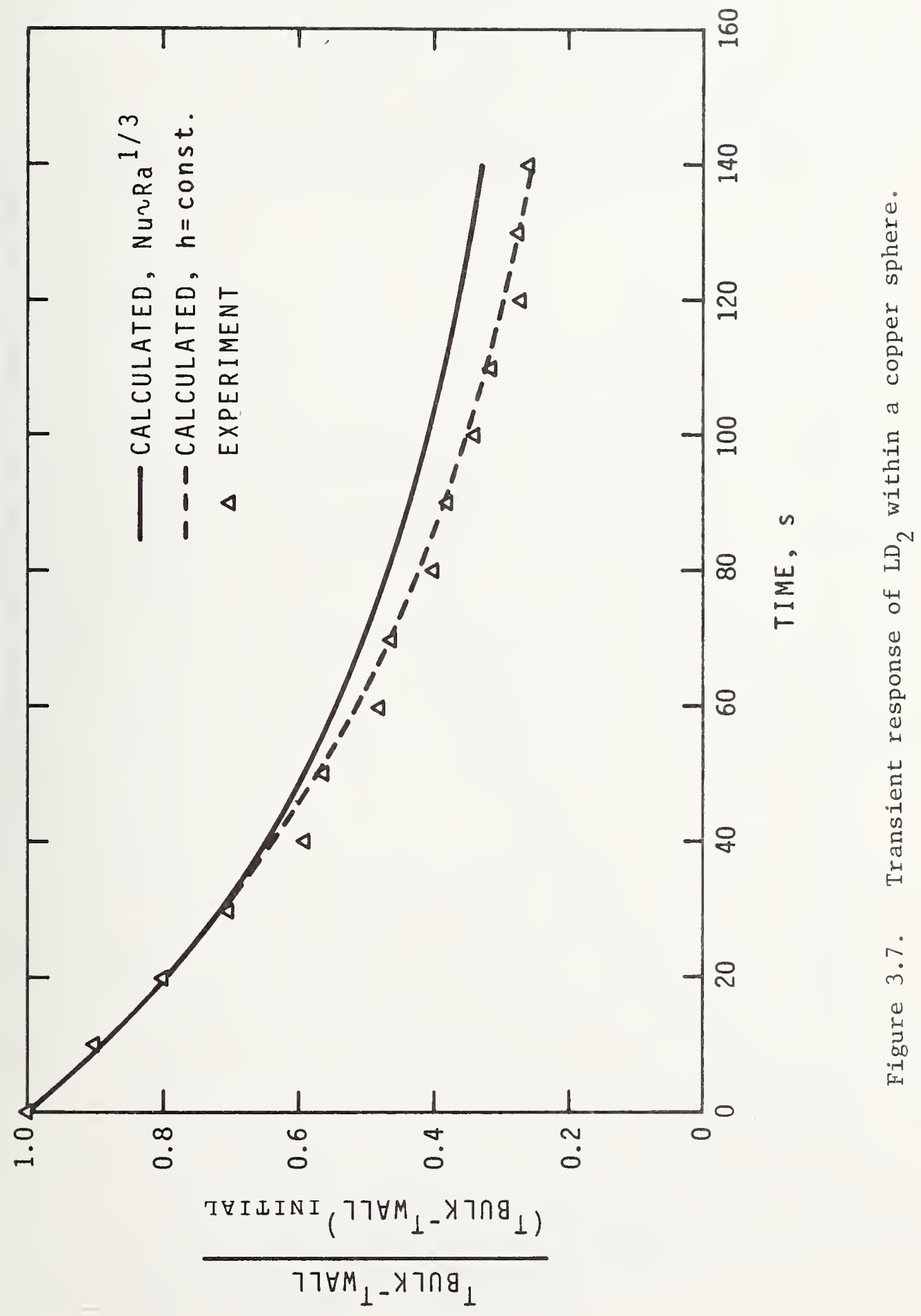




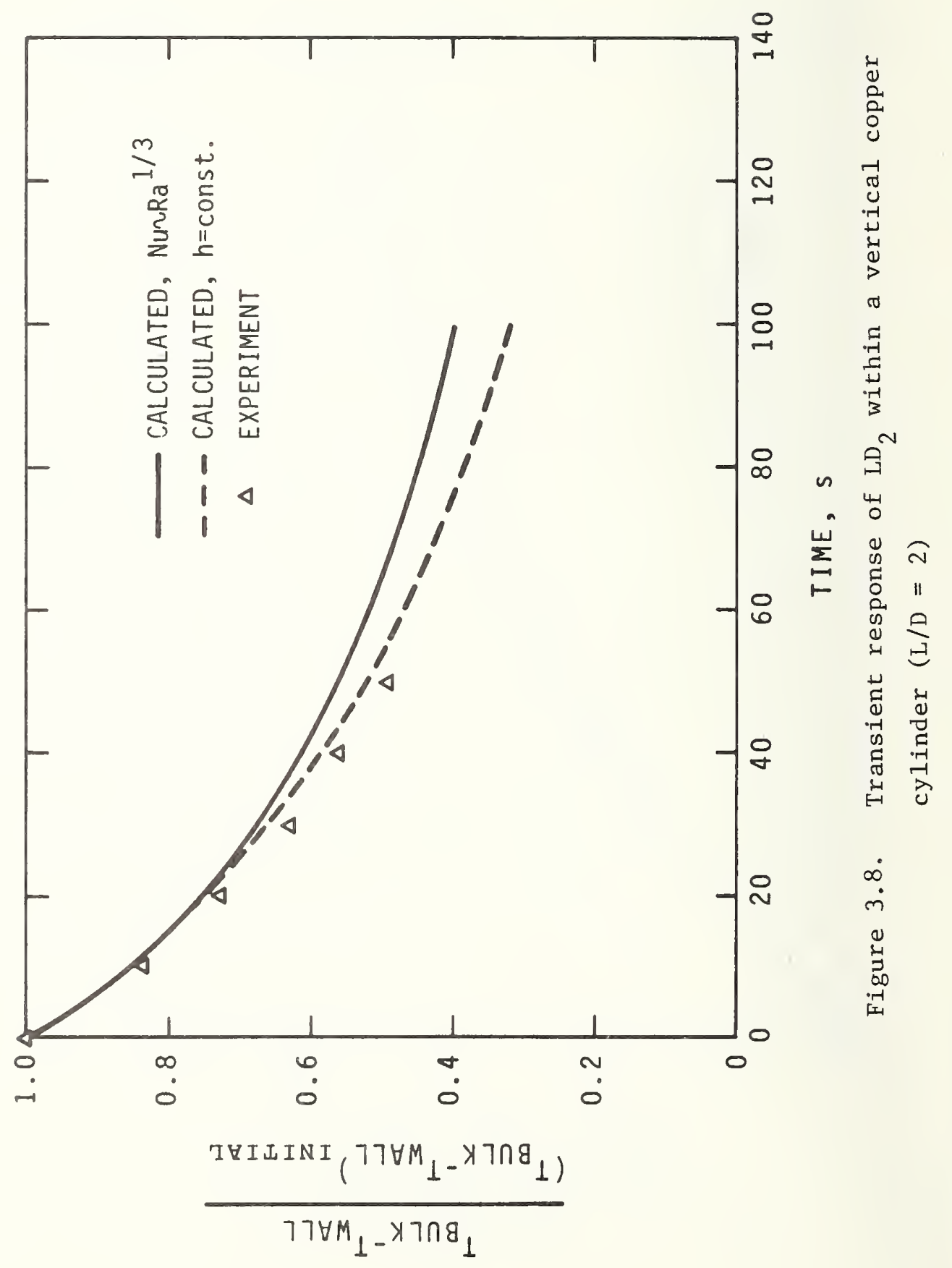


3.7 and 3.8 show cooling curves for two such transient experiments. Both calculated curves are based on the quasi-steady cooling correlations, but the solid curve assumes the heat transfer coefficient depends on the instantaneous value of $\mathrm{T}_{b}-\overline{\mathrm{T}}_{\mathrm{W}}$, while the dashed curve assumes $\mathrm{a}$ constant heat transfer coefficient that is evaluated using $\left(\mathrm{T}_{\mathrm{b}}-\overline{\mathrm{T}}_{\mathrm{W}}\right)_{\text {initial }}$. The constant $h$ curve shows better agreement with the experimental data. This is in accord with the results of Evans and Stefany, [7] who observed constant $h$ cooling in their transient experiments.

\section{Discussion}

\subsection{Temperature Profiles}

The temperature field within a vessel provides considerable information about the convective process. Figure 4.1, which is a composite of the temperatures measured in several different hemisphere experiments, indicates the virtual absence of horizontal temperature gradients within the bulk of the fluids. Less extensive measurements in other vessels gave similar results.

A comparison of the temperature profiles for the sphere, hemisphere, and horizontal cylinder, figure 3.2 indicates that a single dimensionless temperature profile would give a reasonable description of the temperature field within any of these vessels. This is not too surprising considering the similarity of the shapes.

We obtained information on the boundary layer thickness while attempting to measure the inside wall temperature directly. Thermocouples $0.1-\mathrm{mm}$ thick were glued to the inside wall of the stainless steel hemisphere. These thermocouples measured temperatures about midway between the fluid temperature and the calculated wall temperature, indicating a boundary layer thickness of on $1 \mathrm{y}$ a few tenths of a millimeter. This thickness agrees with the value of 1-mm or less observed by Evans et al[3] Thus emerges a picture of a thin boundary layer flow down the walls, and a slowly rising core free of horizontal temperature gradients for the cooling experiments. For the warming experiments the flow directions are reversed. 


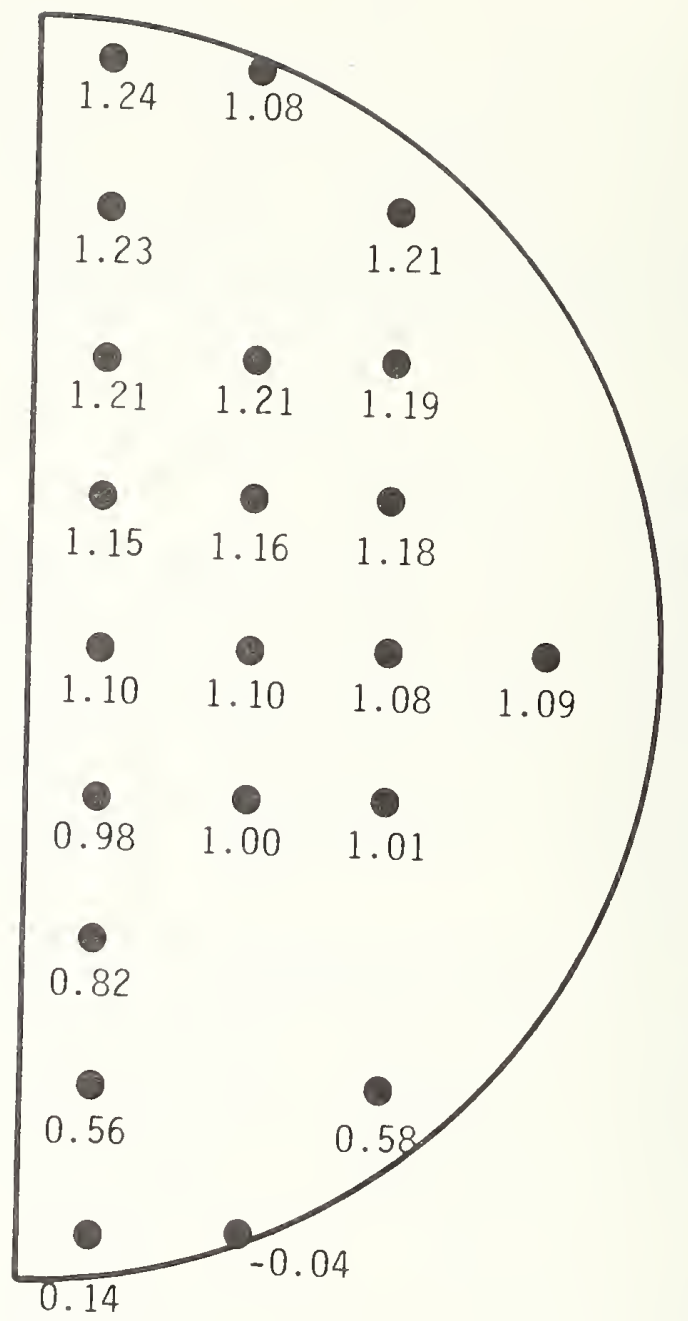

Figure 4.1 Dimensionless temperature, $T *$, within $17.1 \mathrm{~cm}$ diameter hemisphere for cooling experiments. Measurements are in the vertical plane bisecting the hemisphere. 
The relatively small vertical temperature gradient in the upper portion of the sphere, hemispheres, and horizontal cylinder for the cooling experiments (lower portion of the vessel for heating experiments) indicates highly turbulent mixing in this region. Schmidt [6] observed this condition in Schlieren photographs of free convection within a horizontal cylinder. The temperature gradient for cooling in the lower portion of the sphere, hemispheres, and horizontal cylinder indicates that boundary layer fluid enters the core all along this region. If we consider the uniform heat generation analogy, then potential flow from a source at the bottom of the vessel would give

$$
\frac{\partial T^{*}}{\partial(x / L)} \sim \frac{\partial T}{\partial x} \sim \frac{1}{w} \sim \text { Area normal to flow }
$$

as shown in the Appendix B. Thus the temperature gradient should increase proceeding from the bottom to the middle. However, the temperature profiles shown here exhibit the opposite behavior, indicating a substantial deviation from this type flow.

Schmidt ${ }^{[6]}$ measured the vertical temperature profile within spheres during transient heating. His profiles show a maximum temperature difference at the mid-point followed by a small decrease in the $\Delta \mathrm{T}-$ proceeding towards the bottom. In contrast, our heating profiles are nearly isothermal in the lower portion as shown in figure 3.5. The absence of wall temperature data in Schmidt's paper prevents a more quantitative comparison.

The difference between the temperature profiles for the small and large copper hemispheres (figure 3.2) apparently results because the tests with the smaller hemisphere covered the region of transition from laminar to turbulent flow. The Rayleigh number for these tests ranges from $7(10)^{8}$ to $6(10)^{9}$, spanning the approximate transition Rayleigh number of $10^{9}$. At the lower Rayleigh numbers, the $\mathrm{T} *$ 's in the upper portion of the hemisphere were somewhat larger than shown in figure 3.2, while at higher Rayleigh numbers the $\mathrm{T} *$ profile nearly coincides with that of the larger hemisphere, indicating that the turbulence had become nearly fully developed. 
The linear portion of the vertical cylinder temperature profile (figure 3.3) suggests a flow model (similar to that adopted by Evans, Reid and Drake ${ }^{[3]}$ ) consisting of a thin boundary layer at the wall and vertical slug flow of the core. Using this flow model it is possible to predict the core velocity, $w_{c}$, if $\partial T^{*} / \partial(x / L)$ and $N u=f(R a)$ are known. The relationship is probably most easily understood using the internal heat generation approach, although identical results are also obtained for the quasi-steady case. As discussed previously, a heat generating fluid creates a temperature gradient in the core as it rises. In the absence of heat transfer or mixing, this temperature gradient will be linear if the core velocity is constant. Noting that

$$
\frac{\partial T}{\partial x}=\frac{1}{w_{c}} \quad \frac{\partial T}{\partial t}
$$

and that

$$
\rho C_{p} \frac{\partial T}{\partial t}=\frac{q}{V}
$$

it is shown in Appendix B that the core velocity is given by

$$
w_{c}=\frac{4(q / A)}{\rho C_{p} D\left(\frac{\partial T}{\partial x}\right)}
$$

or if $\mathrm{Nu}=\mathrm{C}_{1} \mathrm{Ra} 1 / 3$, then

$$
w_{c}=\frac{4(L / D)(q / A)^{1 / 4}}{\rho C_{p} C_{2} \frac{\partial T^{*}}{\partial(x / L)}}
$$

For $(q / A)=0.1 \mathrm{~W} / \mathrm{cm}^{2}$ the resulting core velocity in these experiments is $0.5 \mathrm{~cm} / \mathrm{s}$.

The I/D dependence of $w_{C}$ in equation 4.4 is to be expected from the continuity equation since the core cross sectional area is proportional to $\mathrm{D}^{2}$, while the boundary layer area is proportional to D. The dependence, $w_{C} \propto L$, indicates that the volume flow rate in the core, and therefore in the boundary layer, is proportional to the cylinder length L. This result compares to

$$
\text { Volume flow rate } \propto \mathrm{L}^{3 / 4}
$$


for free convective laminar flow where $\mathrm{Nu} \propto \mathrm{Ra}^{1 / 4},[26]$ and to

Volume flow rate $\propto L^{1.2}$

for turbulent flow where $\mathrm{Nu} \propto \mathrm{Ra}^{0.4}$, according to integral equation analysis for an isothermal, vertical flat plate. [27] The source of this $w_{c} \propto L$ dependence is the observed independence of $\partial \mathrm{T} * / \partial(\mathrm{x} / \mathrm{L})$ on L. Because the cylinder height, L, was only changed by a factor of 2 , a weak dependence of $\partial \mathrm{T} * / \partial(\mathrm{x} / \mathrm{L})$ on $\mathrm{L}$ would go undetected.

In free convection, heating and cooling are inverses, and inverting either the direction of gravity (coordinate system) or the sign of the temperature difference should have the same effect. Inverting both the coordinate system and the sign of the temperature difference should leave the temperature field unchanged. Figure 4.2 compares the temperature profile within the sphere during cooling with the inverted sphere heating temperature profile, where the inversion is made using the expression

$$
(\mathrm{x} / \mathrm{D})_{\text {inverted }}=1-(\mathrm{x} / \mathrm{D})
$$

i.e., the coordinate system is simply flipped upside down. As might be expected, the agreement between the two sets of data is excellent. The agreement for the copper hemispheres is equally good, but the slope of the vertical cylinder heating curve is slightly higher than the cooling data - probably reflecting the effect of the greater wall temperature gradient. Comparing the horizontal cylinder temperature profiles, the poorer agreement is primarily the result of distortion caused by the slightly negative $\mathrm{T}^{*}$ observed in the top of the cylinder during heating.

The temperature profiles for the stainless steel and copper-plastic hemispheres (figure C.9) are in close agreement with the copper hemisphere profile (figure C.6), indicating no substantial changes in the convection process for the increased wall resistances studied here. The slight increase in the maximum temperature with increased wall 


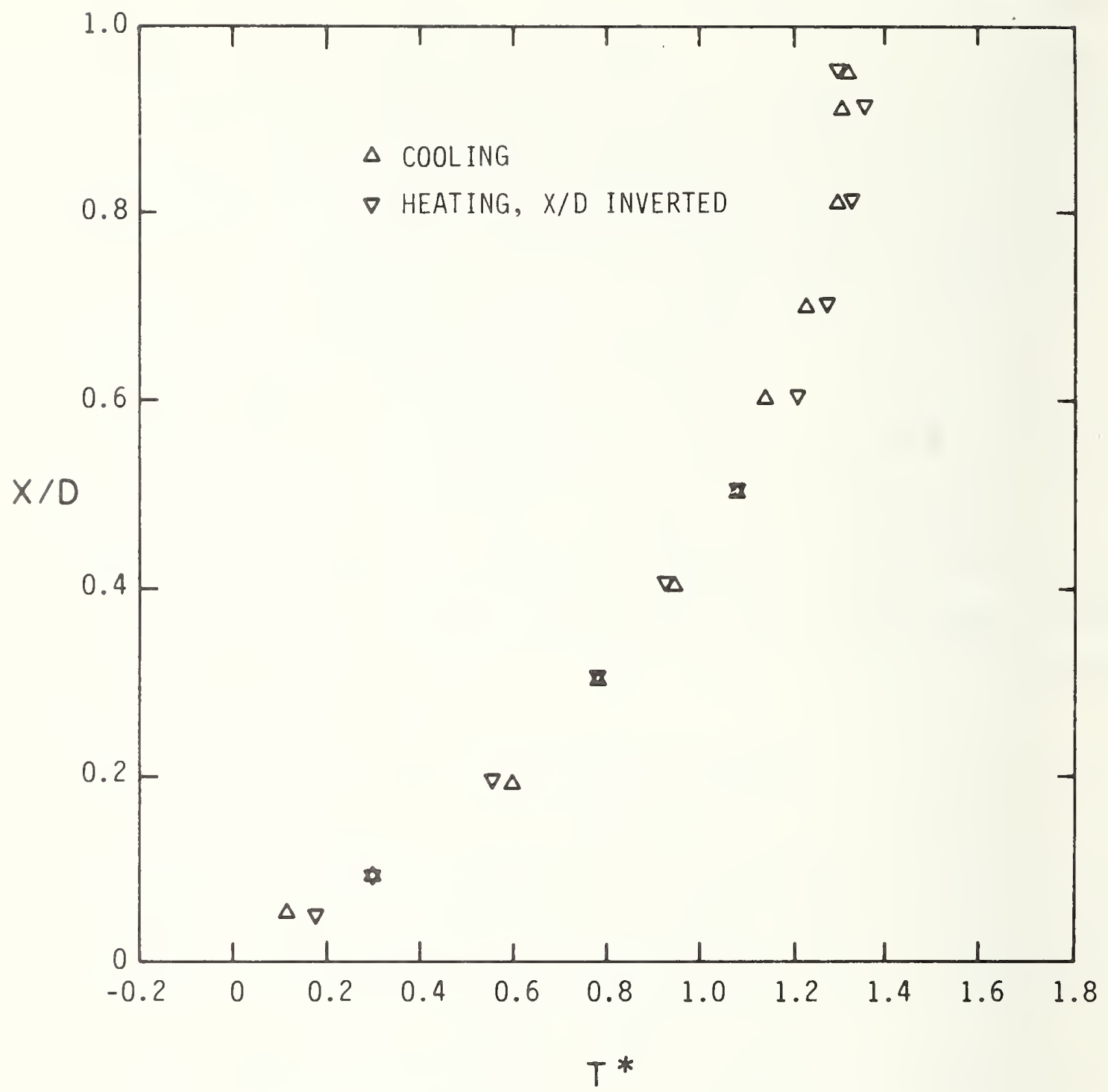

Figure 4.2. Comparison of the vertical temperature distribution within the sphere during cooling with the inverted temperature distribution during warming. 
resistance should be expected because of the concomitant increase in the wall temperature gradient.

The agreement between the heater and quasi-steady cooling temperature profiles is reasonably good for the hemispheres (figure C.10) and poor for the vertical cylinder (figures C.13). Because the core of the hemispheres is highly turbulent even in the quasi-steady cooling experiments, the additional turbulance added by the heater apparently has little effect. In the case of the vertical cylinder, however, the heater evidently causes considerable distortion of the natural flow patterns. In both heater experiments, the maximum dimensionless temperature is only slightly greater than in the cooling experiments.

\subsection{Nusselt Numbers}

The general agreement between the Nusselt numbers for the various shapes (as indicated in figure 3.1) is not too surprising considering that King ${ }^{[28]}$ obtained similar agreement for convection from vertical cylinders and planes, horizontal wires, spheres, and blocks. In both cases this agreement is probably due more to the comparison of surface average heat transfer coefficients rather than to basic similarity in the details of the processes. For instance, Jakob ${ }^{[29]}$ has shown that the average heat transfer coefficient from a horizontal plate is nearly the same as for a vertical plate, in spite of the 2:1 variation in the average heat transfer coefficient between the top and the bottom of the horizontal plate. Because there is no theoretical justification for using a single expression to represent the data for all the shapes, the expressions given in the separate figures of Appendix $C$ are generally recommended.

The bulk of the data is well represented by a Rayleigh number exponent of 1/3, although in a few cases a somewhat lower value was obtained. These lower exponents occur only for the data for a single size vessel, and are probably the result of a combination of factors. The strong temperature dependence of the physical properties is a possible cause, since higher heat fluxes occurred at higher temperatures; use of some average boundary layer temperature would tend to increase 
the exponent. Statistical variations in the slope can also occur, and finally, some of the effect could be real. When both the size and the heat flux are allowed to vary, however, an exponent near $1 / 3$ best represents the process.

Comparing the stainless steel and copper-plastic hemisphere results to the copper hemisphere results (table C.1), we note a general trend toward a lower Nusselt number with increasing wall resistance. Because the inside wall temperatures are calculated rather than measured, the accuracy of these results is lower than for the copper-walled vessels, and a correlation of Nusselt number vs. wall resistance is unfeasible. The experiments using spatially distributed electric heaters show reasonable agreement of the Nusselt number with the quasi-steady cooling results, although the slope of the $\mathrm{Nu} v s$. Ra curves tend to be greater.

In comparing our Nusselt numbers with those in the literature, we find that quasi-steady, turbulent, free convection within enclosed vessels has been investigated neither for the cryogenic fluids studied here, nor for other fluids. Schmidt, ${ }^{[6]}$ reporting on transient turbulent convection $\left(3 \times 10^{8}<\operatorname{Ra}<5 \times 10^{11}\right.$ ) of water and alcohols within spheres, found that $\mathrm{Nu}=0.119 \mathrm{Ra}^{1 / 3}$ using the average wall-to-bulk fluid temperature difference. Evans and Stefany [7] use the expression $\mathrm{Nu}=0.55 \mathrm{Ra}^{1 / 4}$ to fit their transient laminar $\left(6 \times 10^{5}<\mathrm{Ra}<7 \times 10^{9}\right)$ experiments of free convection of water, glycerine, etc., within horizontal and vertical cylinders. Both the Schmidt and the Evans and Stefany results are in close agreement with the expressions recommended by Jakob ${ }^{[28]}$ (based on King's data):

$$
\mathrm{Nu}=0.555 \mathrm{Ra}^{1 / 4} \quad \text { for laminar flow, }
$$

and

$$
\mathrm{Nu}=0.129 \mathrm{Ra}^{1 / 3}
$$

for turbulent natural convection outside horizontal and vertical cylinders, vertical planes, blocks, and spheres. In contrast, we obtain 


$$
\mathrm{Nu}=0.166 \mathrm{Ra}^{1 / 3}
$$

the $\mathrm{LD}_{2}$ and $\mathrm{LN}_{2}$ data with the exponent fixed at $1 / 3$.

Because of the different fluids used and the different mode of heat transfer (quasi-steady instead of transient) this positive 27 percent deviation of our results from the classical Jakob expression is not entirely unexpected. In fact, Deaver and Eckert ${ }^{[9]}$ also observed a substantial positive deviation (28-percent at $\mathrm{Ra}=10^{6}$ ) from the Jakob expression for their quasi-steady laminar experiments with water and ethylene glycol in horizontal cylinders $\left(3 \times 10^{3}<\mathrm{Ra}<10^{7}\right)$. Thus enhanced heat transfer may be a characteristic of quasi-steady natural convection.

In section 2.7 we note a 20 percent uncertainty in the thermal conductivity of $\mathrm{LD}_{2}$. In these experiments, however, the Nusselt numbers for $\mathrm{LD}_{2}$ and $\mathrm{LN}_{2}$ are in excellent agreement, while the deviations of the $\mathrm{LH}_{2}$ data from the other data are minus 5 percent for the 17.1-cm diameter copper hemisphere, and minus 12 percent for the $\mathrm{L} / \mathrm{D}=2$, vertical cylinder. Since it is unlikely that the systematic error in the thermal conductivity of all these fluids is in the same direction, and because the properties of $\mathrm{LH}_{2}$ are better known than those of $\mathrm{LD}_{2}$ and $\mathrm{LN}_{2}$, we revise downward our estimate of the systematic error in the thermal conductivity of $\mathrm{LD}_{2}$ from 20 percent to about 10 percent.

\section{Summary and Conclusions}

The goal of this study was to provide heat transfer design data for liquid hydrogen and deuterium moderators and targets which are used in high energy physics experiments. Because internal heat generation is difficult to achieve in the laboratory, we simulate the internal heat generation with a quasi-steady cooling process. Thus, quasi-steady natural convection of $\mathrm{LD}_{2}, \mathrm{LH}_{2}$, and $\mathrm{LN}_{2}$ within a sphere, hemisphere, horizontal cylinder, and vertical cylinder has been studied experimentally for the case of a nearly uniform wall temperature. 
From this study we conclude:

1. A single expression,

$$
\mathrm{Nu}=0.104 \mathrm{Ra}^{0.352}
$$

correlates the $\mathrm{LN}_{2}$ and $\mathrm{LH}_{2}$ data over the range $7 \times 10^{8}<\mathrm{Ra}<6 \times 10^{11}$ with a standard deviation of 10 percent, whereas the hydrogen Nusselt numbers are 8 percent lower. In all cases the thermal properties listed in table 2.2 should be used in applying the correlation, since it was developed using these property values. In applying this correlation to other fluids, an additional systematic error of 10 percent could result because of the uncertainty in the thermal properties (principally in the thermal conductivity) of liquid deuterium.

2. An enhancement of heat transfer may be characteristic of quasisteady free convection within enclosures because the Nusselt numbers for both these results and those of Deaver and Eckert ${ }^{[9]}$ exceed the Nusselt numbers typical of transient convection within enclosures by about 27 percent.

3. The temperature field within the vessels is characterized by the virtual absence of horizontal temperature gradients - except for a thin boundary layer at the wall. For fully developed turbulent flow the dimensionless vertical temperature profile is independent of Rayleigh number for a given vessel shape. The temperature profiles for the sphere, hemisphere, and horizontal cylinder are nearly identical (figure 3.2), while the S profile for the vertical cylinders is independent of $L / D$ for $L / D=2$ and 4 .

4. The effect of wall resistance is smal1. Hemispheres having a significant wall resistance (greater wall temperature gradient) exhibited only a small reduction in the Nusselt number compared to the low wall resistance hemispheres.

5. Use of spatially distributed electric heaters gives Nusselt numbers in reasonable agreement with the quasi-steady results, 
although the slope of the $\mathrm{Nu}$ vs. Ra curves tends to be greater with the heater. The agreement between the heater and the quasi-steady cooling temperature profiles is good for the hemispheres, and poor for the vertical cylinder. In both heater experiments the maximum temperature is slightly overestimated.

Finally, correlation of the Nusselt numbers for the variety of shapes tested here by a single expression, suggests that this correlation may apply to other shapes as well, provided they have a modest aspect ratio. Further evidence in support of the possibly greater generality of the results is the existence of a nearly universal vertical temperature profile for vessels with both end and side wall cooling (spheres, hemispheres and horizontal cylinders).

\section{Acknowledgments}

A number of people in the Cryogenics Division contributed to the successful completion of this study. In particular I wish to thank: R. O. Voth and C. F. Sindt, who aided in the design of the apparatus; L. M. Anderson, who built and helped operate the apparatus; and W. J. Hall who wrote the data reduction programs. 
$\mathrm{A}$

$\mathrm{C}$

$\mathrm{C}_{1}$

$\mathrm{C}_{2}$

C

D

$\mathrm{E}$

h

i

$\mathrm{k}$

L

m

$\mathrm{Nu}$

n

$\mathrm{p}$

q

$\mathrm{q}_{\mathrm{v}}$

$\mathrm{Ra}$

t

$\mathrm{T}$

$T * 3$

$\mathrm{u}$

U

V

$\mathrm{V}$

wall surface area, $\mathrm{cm}^{2}$

modified specific heat $=C_{p}+\beta\left(i_{j}-i\right)$

proportionality constant in the Nusselt - Rayleigh number

correlation defined by $\mathrm{Nu}=\mathrm{C}_{1} \mathrm{Ra}^{\mathrm{n}}$

proportionality constant defined by equations $7 \mathrm{~B}$ and $12 \mathrm{~B}$.

specific heat at constant pressure

diameter

total energy

average heat transfer coefficient

specific enthalpy

thermal conductivity

cylinder length

mass

Nusselt number $=\frac{h D}{k}=\frac{q D}{k A\left(T_{b}-\bar{T}_{w}\right)}$

Rayleigh number exponent

pressure

heat transfer rate, watts

rate of internal heat generation per unit volume

Rayleigh number $=\frac{g \beta \rho^{2} C_{p} D^{3}\left(T_{b}-\bar{T}_{w}\right)}{\mu \mathrm{k}}$

For vertical cylinders the characteristic length is L.

time

$\begin{aligned} & \text { absolute temperature } \\ & \text { dimensionless temperature }\end{aligned}=\frac{T-\bar{T}_{W}}{T_{b}-\bar{T}_{W}}$

specific internal energy

total internal energy

total volume

specific volume 


$\begin{array}{ll}W & \text { velocity } \\ W & \text { work } \\ \vec{W} & \text { velocity vector } \\ \mathrm{x} & \text { position }\end{array}$

\section{Greek}

thermal expansivity $=\frac{1}{V}\left(\frac{\partial V}{\partial T}\right)$

$\theta$

dimensionless temperature gradient $=\frac{\partial \mathrm{T} *}{\partial(\mathrm{x} / \mathrm{L})}$

$\mu \quad$ viscosity

p density

$\sigma$

standard deviation

Subscripts

b

bulk fluid

c

core

W

interior wall surface 
1. H. Z. Barakat and J. A. Clark, Analytical and Experimental Study of the Transient Laminar Natural Convection Flows in Partially Filled Liquid Containers, Proc. 3rd Int. Heat Transfer Conf., Chicágo $\underline{2}$, $152-162(1966)$.

2. J. D. Hellums and S. W. Churchill, Computation of Natural Convection by Finite Difference Methods, Proc. 1961 Int. Heat Transfer Conf., 985-994. ASME, New York (1961).

3. L. B. Evans, R. C. Reid, and E. M. Drake, Transient Natura1 Convection in a Vertical Cylinder, AIChE J., 14, 251-259 (1968).

4. M. J. Lighthill, Theoretical Considerations on Free Convection in Tubes, Quart. J. Mech. App1. Math, 6, 398-439 (1953).

5. F. G. Hammitt and Paul T. Chu, Transient Internal Natural Convection Heating and Cooling of Closed, Vertical, Cylindrical Vessels, ASME No. 62-WA-309, 1-12 (1962).

6. E. Schmidt, Versuche zum Warmeubergang bei naturlicher Konvection, Chem. Ing. Tech. 28, 175-180 (1956).

7. L. B. Evans and N. E. Stefany, An Experimental Study of Transient Heat Transfer to Liquids in Cylindrical Enclosures, Chemical Engineering Progress Symposium Series, 62, No. 64, pp. 209-215. AIChE, New York (1966).

8. H. G. Maahs, Transient Natural Convection Heat Transfer in a Horizontal Cylinder, Ph.D. dissertation, Chem. Library, U. of Wash. (1964).

9. F. K. Deaver and E. R. G. Eckert, An Interferomatic Investigation of Convective Heat Transfer in a Horizontal Fluid Cylinder with Wa11 Temperature Increasing at a Uniform Rate, Heat Transfer 1970 (Proc. 4th Int. Heat Transfer Conf., Paris-Versailles 1970), Vol. IV, Elsevier, Amsterdam (1970).

10. J. A. Clark, A Review of Pressurization, Stratification, and Interfacial Phenomena, International Advances in Cryogenic Engineering, K. D. Timmerhaus (ed.), Sections M-U, pp. 259-283. Plenum Press, New York (1965).

11. R. G. Schwind and G. C. Vliet, Observations and Interpretations of Natural Convection and Stratification in Vesse1s, Proc. of the 1964 Heat Transfer and Fluid Mechanics Institute, W. H. Giedt and S. Levy (eds.), pp. 51-68. Stanford University Press, Stanford, Calif. (1964). 
12. J.W. Tatom and W. O. Carlson, Transient Turbulent Free Convection in Closed Containers, Proc. 3rd Int. Heat Transfer Conf., Chicago, 2, AIChE, N. Y. 163-171 (1966).

13. L. L. Sparks and R. L. Powell, Low Temperature Thermocouples: $\mathrm{kp}$, "normal" silver, and copper versus $\mathrm{Au}-0.02$ at \% $\mathrm{Fe}$ and $\mathrm{Au}$ -0.07 at \% Fe, J. Res. Nat. Bur. Stand. (U.S.), 76A (Phys. and (hem.), No. 3, 263-283 (May-June 1972).

14. R. Prydz, The Thermodynamic Properties of Deuterium. Nat. Bur. Stand. (U.S.) unpublished report (April 1967).

15. E. G. Brentari and R. V. Smith, Nucleate and Film Pool Boiling Design Correlations for $\mathrm{O}_{2}, \mathrm{~N}_{2}, \mathrm{H}_{2}$ and He, International Advances in Cryogenic Engineering, K. D. Timmerhaus (ed.), Sections M-U, PP. 259-283. Plenum Press, New York (1965).

16. J. P. Brouwer, A. M. Vossepoel, C. J. N. Van Den Meijdenberg, and J. J. M. Beenakker, Specific Heat of the Liquid Mixtures of Teon and Hydrogen Isotopes in the Phase Separation Region II. The System Ne-D, Physica 50, pp. 125-148, North Holland Publishing Company (1970).

17. E. C. Kerr, E. B. Rifkin, H. L. Johnson, and J. T. Clarke, Condensed Gas Calorimetry II. Heat Capacity of Ortho-deuterium Between 13.1 and $23.6 \mathrm{~K}$ Melting and Boiling Points, Heats of Fusion and Vaporization. Vapor Pressure of Liquid Ortho-deuterium, J. Amer. Chem. Soc. 73 (1951).

18. V. G. Konareva and X. S. Rudenko, Measurements of the Viscosity of Hydrogen Isotopes Along the Curve of Liquid-vapor Equilibrium, Zh. Fiz. Khim. 41 No. 9 (1967).

19. H. M. Roder, G. E. Childs, R. D. McCarty, P. E. Angerhofer, Survey of the Properties of the Hydrogen Isotopes Below Their Critical Temperatures, Nat. Bur. Stand. (U.S.) Tech. Note 641 113 pages (Aug. 1973).

20. H. M. Roder, L. A. Weber, and R. D. Goodwin, Thermodynamic and Related Properties of Parahydrogen from the Triple Point to $100^{\circ} \mathrm{K}$ at Pressures to 340 Atmospheres, Nat. Bur. Stand. (U.S.) Monogr. 94, 110 pages (Aug. 1965).

21. R. D. McCarty and L. A. Weber, Thermophysical Properties of Parahydrogen from the Freezing Liquid Line to $5000 \mathrm{R}$ for Pressures to 10,000 psia, Nat. Bur. Stand. (U.S.) Tech. Note 617, 169 pages (April 1972). 
22. T. R. Strobridge, The Thermodynamic Properties of Nitrogen from 64 to $300^{\circ} \mathrm{K}$ Between 0.1 and 200 Atmospheres, Nat. Bur. Stand. (U.S.), Tech. Note 129 (Jan. 1962).

23. H. J. M. Hanley, R. D. McCarty and W. M. Haynes, The Viscosity and Thermal Conductivity Coefficients for Dense Gaseous Liquid Argon, Krypton, Xenon, Nitrogen and Oxygen, J. Phys. Chem. Ref. Data $\underline{3}$ (9) $(1974)$.

24. R. W. Powers, R. W. Mattox, and H. L. Johnston, Thermal Conductivity of Condensed Gases. II The Thermal Conductivities of Liquid Normal and of Liquid Parahydrogen from 15 to 27 degrees K, J. Am. Chem. Soc. Vol. 76, 5972-73 (1954).

25. H. M. Roder and D. E. Diller, Thermal Conductivity of Gaseous and Liquid Hydrogen, J. Chem. Phys, 52, 11, 5928-49 (1970).

26. W. M. Rohsenow and H. Y. Choi, Heat, Mass, and Momentum Transfer, p. 162, Prentice-Hal1, Inc., Englewood Cliffs, New Jersey (1961).

27. Ibid., p. 204.

28. M. Jakob, Heat Transfer, Vo1. 1, p. 530, John Wiley, New York (1959).

29. M. Jakob, Heat Transfer, Vol. 1, p. 532, John Wiley, New York (1959). 


\section{Heat Capacity During Cooling}

As the vessel cools, fluid enters it at a temperature which is generally cooler than the bulk temperature of the enclosed fluid. If we consider a control volume around the vessel, then the First Law of Thermodynamics may be written as

$$
d E=d Q-d W+\sum_{j} i_{j} d m_{j}
$$

Noting that there is no external work done on the control volume,

$$
\mathrm{dW}=0 \text {; }
$$

and equating $E$ and $U$, we may write

$$
\mathrm{dE}=\mathrm{mdu}+\mathrm{udm} \text {. }
$$

For a constant volume process, conservation of mass gives

$$
\mathrm{dm}=-\frac{\mathrm{mdv}}{\mathrm{v}}
$$

Combining equations $1 \mathrm{~A}$ through $4 \mathrm{~A}$, and dividing by dt to obtain the time rate of change, we have

$$
\text { m }\left[\frac{d u}{d t}+\frac{1}{v} \frac{d v}{d t}\left(i_{j}-u\right)\right]=q \text {. }
$$

Noting that

$$
\frac{\mathrm{d} u}{\mathrm{dt}}=\left(\frac{\mathrm{du}}{\mathrm{dT}}\right)\left(\frac{\mathrm{dT}}{\mathrm{dt}}\right)
$$

and that 


$$
\frac{d v}{d t}=\left(\frac{d v}{d T}\right)\left(\frac{d T}{d t}\right)
$$

equation (5A) becomes

$$
m \frac{d T}{d t}\left[\frac{d u}{d T}+\frac{1}{v} \frac{d v}{d T}\left(i_{j}-u\right)\right]=q \text {. }
$$

For the constant pressure process assumed here

$$
\frac{1}{v}\left(\frac{d v}{d T}\right)=\beta
$$

and

$$
\frac{d u}{d T}=C_{p}-\beta p v=C_{p}-\beta(i-u) .
$$

Equation (6A) now becomes

$$
m \frac{d T}{d t}\left[C_{p}+\beta\left(i_{j}-i\right)\right]=q
$$

or if we define a modified specific heat, $C$, as

$$
c=C_{p}+\beta\left(i_{j}-i\right),
$$

we can finally write

$$
q=m C \frac{d T}{d t} \text {. }
$$




\section{APPENDIX B}

Velocity in the Core of a Vertical Cylinder

Consider a model (similar to that adopted by Evans, Reid and Drake[3], which consists of a slow moving cylindrical core with a uniform vertical velocity, $w_{C}$, and a thin annular boundary layer. The vertical velocity in the core is related to the vertical temperature gradient by a common expression for both quasi-steady cooling and uniform internal heat generation - as well as for the inverses of these processes. We will consider the quasi-steady cooling core first.

\section{B.1 Quasi-Steady Cooling}

For the control volume below, assuming no axial or transverse conduction, an energy balance for a constant density fluid yields:

$$
\begin{aligned}
& p{ }_{C} C_{p}\left(T+\frac{\partial T}{\partial x} d x\right) \\
& \operatorname{pdxc}_{\mathrm{p}} \frac{\partial T}{\partial t} \quad+\cdots \text { control volume } \\
& p w_{C} C_{p} T \\
& \rho w_{C} C_{p} \frac{\partial T}{\partial x} d x=\rho d x C_{p} \frac{\partial T}{\partial t}
\end{aligned}
$$

or,

$$
w_{C} \frac{\partial T}{\partial x}=\frac{\partial T}{\partial t}
$$

For quasi-steady state the temperature at all points within the vessel changes uniformly, so that we may write

$$
\rho V C_{p} \frac{\partial T}{\partial t}=q
$$

Noting that

$$
V=\frac{\pi D^{2}}{4} \quad I=\frac{A D}{4},
$$


we obtain

$$
\frac{\partial T}{\partial t}=\frac{4(q / A)}{\rho C_{p} D}
$$

Combining equations $(1 B)$ and (2B) yields the core velocity, ${ }_{c}$, as a function of the core temperature gradient and the wall heat flux:

$$
w_{c}=\frac{4(q / A)_{w}}{\rho C_{p} D\left(\frac{\partial T}{\partial x}\right)_{c}} .
$$

The core temperature gradient, $(\partial \mathrm{T} / \partial \mathrm{x})_{\mathrm{c}}$, may be eliminated from equation (3B) in the following manner. From the experiments, we note that

$$
\frac{\partial \mathrm{T} *}{\partial(\mathrm{x} / \mathrm{L})}=\text { Constant }=\theta
$$

over much of the length of the vertical cylinders. Since the dimensionless temperature difference, $\mathrm{T}^{*}$, is defined as

$$
\mathrm{T} * \equiv \frac{\mathrm{T}-\overline{\mathrm{T}}_{\mathrm{W}}}{\mathrm{T}_{\mathrm{b}}-\overline{\mathrm{T}}_{\mathrm{W}}},
$$

the core temperature gradient becomes

$$
\left(\frac{\partial \mathrm{T}}{\partial \mathrm{x}}\right)_{c}=\frac{\left(\mathrm{T}_{\mathrm{b}}-\overline{\mathrm{T}}_{\mathrm{w}}\right) \theta}{\mathrm{L}}
$$

The characteristic temperature difference, $\mathrm{T}_{\mathrm{b}}-\overline{\mathrm{T}}_{\mathrm{W}}$, is eliminated from equation (5B) using the heat transfer correlation

$$
\mathrm{Nu}=\mathrm{C}_{1} \mathrm{Ra}^{\mathrm{n}}
$$

Employing the definitions of $\mathrm{Nu}$ and $\mathrm{Ra}$, equation (6B) may be transformed to 


$$
T_{b}-\bar{T}_{W}=\frac{(q / A)^{\frac{1}{n+1}} D^{\frac{1-3 n}{n+1}}}{C_{1}^{\frac{1}{n+1}}\left[\frac{g \beta p^{2} C_{P}}{\mu k^{\frac{n-1}{n}}}\right] \frac{n}{n+1}} ;
$$

or defining

$$
C_{2} \equiv \frac{1}{C_{1}^{\frac{1}{n+1}}\left[\frac{g \beta p^{2} C_{p}}{\mu k \frac{n-1}{n}}\right]^{\frac{n}{n+1}}},
$$

we obtain

$$
T_{b}-\bar{T}_{W}=C_{2}(q / A)^{\frac{1}{n+1}} D^{\frac{1-3 n}{n+1}} .
$$

Combining equations (5B) and ( $8 B$ ) yields

$$
\left(\frac{\partial T}{\partial x}\right)_{C}=\frac{C_{2}(q / A)^{\frac{1}{n+1}} D^{\frac{1-3 n}{n+1}} \theta}{L}
$$

Using (9B) to eliminate the core temperature gradient from equation (3B) gives the core velocity as a function of the wall heat flux, the fluid properties, and the geometry: 


$$
w_{C}=\frac{4(L / D)(q / A)_{w}^{\frac{n}{n+1}} D^{\frac{3 n-1}{n+1}}}{\rho C_{p} C_{2} \theta} .
$$

For $\mathrm{n}=\frac{1}{3}$, equation $(10 \mathrm{~B})$ becomes

$$
w_{c}=\frac{4(\mathrm{~L} / \mathrm{D})(\mathrm{q} / \mathrm{A})_{\mathrm{w}}^{1 / 4}}{\rho \mathrm{C}_{\mathrm{p}} \mathrm{C}_{2} \theta}
$$

and $\mathrm{C}_{2}$ is given by

$$
C_{2}=\frac{1}{\left(C_{1}\right)^{3 / 4}\left[\frac{g \beta p^{2}{ }^{2} C_{p}}{\mu}\right]^{1 / 4}} \text {. }
$$

Evaluation of (11B) at a wall heat flux of $0.1 \mathrm{~W} / \mathrm{cm}^{2}$ gives a core velocity of $0.5 \mathrm{~cm} / \mathrm{s}$ for $\mathrm{LD}_{2}$.

\section{B.2 Internal Heat Generation}

Following a fluid element as it rises in the core, and assuming no axial or transverse conduction, an energy balance for a constant density fluid gives

$$
\rho C_{p} \frac{\partial T}{\partial t}=q_{v}
$$

For steady state the core temperature gradient is

$$
\left(\frac{\partial T}{\partial x}\right)_{c}=\left(\frac{\partial T}{\partial t}\right)\left(\frac{\partial t}{\partial x}\right)=\left(\frac{\partial T}{\partial t}\right) \frac{1}{w_{c}}
$$

or rearranging,

$$
\frac{\partial T}{\partial t}=w_{c}\left(\frac{\partial T}{\partial x}\right)_{c} .
$$


Combining equations (13B) and (14B) yields

$$
w_{c}=\frac{q_{v}}{\rho C_{p}\left(\frac{\partial T}{\partial x}\right)_{c}} \text {. }
$$

For a cylinder insulated at the ends

$$
q_{v}=\frac{4(q / A)}{D} \text {, }
$$

and (15B) becomes

$$
w_{c}=\frac{4(q / A)_{w}}{\rho C_{p} D\left(\frac{\partial T}{\partial x}\right)_{c}}
$$

which is identical to the result for the quasi-steady cooling case, equation (3B). The remainder of the analysis is the same as in section B.1. 
APPENDIX C

Experimental Results

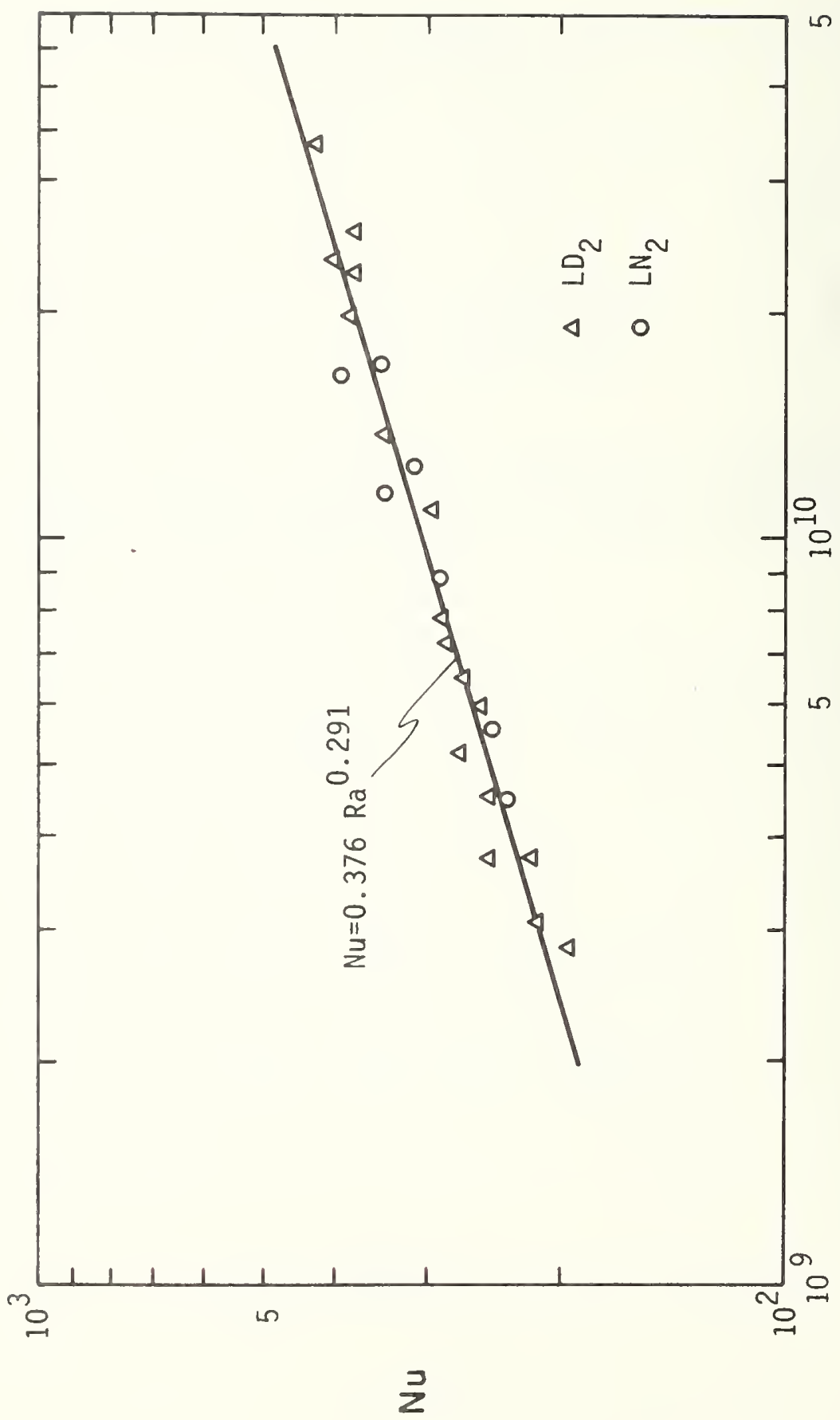

की

ن. 


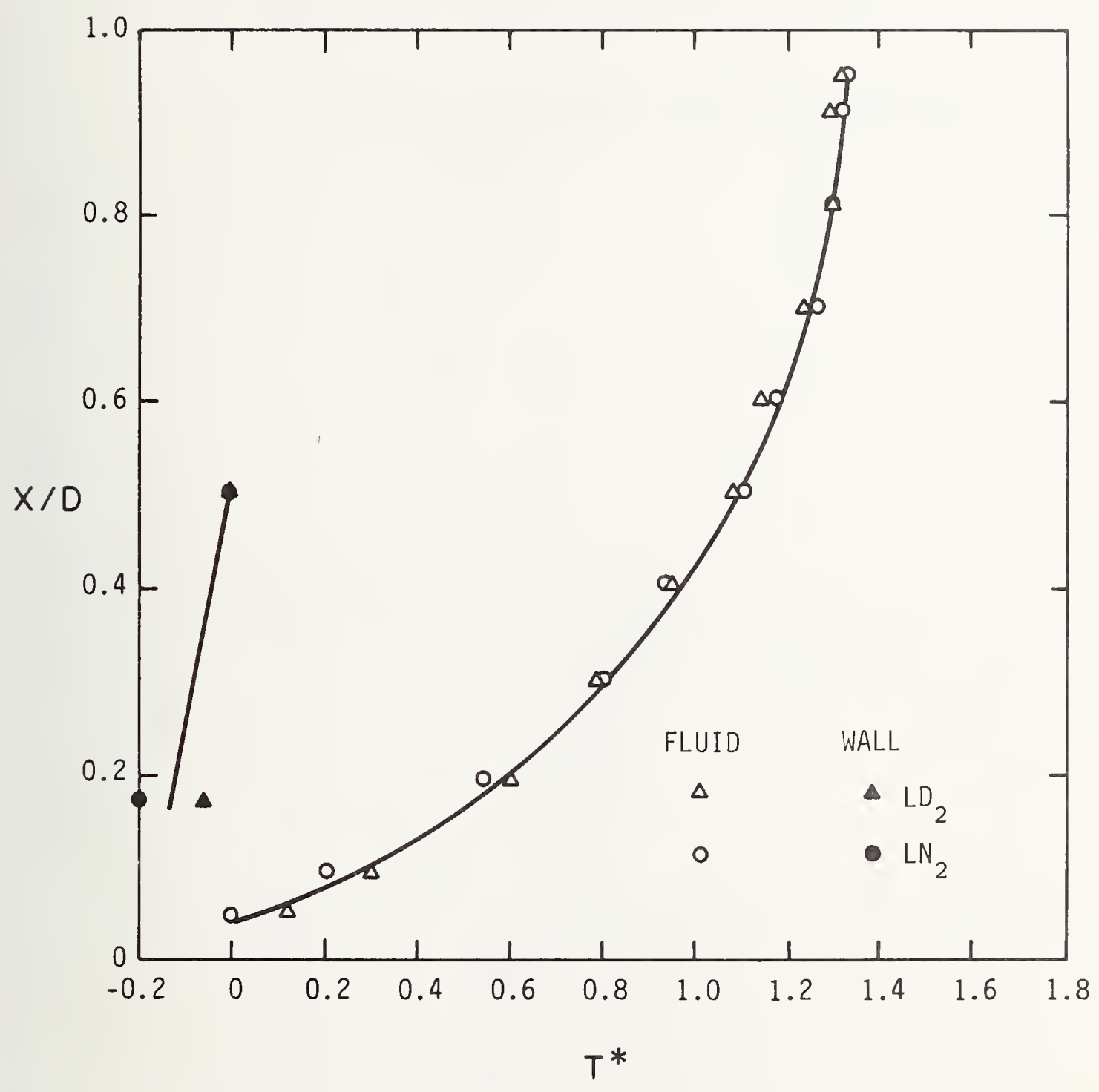

Figure C.2. Sphere (copper wall) - vertical temperature distribution for cooling experiments. 


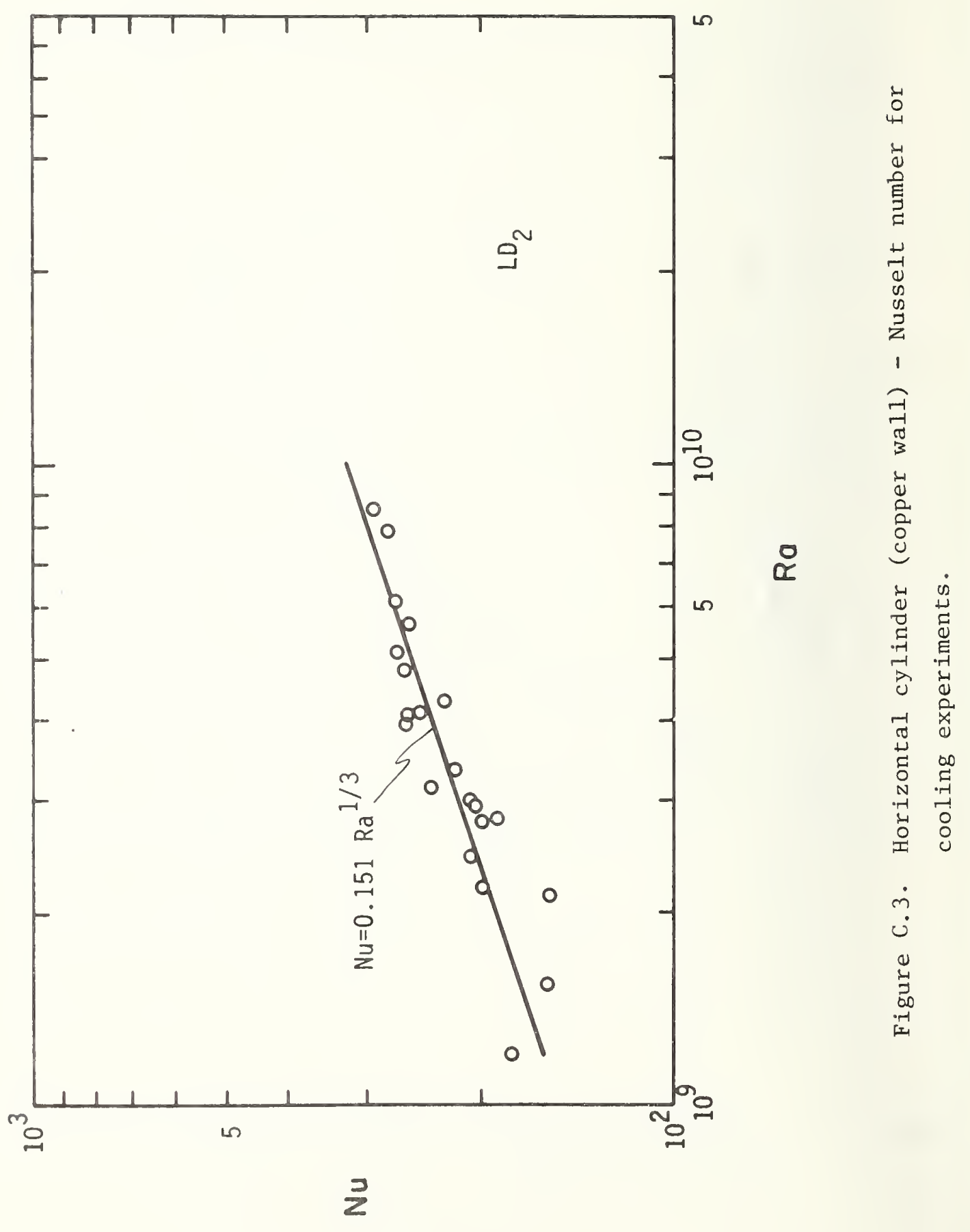




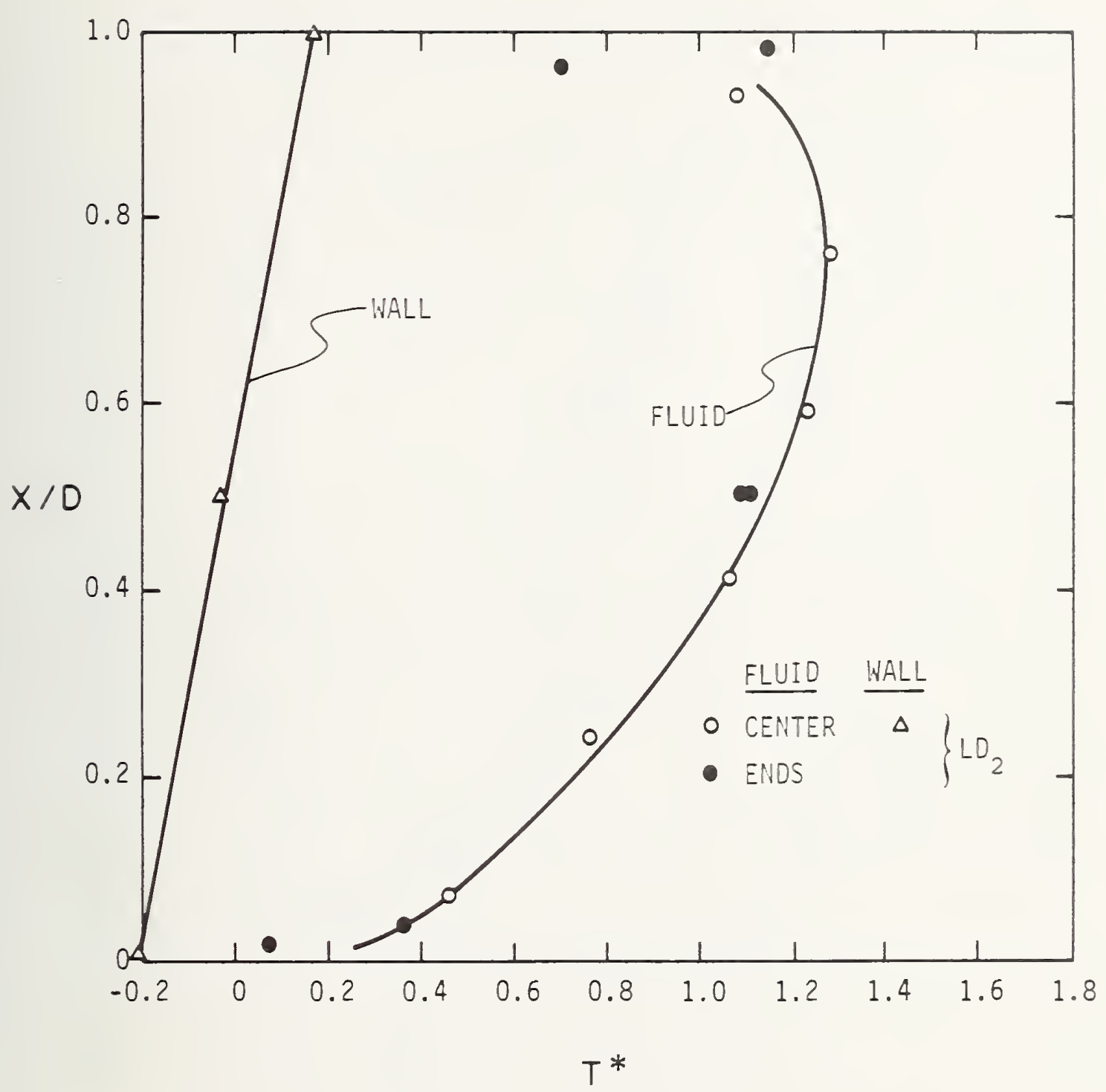

Figure C.4. Horizontal cylinder (copper wall) - vertical temperature distribution. 


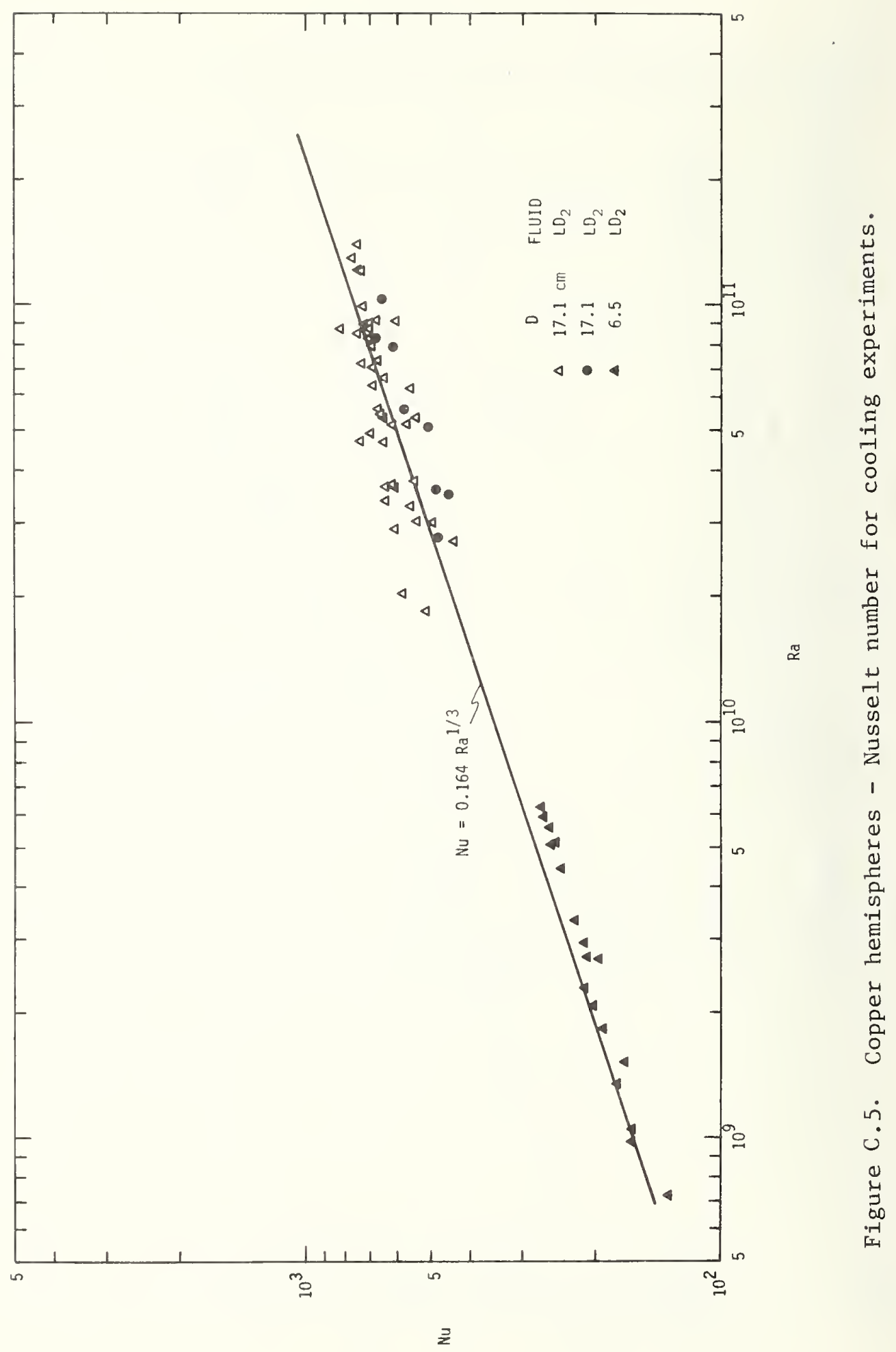




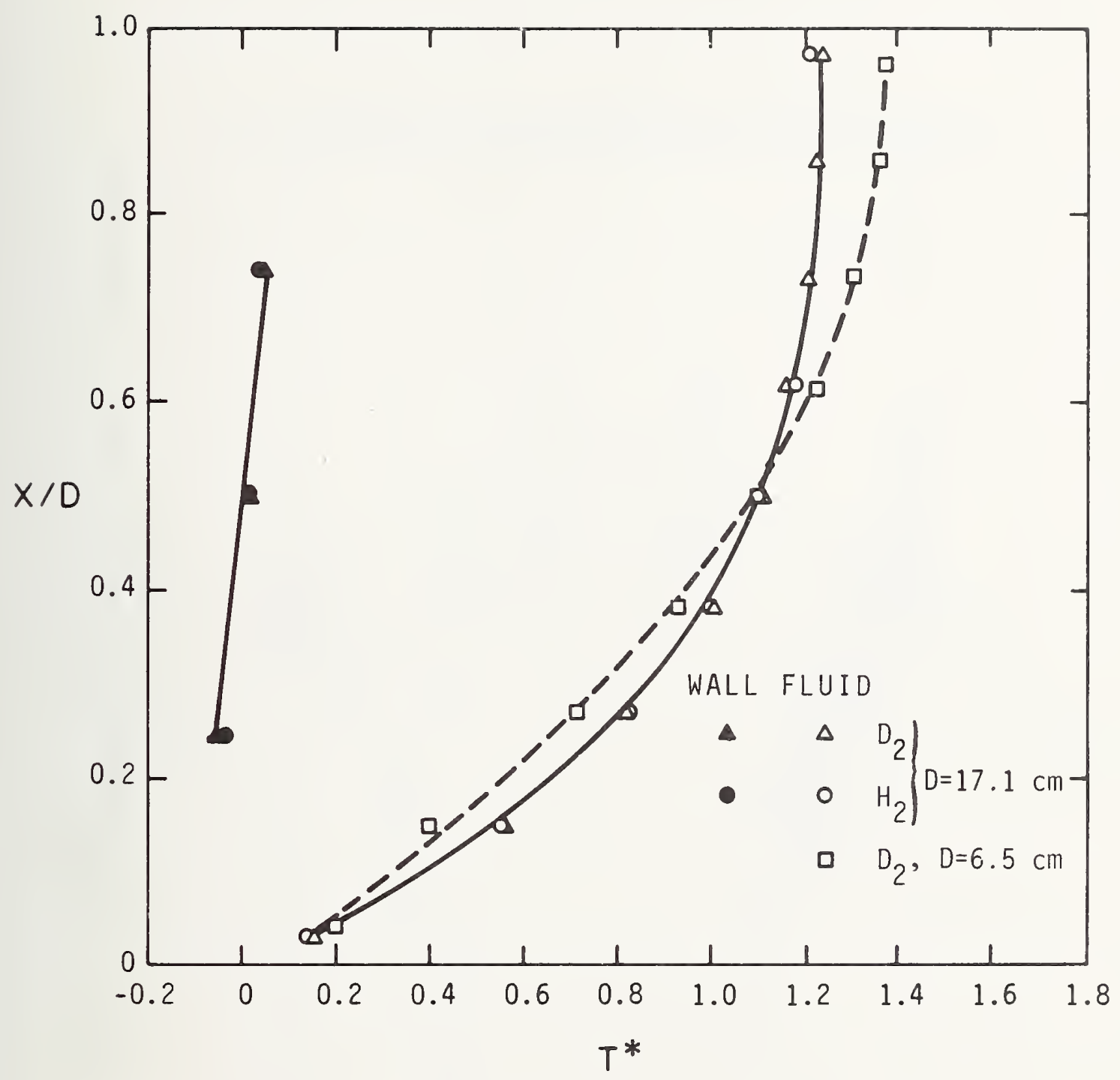

Figure C.6. Copper hemispheres - vertical temperature distribution for cooling experiments. 


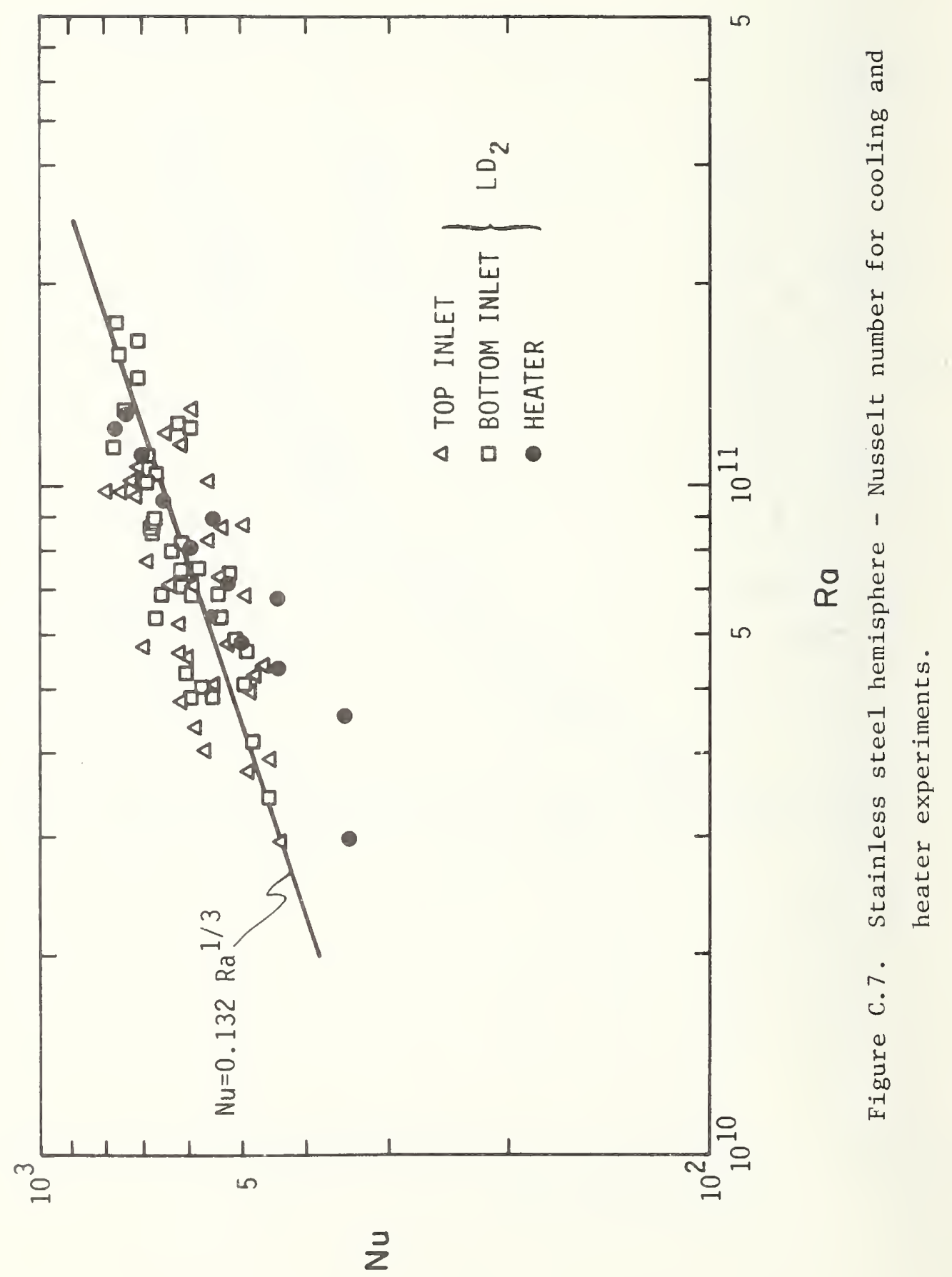




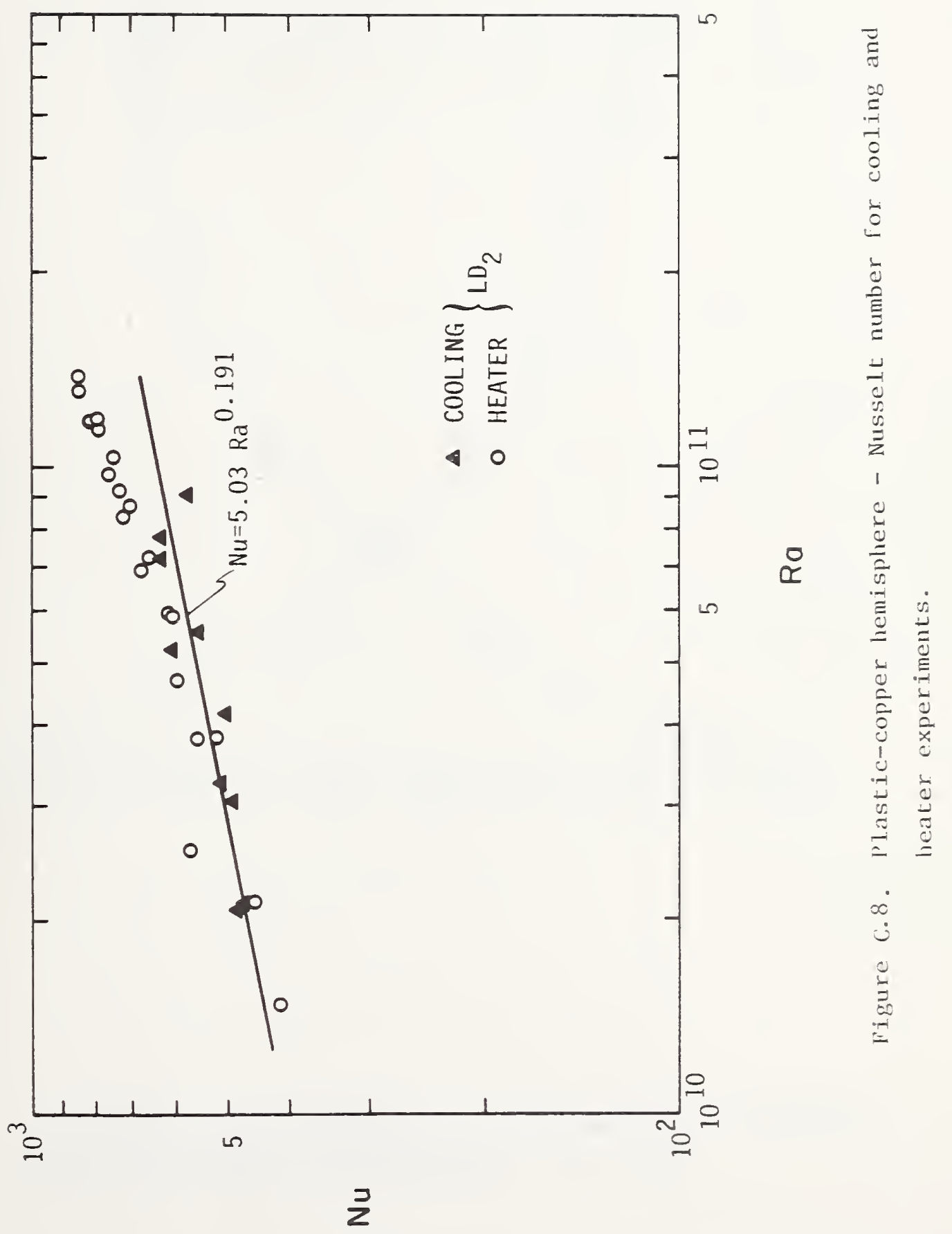




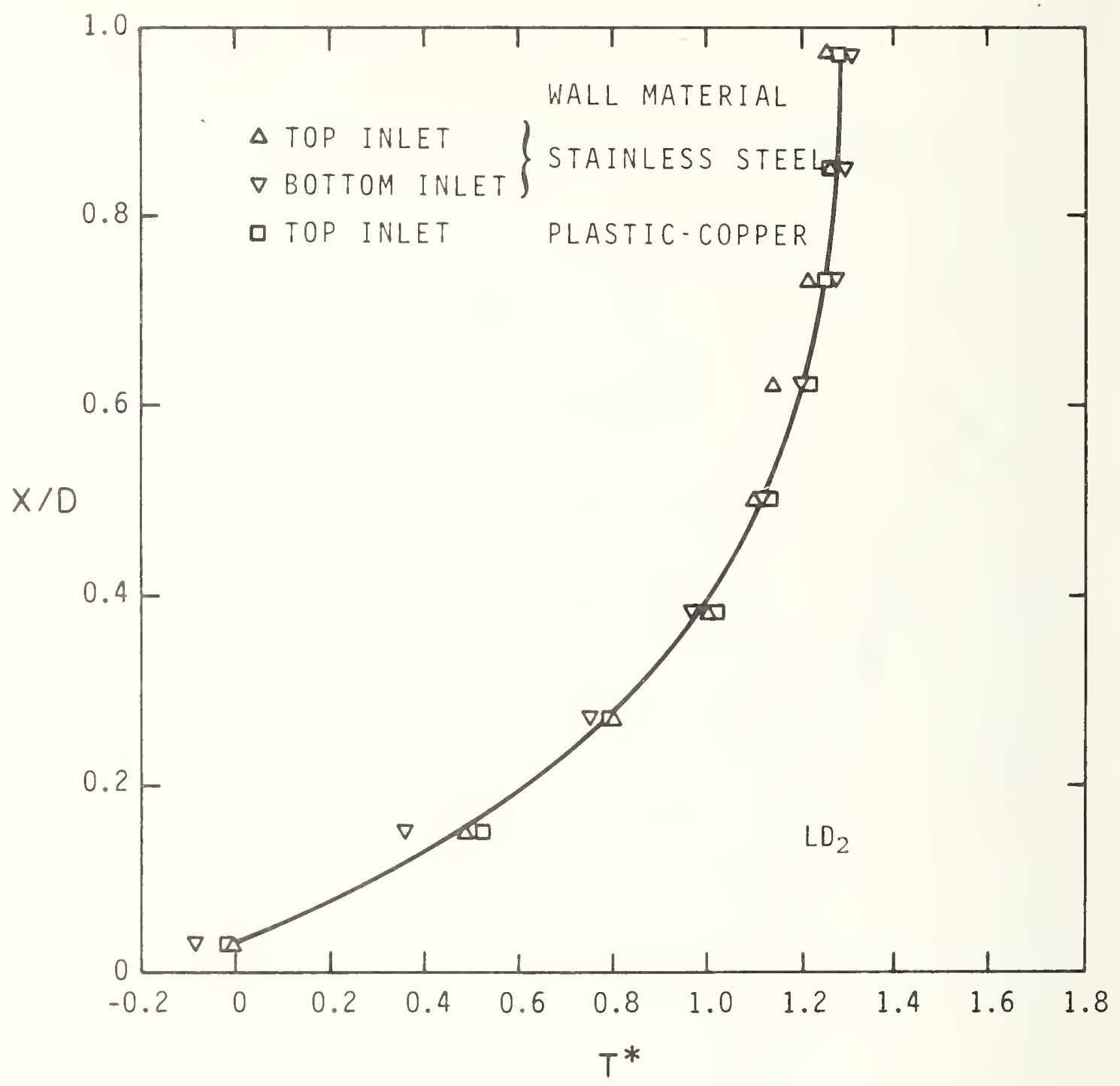

Figure C.9. Stainless steel and plastic-copper hemisphere - vertical temperature distribution for cooling experiments. 


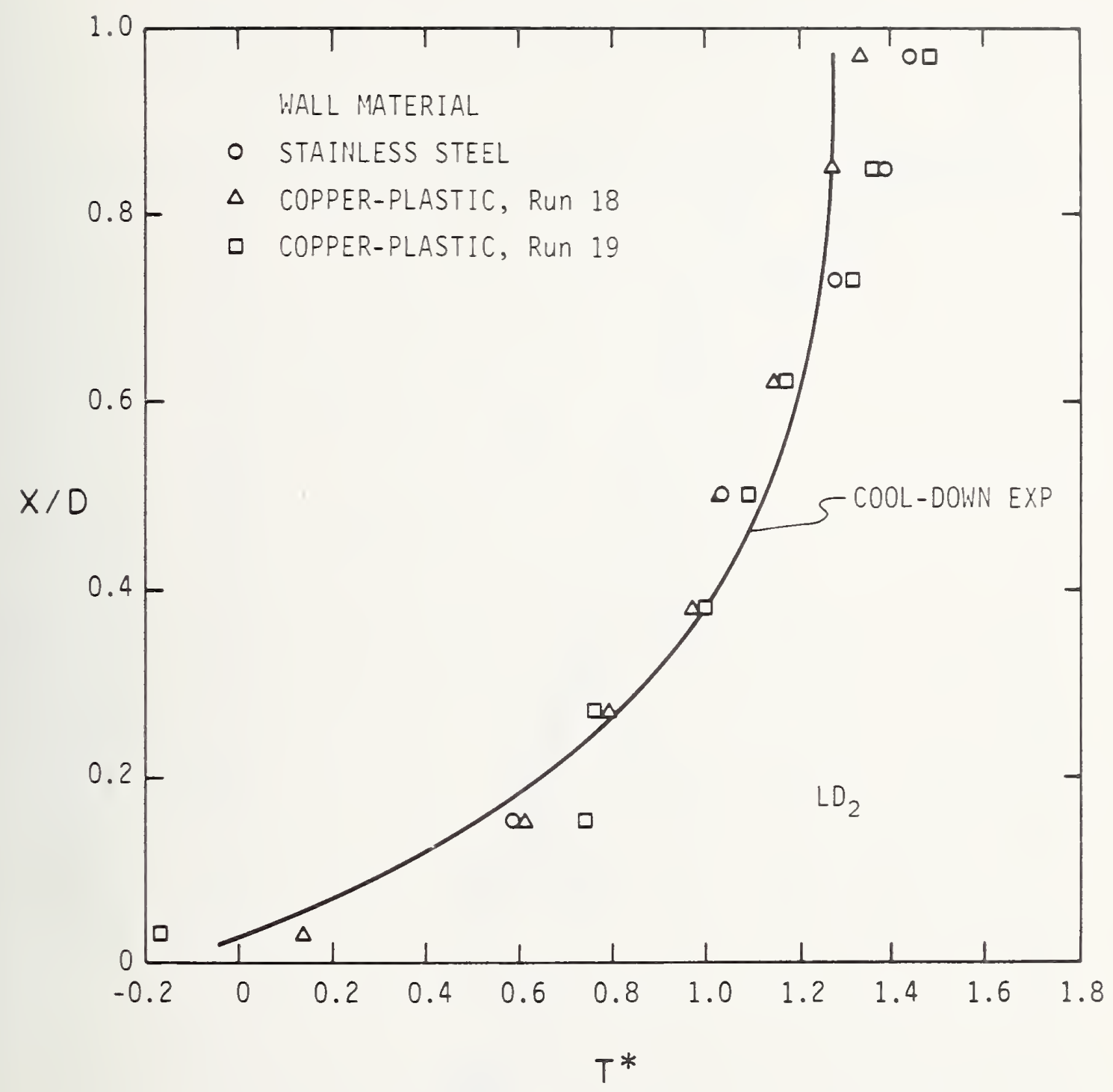

Figure C.10. Stainless steel and plastic-copper hemispheres with heaters vertical temperature distribution. 


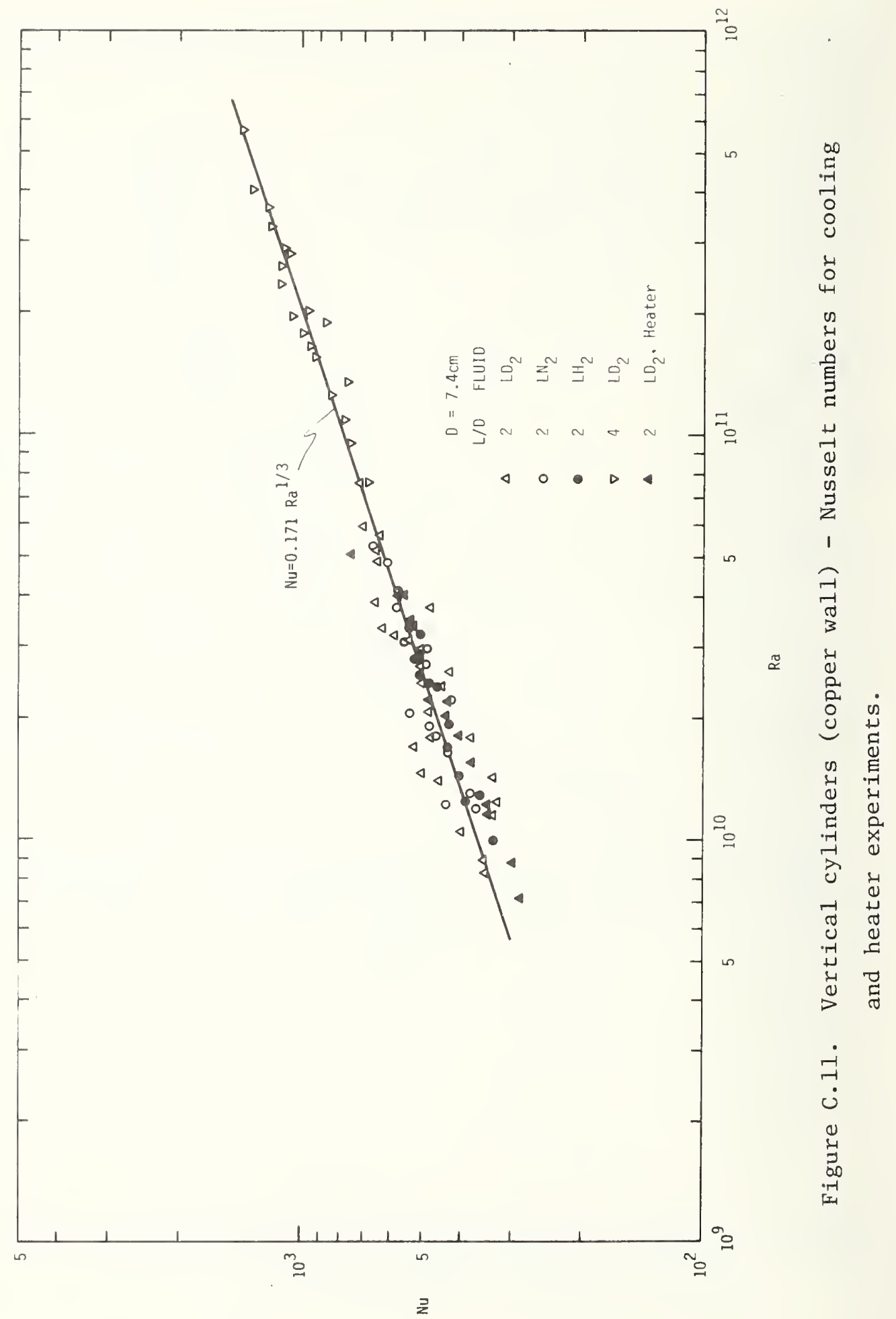




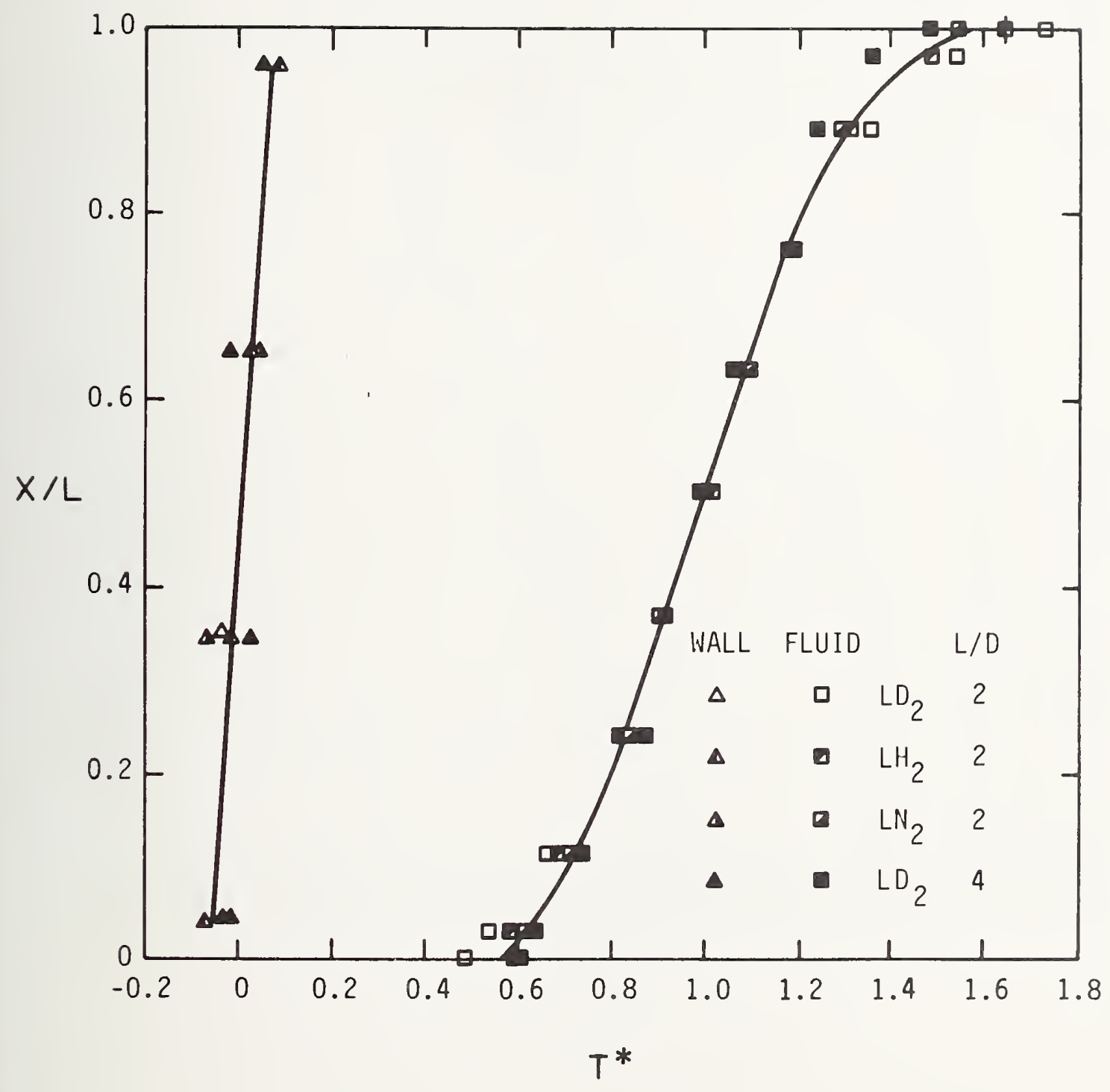

Figure C.12. Vertical cylinders (copper wall) - vertical temperature distribution for cooling experiments. 


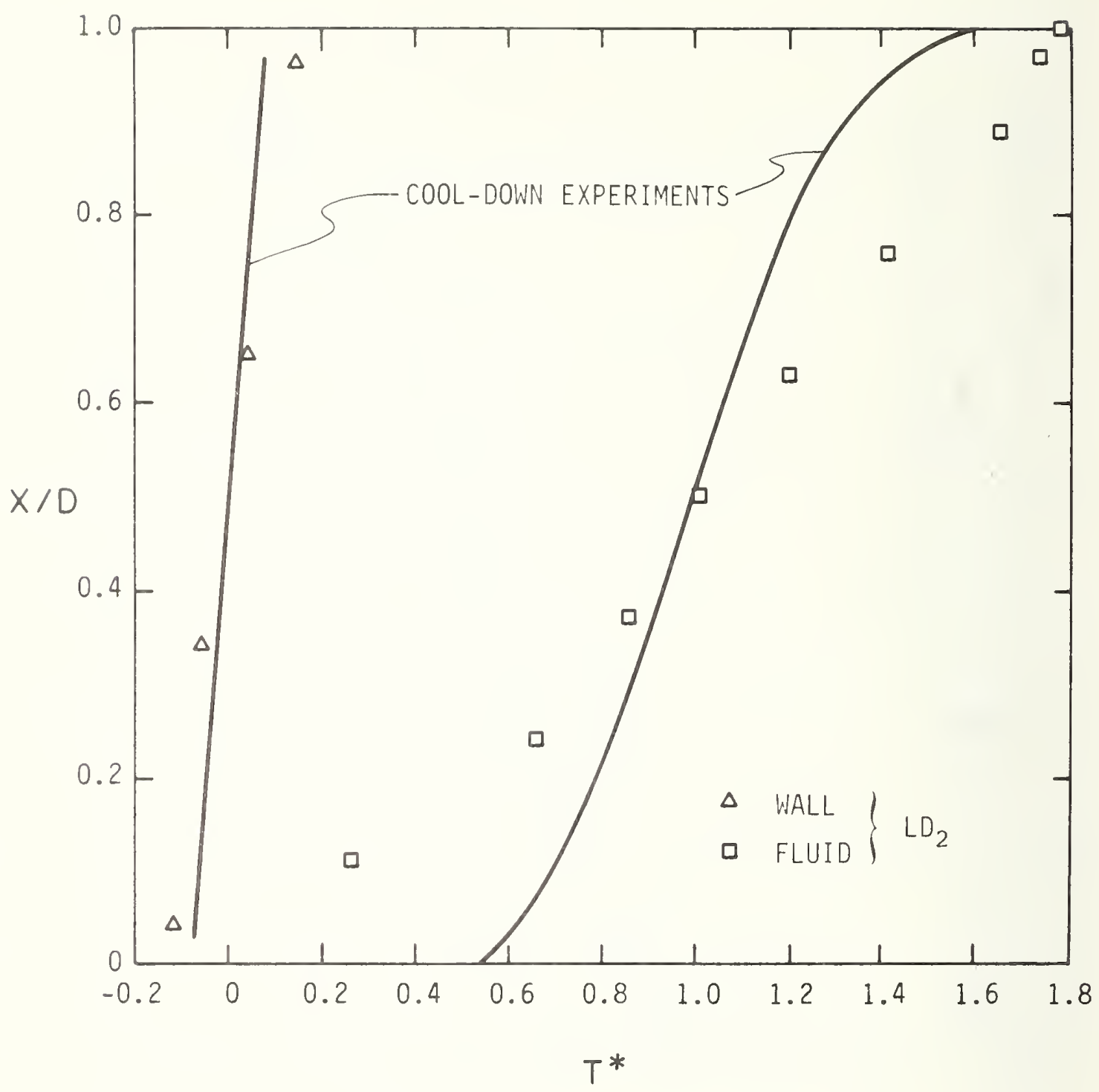

Figure C.13. Vertical cylinder (copper wall) with heater $(\mathrm{L} / \mathrm{D}=2)$ vertical temperature distribution. 


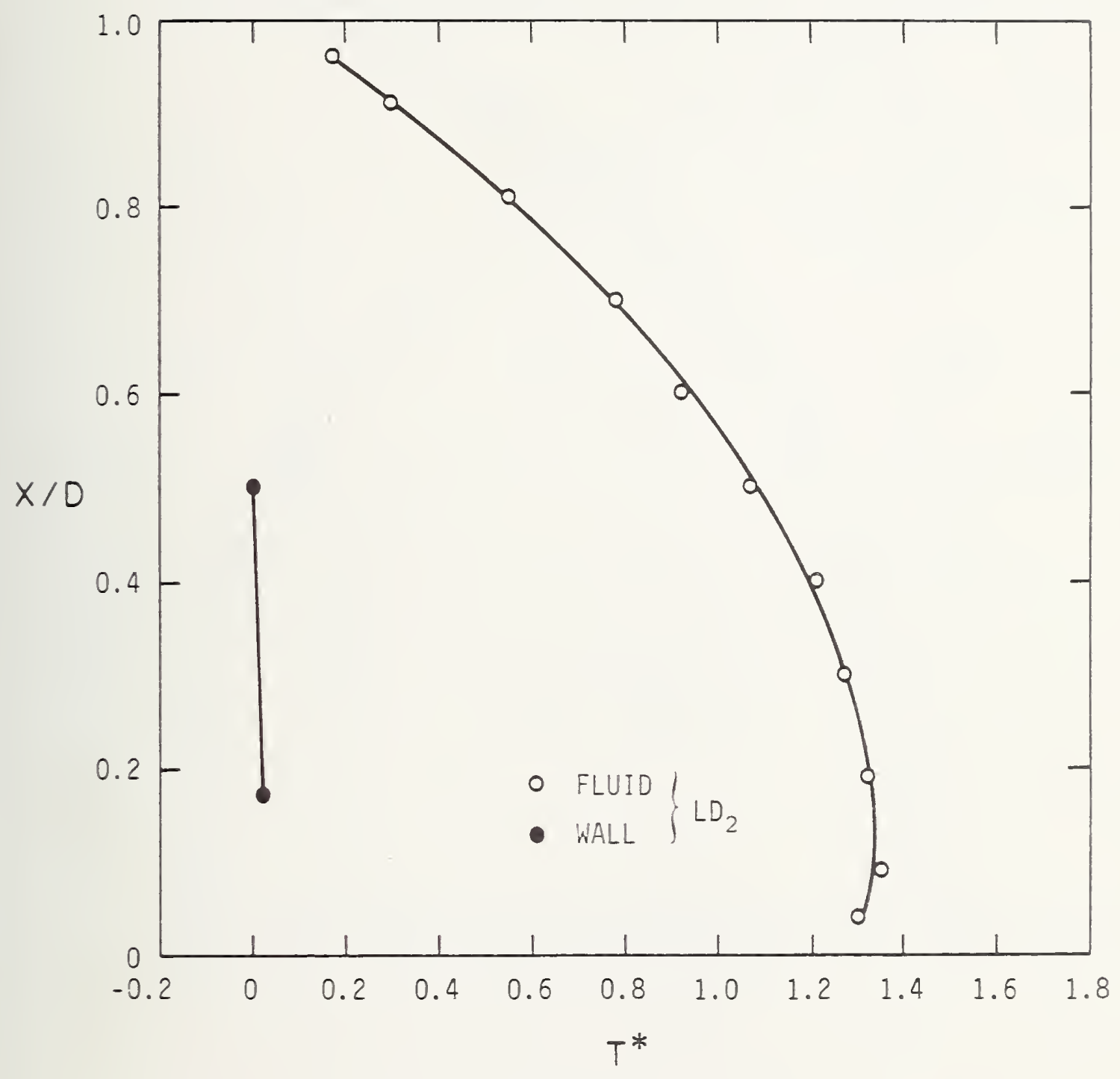

Figure C.14. Sphere (copper wall) - vertical temperature profile for warming experiments. 


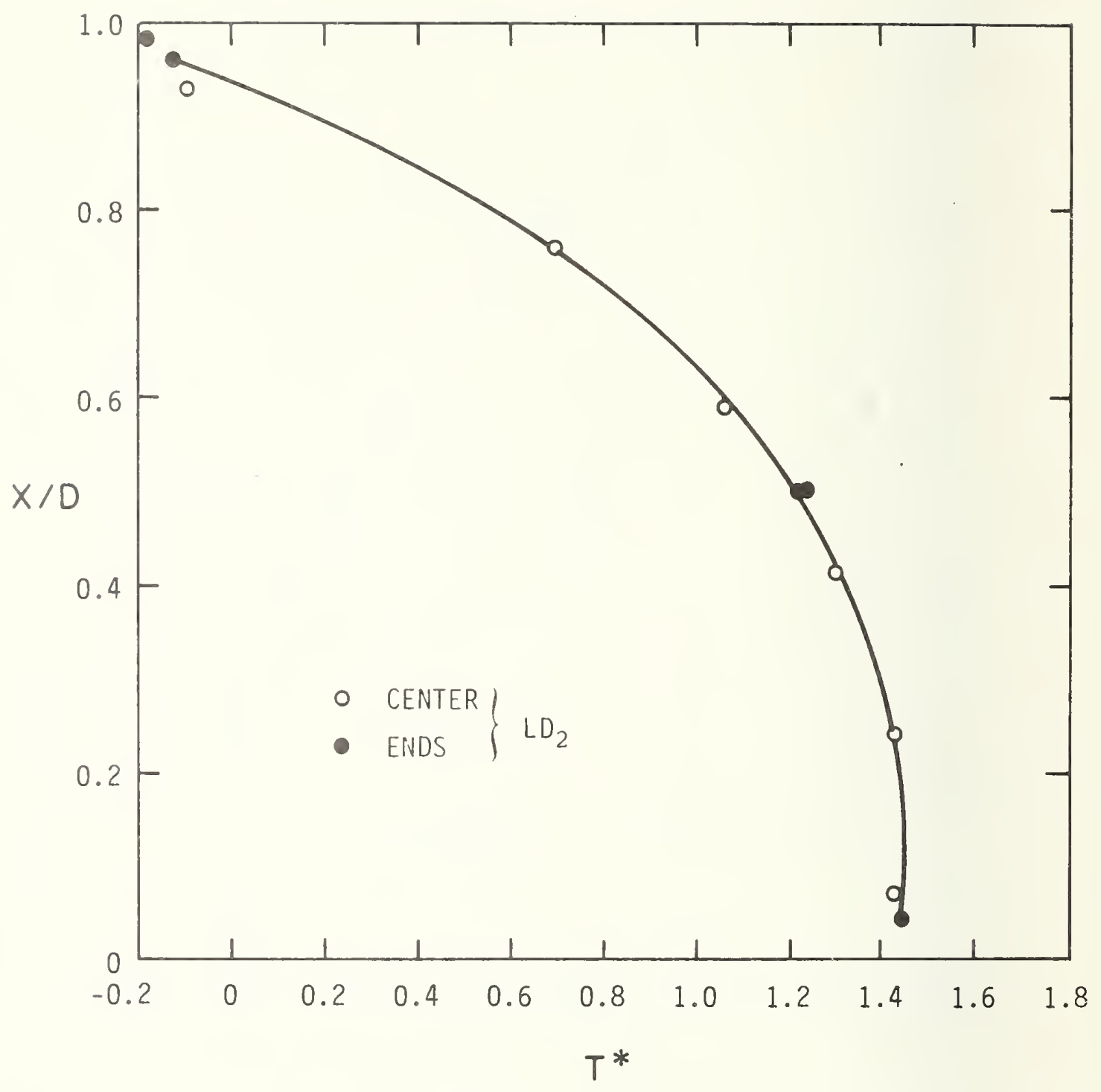

Figure C.15. Horizontal cylinder (copper wall) - vertical temperature distribution for warming experiments. 


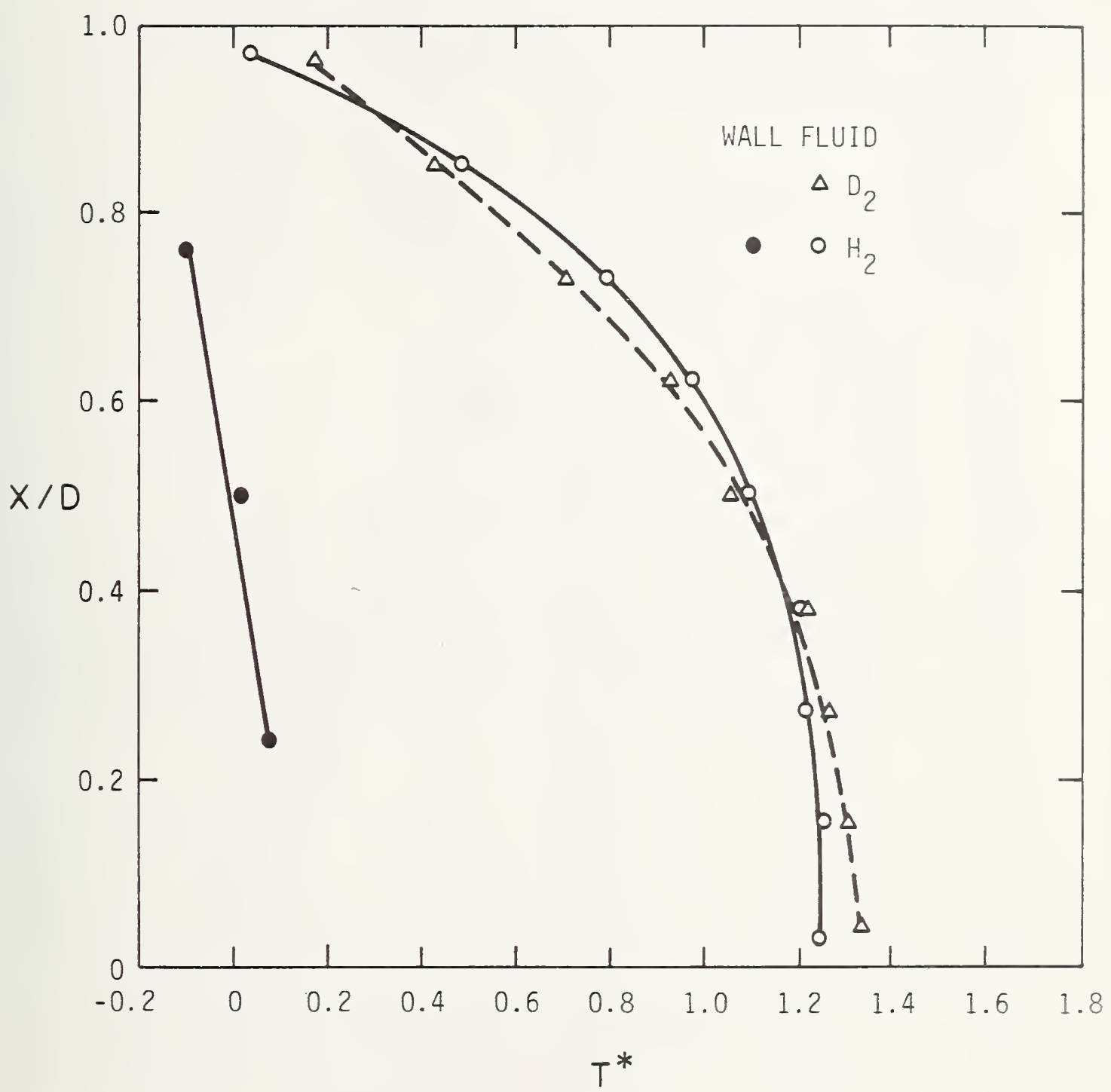

Figure C.16. Copper hemisphere $(D=17.1 \mathrm{~cm})$ - vertical temperature distribution for warming experiments. 


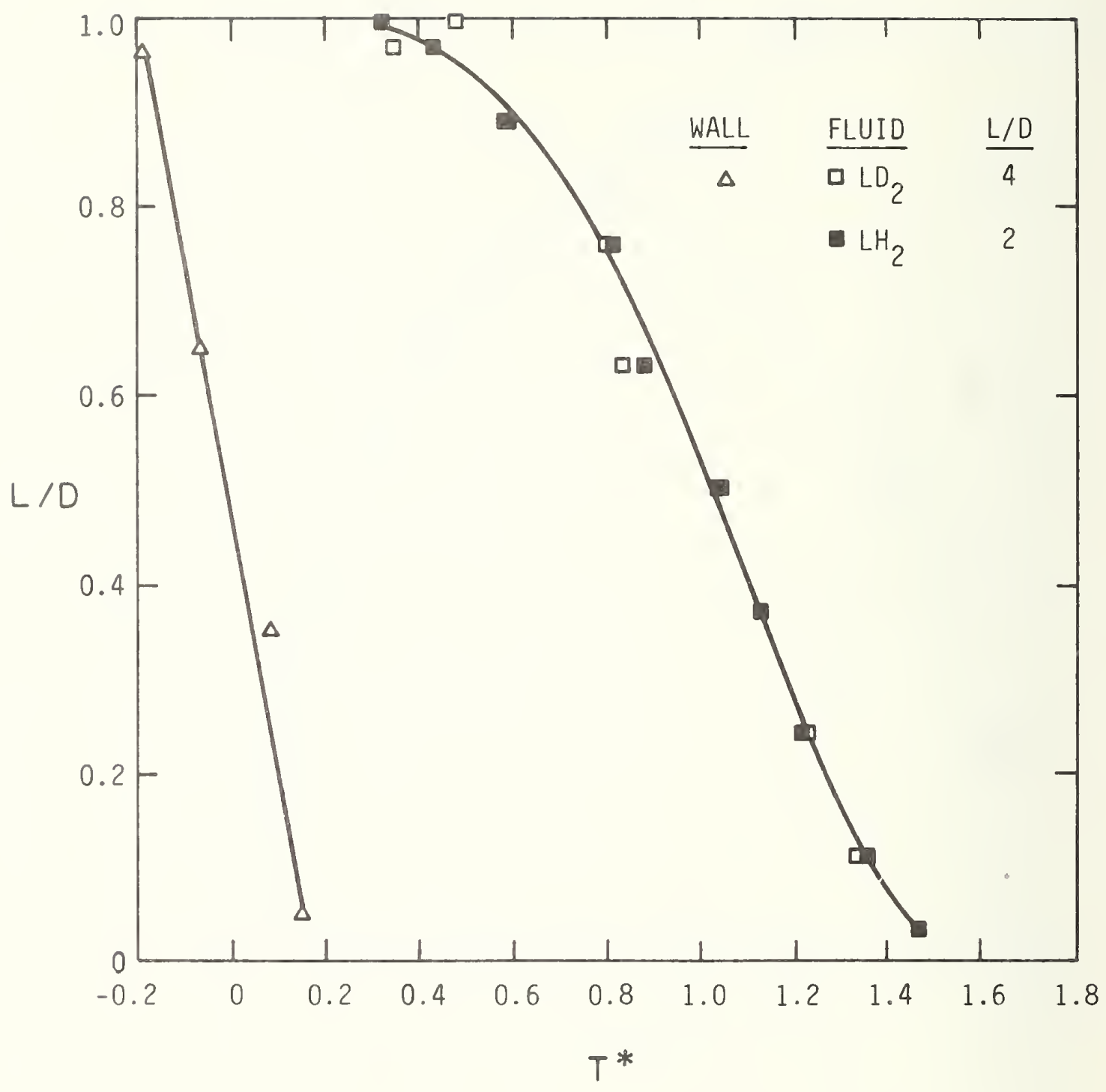

Figure C.17. Vertical cylinders (copper wall) - vertical temperature distribution for warming experiments. 
Table C.1.

Correlation results using the expression $\mathrm{Nu}=\mathrm{C}_{1} \mathrm{Ra}^{\mathrm{n}}$.

\begin{tabular}{|c|c|c|c|c|}
\hline Test Vessel & Fluid & $\mathrm{C}_{1}$ & $\mathrm{n}$ & $\begin{array}{l}\text { Std. Dev., } \\
\text { in } \mathrm{Nu}\end{array}$ \\
\hline $\begin{array}{l}\text { Sphere (copper) } \\
D=9.8 \mathrm{~cm}\end{array}$ & $\mathrm{LD}_{2}$ & $\begin{array}{l}0.446 \\
0.974 \\
0.140\end{array}$ & $\begin{array}{c}0.284 \\
1 / 4 \\
1 / 3\end{array}$ & $\begin{array}{l}4.2 \\
5.0 \\
5.9\end{array}$ \\
\hline $\begin{array}{l}\text { Sphere (copper) } \\
D=9.8 \mathrm{~cm}\end{array}$ & $\mathrm{LN}_{2}$ & $\begin{array}{l}0.162 \\
0.140\end{array}$ & $\begin{array}{l}0.327 \\
1 / 3\end{array}$ & $\begin{array}{l}7.0 \\
7.0\end{array}$ \\
\hline $\begin{array}{l}\text { Copper Hemisphere } \\
D=6.5 \mathrm{~cm}\end{array}$ & $\mathrm{LD}_{2}$ & $\begin{array}{l}0.470 \\
0.935 \\
0.150\end{array}$ & $\begin{array}{c}0.281 \\
1 / 4 \\
1 / 3\end{array}$ & $\begin{array}{l}3.0 \\
3.6 \\
3.8\end{array}$ \\
\hline $\begin{array}{l}\text { Copper Hemisphere } \\
D=17.1 \mathrm{~cm}\end{array}$ & $\mathrm{LD}_{2}$ & $\begin{array}{l}5.19 \\
1.32 \\
0.164\end{array}$ & $\begin{array}{c}0.195 \\
1 / 4 \\
1 / 3\end{array}$ & $\begin{array}{r}8.6 \\
9.1 \\
11.1\end{array}$ \\
\hline $\begin{array}{l}\text { Copper Hemisphere } \\
D=17.1 \mathrm{~cm}\end{array}$ & $\mathrm{LH}_{2}$ & $\begin{array}{l}0.197 \\
1.16 \\
0.147\end{array}$ & $\begin{array}{c}0.321 \\
1 / 4 \\
1 / 3\end{array}$ & $\begin{array}{l}5.2 \\
6.0 \\
5.2\end{array}$ \\
\hline $\begin{array}{l}\text { Stainless Steel Hemisphere } \\
D=17.1 \mathrm{~cm}\end{array}$ & $\mathrm{LD}_{2}$ & $\begin{array}{l}0.349 \\
0.141\end{array}$ & $\begin{array}{l}0.297 \\
1 / 3\end{array}$ & $\begin{array}{l}10.2 \\
10.4\end{array}$ \\
\hline $\begin{array}{l}\text { Stainless Steel Hemisphere } \\
\text { With Heater } D=17.1 \mathrm{~cm}\end{array}$ & $\mathrm{LD}_{2}$ & $\begin{array}{l}5.15(10)^{-5} \\
0.132\end{array}$ & $\begin{array}{l}0.645 \\
1 / 3\end{array}$ & $\begin{array}{r}6.3 \\
13.0\end{array}$ \\
\hline $\begin{array}{l}\text { Plastic - Copper Hemisphere } \\
D=17.1 \mathrm{~cm}\end{array}$ & $\mathrm{LD}_{2}$ & $\begin{array}{l}5.03 \\
1.17 \\
0.150\end{array}$ & $\begin{array}{l}0.191 \\
1 / 4 \\
1 / 3\end{array}$ & $\begin{array}{l}5.6 \\
6.3 \\
8.9\end{array}$ \\
\hline $\begin{array}{l}\text { Plastic - Copper Hemisphere } \\
\text { With Heater }\end{array}$ & $\mathrm{LD}_{2}$ & $\begin{array}{l}0.187 \\
0.162\end{array}$ & $\begin{array}{l}0.328 \\
1 / 3\end{array}$ & $\begin{array}{l}4.5 \\
4.5\end{array}$ \\
\hline $\begin{array}{l}\text { Horizontal Cylinder (copper) } \\
D=7.4 \mathrm{~cm}\end{array}$ & $\mathrm{LD}_{2}$ & $\begin{array}{l}0.259 \\
0.151\end{array}$ & $\begin{array}{l}0.309 \\
1 / 3\end{array}$ & $\begin{array}{l}7.8 \\
8.0\end{array}$ \\
\hline $\begin{array}{l}\text { Vertical Cylinder (copper) } \\
\mathrm{D}=7.4 \mathrm{~cm}, \mathrm{~L} / \mathrm{D}=2\end{array}$ & $\mathrm{LD}_{2}$ & $\begin{array}{l}0.109 \\
0.171\end{array}$ & $\begin{array}{l}0.352 \\
1 / 3\end{array}$ & $\begin{array}{l}10.8 \\
10.8\end{array}$ \\
\hline $\begin{array}{l}\text { Vertical Cylinder (copper) } \\
D=7.4 \mathrm{~cm}, L / D=2\end{array}$ & $\mathrm{LH}_{2}$ & $\begin{array}{l}0.00554 \\
0.163\end{array}$ & $\begin{array}{l}0.379 \\
1 / 3\end{array}$ & $\begin{array}{l}4.0 \\
4.3\end{array}$ \\
\hline
\end{tabular}


Table C.1Continued.

Correlation results using the expression $\mathrm{Nu}=\mathrm{C}_{1} \mathrm{Ra}^{\mathrm{n}}$.

\begin{tabular}{|c|c|c|c|c|}
\hline Test Vessel & Fluid & $\mathrm{C}_{1}$. & $\mathrm{n}$ & $\begin{array}{l}\text { Std. Dev., } \\
\text { in } \mathrm{Nu}\end{array}$ \\
\hline $\begin{array}{l}\text { Vertical Cylinder (copper) } \\
\mathrm{D}=7.4 \mathrm{~cm}, \mathrm{~L} / \mathrm{D}=2\end{array}$ & $\mathrm{LN}_{2}$ & $\begin{array}{l}0.212 \\
0.170\end{array}$ & $\begin{array}{l}0.324 \\
1 / 3\end{array}$ & $\begin{array}{l}7.2 \\
7.2\end{array}$ \\
\hline $\begin{array}{l}\text { Vertical Cylinder (copper) } \\
\text { With Heater, } \mathrm{D}=7.4 \mathrm{~cm}, \mathrm{~L} / \mathrm{D}=2\end{array}$ & $\mathrm{LD}_{2}$ & $\begin{array}{l}4.51(10)^{-3} \\
1.62\end{array}$ & $\begin{array}{l}0.483 \\
1 / 3\end{array}$ & $\begin{array}{l}5.0 \\
8.6\end{array}$ \\
\hline $\begin{array}{l}\text { Vertical Cylinder (copper) } \\
\mathrm{D}=7.4 \mathrm{~cm}, \mathrm{~L} / \mathrm{D}=4\end{array}$ & $\mathrm{LD}_{2}$ & $\begin{array}{l}0.0720 \\
0.170\end{array}$ & $\begin{array}{l}0.366 \\
1 / 3\end{array}$ & $\begin{array}{l}5.2 \\
5.5\end{array}$ \\
\hline Sphere (copper) & $\mathrm{LD}_{2} \& \mathrm{LN}_{2}$ & 0.376 & 0.291 & 5.4 \\
\hline$D=9.8 \mathrm{~cm}$ & & 0.140 & $1 / 3$ & 6.3 \\
\hline $\begin{array}{l}\text { Copper Hemispheres } \\
D=6.5 \mathrm{~cm}, 17.1 \mathrm{~cm}\end{array}$ & $\mathrm{LD}_{2}$ & $\begin{array}{l}0.263 \\
0.164\end{array}$ & $\begin{array}{l}0.314 \\
1 / 3\end{array}$ & $\begin{array}{l}16.6 \\
16.9\end{array}$ \\
\hline $\begin{array}{l}\text { Vertical Cylinders } \\
\mathrm{D}=7.4 \mathrm{~cm}, \mathrm{~L} / \mathrm{D}=2,4\end{array}$ & $\mathrm{LD}_{2}$ & $\begin{array}{l}0.152 \\
0.171\end{array}$ & $\begin{array}{l}0.338 \\
1 / 3\end{array}$ & $\begin{array}{l}7.8 \\
7.8\end{array}$ \\
\hline $\begin{array}{l}\text { All Copper Vessels } \\
\text { Cooling }\end{array}$ & $\mathrm{LD}_{2}$ & $\begin{array}{l}0.104 \\
0.166\end{array}$ & $\begin{array}{l}0.352 \\
1 / 3\end{array}$ & $\begin{array}{l}10.7 \\
11.0\end{array}$ \\
\hline $\begin{array}{l}\text { All Copper Vessels } \\
\text { Cooling }\end{array}$ & $\begin{array}{l}\text { All } \\
\text { Fluids }\end{array}$ & $\begin{array}{l}0.939 \\
0.165\end{array}$ & $\begin{array}{l}0.356 \\
1 / 3\end{array}$ & $\begin{array}{l}10.4 \\
10.6\end{array}$ \\
\hline $\begin{array}{l}\text { All Copper Vessels } \\
\text { Warming }\end{array}$ & $\mathrm{LD}_{2}$ & $\begin{array}{l}0.104 \\
0.177\end{array}$ & $\begin{array}{l}0.355 \\
1 / 3\end{array}$ & $\begin{array}{l}17.1 \\
17.9\end{array}$ \\
\hline
\end{tabular}




\begin{tabular}{|c|c|c|c|}
\hline $\begin{array}{l}\text { U.S. DEPT. OF COMM. } \\
\text { BIBLIOGRAPHIC DATA } \\
\text { SHEFT }\end{array}$ & $\begin{array}{l}\text { 1. PUBLICATION OR REPORT NO. } \\
\text { NBS-IR 75-807 }\end{array}$ & $\begin{array}{l}\text { 2. Gov't Accession } \\
\text { No. }\end{array}$ & 3. Recipient"s Accession No. \\
\hline \multirow{2}{*}{\multicolumn{3}{|c|}{$\begin{array}{l}\text { 4. TITIE AND SUBTITLE } \\
\text { TURBULENT NATURAL CONVECTION OF LIQUID } \\
\text { DEUTERIUM, HYDROGEN , AND NITROGEN WITHIN } \\
\text { ENCLOSED VESSELS }\end{array}$}} & $\begin{array}{l}\text { 5. Publication Date } \\
\text { February } 1975\end{array}$ \\
\hline & & & 6. Performing Organization Code \\
\hline \multicolumn{3}{|l|}{$\begin{array}{l}\text { 7. AUHHOR(S) } \\
\text { David E. Daney }\end{array}$} & 8. Performing Organ. Report No. \\
\hline \multirow{2}{*}{\multicolumn{3}{|c|}{$\begin{array}{l}\text { 9. PERFORMING ORGANIZATION NAME AND ADDRESS } \\
\qquad \begin{array}{l}\text { NATIONAL BUREAU OF STANDARDS } \\
\text { DEPARTMENT OF COMMERCE } \\
\text { WASHINGTON, D.C. } 20234\end{array}\end{array}$}} & $\begin{array}{l}\text { 10. Project/Task/Work Unit No. } \\
2754450\end{array}$ \\
\hline & & & $\begin{array}{l}\text { 11. Contract/Grant No. } \\
\text { SANL } 351\end{array}$ \\
\hline \multirow{2}{*}{\multicolumn{3}{|c|}{$\begin{array}{l}\text { 12. Spunsoring Organization Name and Complete Address (Street, City, State, ZIP) } \\
\text { Lawrence Livermore Laboratory } \\
\text { University of California } \\
\text { P. O. Box } 808 \\
\text { Livermore, California } 94550\end{array}$}} & $\begin{array}{l}\text { 13. Type of Report \& Period } \\
\text { Covered } \\
\text { Final }\end{array}$ \\
\hline & & & 14. Sponsoring Agency Code \\
\hline
\end{tabular}

16. ABSTRACT (A 200-word or less factual summary of most significant information. If document includes a significant bibliography or literature survey, mention it here.)

Quasi-steady natural convection of liquid deuterium, hydrogen, and nitrogen within a sphere, hemisphere, horizontal cylinder, and vertical cylinder has been studied experimentally for the case of a nearly isothermal wall. A single expression relating the Nusselt and Rayleigh numbers,

$$
\mathrm{Nu}=0.104 \mathrm{Ra}^{0.352} \text {, }
$$

fits the deuterium and nitrogen data over the range $7 \times 10^{8}<\mathrm{Ra}<6 \times 10^{11}$, while the hydrogen Nusselt numbers are 8 percent lower. The temperature field within the vessels is virtually free of horizontal temperature gradients. A single dimensionless temperature profile characterizes the vertical temperature distribution for each vessel shape, with the profiles for the sphere, hemisphere, and horizontal cylinder being nearly identical.

17. KIYY WORDS (six to twelve entries; alphabetical order; capitalize only the first letter of the first key word unless a proper nume; separated by semicolons) Cryogenic; heat transfer; hemisphere; horizontal cylinder; liquid deuterium, liquid hydrogen, liquid nitrogen; natural convection; sphere; vertical cylinder.

\section{A!AII.AIII.ITY}

For Official Distribution. Do Not Rclease to NTIS

Order From Sup. of Doc., U.S. Government Printing Oifice Washington, D.C. 20402 , SDCat. No.C13

[. Order lirom National Technical Information Service (NTIS) Springfield, Virginia $2215 \mathrm{I}$

\begin{tabular}{|l|l|}
\hline $\begin{array}{l}\text { 19. SECURITY CLASS } \\
\text { (THIS REPURT) }\end{array}$ & 21. NO. OF PAGES \\
UNCL ASSIFIED & \\
\hline $\begin{array}{l}\text { 20. SECURITY CLASS } \\
\text { (THIS PAGE) } \\
\text { UNCLASSIFIED }\end{array}$ & 22. Price \\
\hline
\end{tabular}




$$
\text { . }
$$

